Milena Vaz Bonini

\title{
Relação entre alterações de linguagem e déficits cognitivos \\ não linguísticos em indivíduos afásicos após acidente vascular encefálico
}

Dissertação apresentada à Faculdade de Medicina da Universidade de São Paulo para obtenção do título de Mestre em Ciências

Área de concentração: Neurologia Orientadora: Dra. Márcia Radanovic

SÃO PAULO

2010 
Milena Vaz Bonini

\section{Relação entre alterações de linguagem e déficits cognitivos \\ não linguísticos em indivíduos afásicos após acidente vascular encefálico}

Dissertação apresentada à Faculdade de Medicina da Universidade de São Paulo para obtenção do título de Mestre em Ciências

Área de concentração: Neurologia Orientadora: Dra. Márcia Radanovic

SÃO PAULO

2010 
Dados Internacionais de Catalogação na Publicação (CIP)

Preparada pela Biblioteca da

Faculdade de Medicina da Universidade de São Paulo

Creprodução autorizada pelo autor

Bonini, Milena Vaz

Relação entre alterações de linguagem e déficits cognitivos não lingüísticos em indivíduos afásicos após acidente vascular encefálico / Milena Vaz Bonini. -São Paulo, 2010.

Dissertação(mestrado)--Faculdade de Medicina da Universidade de São Paulo. Departamento de Neurologia.

Área de concentração: Neurologia.

Orientador: Márcia Radanovic.

Descritores: 1.Afasia 2.Transtornos cognitivos 3.Acidente cerebral vascular 4.Linguagem 5.Cognição

USP/FM/SBD-097/10 
DEDICATÓRIA

Aos meus amados pais, Wilson e Altair, pelo amor incondicional, por toda a dedicação e incentivo em todos os momentos de minha vida, meu profundo agradecimento. Ao meu esposo Eliandro, a quem tanto amo, pelo apoio, companheirismo e paciência. Este trabalho, que é a realização de um sonho, é dedicado a vocês! 


\section{AGRADECIMENTOS}

À minha orientadora, Dra. Márcia Radanovic, por todo o apoio, pela confiança, paciência e grande disponibilidade. Indiscutivelmente, um modelo de pesquisadora a ser seguido.

À Profa. Dra. Letícia Lessa Mansur, por ter despertado meu interesse pela fascinante área da Neurolinguística, pela presença constante em minha vida profissional e pelas importantes contribuições para a realização deste trabalho.

Ao Prof. Dr. Milberto Scaff, pela preciosa contribuição para a finalização desta pesquisa.

Ao Prof. Dr. Paulo Andrade Lotufo e à Profa. Dra. Isabela Benseñor, pelas valiosas sugestões na reta final da pesquisa.

Ao Prof. Dr. Luis Marcelo Inaco Cirino, pelo valioso incentivo à minha pesquisa.

Ao Dr. Cláudio Sakurada, pela compreensão e ajuda em momentos cruciais.

À toda a equipe do Programa de Assistência Domiciliária do HU-USP, pelo apoio e pela torcida diária. 
Às fonoaudiólogas Karina Bühler e Renata Moreira, pela amizade e por todas as orientações e conselhos tão valiosos.

À fonoaudióloga Marília Barbieri, pelo auxílio na captação de participantes para esta pesquisa.

A todos os participantes da pesquisa, pela boa vontade e pela persistência.

À querida amiga Flavia, com quem pude dividir as angústias, a ansiedade e as alegrias que fazem parte do processo de aprendizado do "querer ser" pesquisador.

A todos os meus familiares - irmãos, tios, sobrinhos, padrinhos, primos, cunhados -, pessoas tão importantes em minha vida, pela fervorosa torcida para que eu alcançasse este objetivo e pela compreensão nos momentos em que estive ausente.

À minha cunhada Tatiana, pelo apoio também técnico, quando esta pesquisa estava apenas começando.

A Deus, Senhor de todas as coisas, por todas as bênçãos que recebo e que são renovadas a cada dia. 


\section{NORMATIZAÇÃO ADOTADA}

Esta dissertação está de acordo com as seguintes normas, em vigor no momento desta publicação:

Referências: adaptado de International Committtee of Medical Journals Editors (Vancouver)

Universidade de São Paulo. Faculdade de Medicina. Serviço de Biblioteca e Documentação. Guia de apresentação de dissertações, teses e monografias. Elaborado por Anneliese Carneiro da Cunha, Maria Julia de A. L. Freddi, Maria F. Crestana, Marinalva de Souza Aragão, Suely Campos Cardoso, Valéria Vilhena. $2^{\underline{a}}$ Ed. São Paulo: Serviço de Biblioteca e Documentação; 2005.

Abreviaturas dos títulos dos periódicos de acordo com List of Journals Indexed in Índex Medicus. 


\section{SUMÁRIO}

Lista de abreviaturas e siglas

Lista de quadros

Lista de tabelas

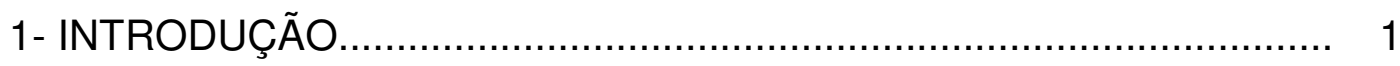

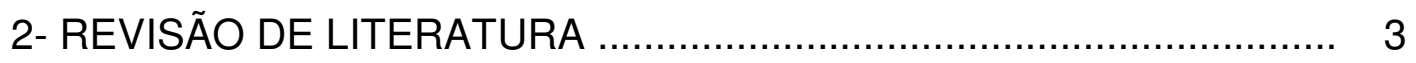

2.1 - Acidente Vascular Encefálico ................................... 3

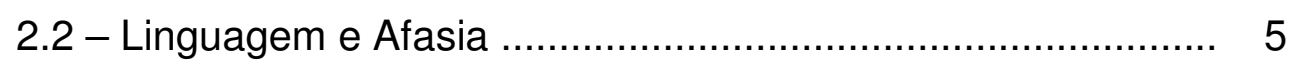

2.3 - Afasia e Funções Cognitivas Não Linguísticas .................... 15

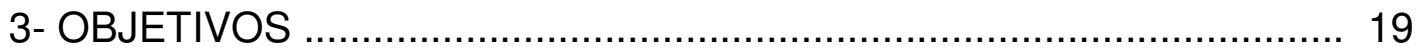

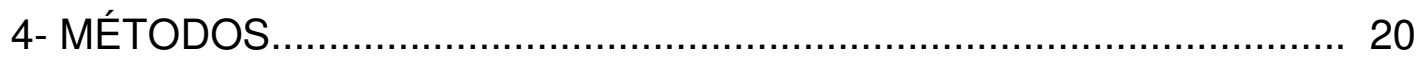

3.1 - Captação dos sujeitos .......................................... 20

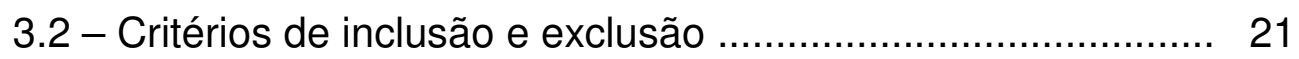

3.3 - Materiais e procedimentos .......................................... 22

3.4 - Análise estatística dos dados ....................................... 28

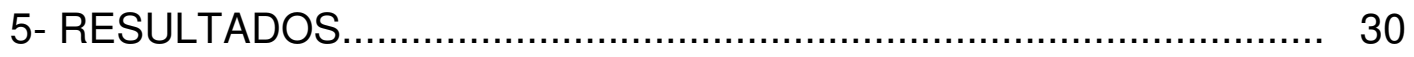



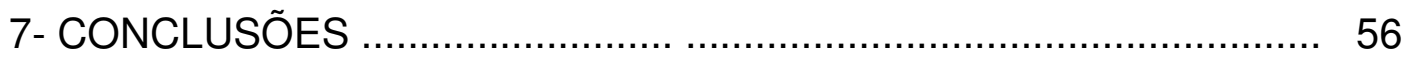

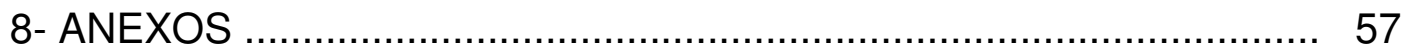



Apêndices 


\section{LISTA DE ABREVIATURAS E SIGLAS}

ACL - Aphasia Check List

$\mathrm{AF}$ - afásicos

AFg - afásicos graves

AFI - afásicos leves

AVE - Acidente vascular encefálico

AVE $\mathrm{h}$ - Acidente vascular encefálico hemorrágico

AVE i - Acidente vascular encefálico isquêmico

CLQT - Cognitive Linguistic Quick Test

et al. - e outros

EMMA - Estudo da Morbidade e Mortalidade do Acidente Vascular Cerebral

GANBA - Global Aphasic Neuropsychological Battery

HD - hemisfério direito

$\mathrm{HE}$ - hemisfério esquerdo

HIP - hemorragia intraparenquimatosa

HSA - Hemorragia subaracnóide

HU / USP - Hospital Universitário da Universidade de São Paulo

NAF D - não afásicos com lesão em hemisfério direito

NAF E - não afásicos com lesão em hemisfério esquerdo

SAQOL-39 - The Stroke and Aphasia Quality of Life Scale - 39-item version

SBPV - substância branca periventricular

TBDA - Teste de Boston para o Diagnóstico da Afasia

TC - Tomografia Computadorizada

TNB - Teste de Nomeação de Boston 


\section{LISTA DE QUADROS}

Quadro 1 - Lesões anteriores (frontais) e sintomatologia ......................... 10

Quadro 2 - Lesões posteriores (temporais / parietais) e sintomatologia .... 11

Quadro 3 - Lesões combinadas (fronto-parieto-temporais)

e sintomatologia .11 


\section{LISTA DE TABELAS}

Tabela 1 - Caracterização da amostra, segundo dados demográficos, tempo transcorrido entre o icto e a avaliação, escores nas escalas de Hamilton e SAQOL-39, tipo de AVE e lateralidade da lesão 30

Tabela 2 - Alterações neurológicas nos grupos

Tabela 3 - Distribuição da localização da lesão nos grupos de afásicos e não afásicos

Tabela 4 - Distribuição da amostra de afásicos, segundo a classificação das afasias, gravidade e localização da lesão 33

Tabela 5 - Distribuição da localização das lesões segundo a gravidade da afasia

Tabela 6 - Desempenho dos afásicos e não afásicos no Teste de Boston para Diagnóstico da Afasia, Teste de Nomeação de Boston e nas provas de Fluência Verbal

Tabela 7 - Desempenho dos afásicos e não afásicos nas provas de Praxias Gestuais

Tabela 8 - Desempenho dos afásicos e não afásicos nas provas de

Praxias Gestuais, segundo a gravidade da afasia 38

Tabela 9 - Desempenho dos afásicos e não afásicos nas provas Cognitivas 39 
Tabela 10 - Comparação entre afásicos e não afásicos nas provas cognitivas, segundo a gravidade da afasia ......

Tabela 11 - Correlações entre as provas de praxias gestuais e a gravidade da afasia 43 


\section{RESUMO}

Bonini MV. Relação entre alterações de linguagem e déficits cognitivos não linguísticos em indivíduos afásicos após acidente vascular encefálico [dissertação]. São Paulo: Faculdade de Medicina, Universidade de São Paulo; 2010.

A interface entre a linguagem e demais funções cognitivas tem sido objeto de estudo e a ampla e extensa distribuição dos circuitos neuronais torna o tema bastante complexo. A dificuldade em avaliar o desempenho cognitivo de afásicos faz com que estes pacientes sejam excluídos em estudos que buscam descrever alterações cognitivas após AVE. A avaliação de linguagem, isoladamente, não permite predizer o desempenho em outras habilidades cognitivas. Além disso, o processamento da linguagem se apóia nas habilidades de atenção, memória e funções executivas. A literatura nacional é escassa neste tema. Este trabalho teve como objetivos: avaliar o desempenho dos indivíduos afásicos em tarefas cognitivas não linguísticas (atenção, memória verbal e não verbal, funções executivas e habilidades visuoespaciais), comparar o desempenho dos afásicos e não afásicos nestas tarefas e relacionar o desempenho dos afásicos nas tarefas cognitivas não linguísticas com a gravidade da afasia. Participaram da pesquisa 47 indivíduos, maiores de 18 anos, de ambos os gêneros, com escolaridade mínima de dois anos, e diagnóstico de primeiro episódio de AVE, confirmado por TC de crânio. Aplicada a seguinte bateria de testes: 
Protocolo de Praxias Gestuais (TBDA), Fluência verbal semântica (animais) e Fonológica (FAS), Teste de Trilhas A e B, Teste de Cancelamento, Aprendizado de Palavras (CERAD), Aprendizado de Figuras (BBRC-Edu), Praxias construtivas (CERAD), Extensão de Dígitos (ED) e Desenho do Relógio (TDR). A amostra foi dividida em três grupos: afásicos ( $A F, n=21$ ), não afásicos com lesão em hemisfério esquerdo (NAF $E, n=17)$ e não afásicos com lesão em hemisfério direito (NAF $D, n=9$ ). $O$ grupo de afásicos foi também subdividido em grupos grave (AFg) e leve (AFI). Não houve diferença estatisticamente significante entre os grupos nas provas de Cancelamento, Teste de Trilhas, Praxias Construtivas. Os afásicos apresentaram pior desempenho, em comparação aos grupos NAF E e NAF D, nas provas de fluência semântica, praxias gestuais, ED (ordens direta e inversa), Aprendizado de Palavras, Evocação das Praxias Construtivas (pontuação total), Aprendizado de Figuras e TDR. Na prova de extensão de dígitos, ordem direta, constatou-se pior desempenho do grupo AFg, em comparação ao AFI. Foi encontrada correlação entre a gravidade da afasia e o desempenho no teste de extensão de dígitos em ordem direta ( $r h o=0,860, p=0,0001$ ) e ordem inversa ( $r h o=0,543, p=0,0152$ ), e nas provas de praxias gestuais, especialmente nas praxias bucofaciais e respiratórias (rho $=0,708, p=0,016)$. Constatou-se pior desempenho dos grupos AF e NAF E, em comparação ao grupo NAF D, nas provas de reconhecimento de palavras, Aprendizado de Figuras e TDR. Fatores como prejuízo na expressão oral e hemiparesia interferiram no desempenho dos sujeitos afásicos. A literatura aponta e o estudo confirma que os afásicos 
demonstram grande variabilidade no desempenho. Mostram-se necessários instrumentos mais adequados para a avaliação das habilidades não linguísticas em afásicos, além de estudos que possam ser replicados em diferentes populações. A avaliação do afásico que não considere somente as habilidades linguísticas, mas também outras funções cognitivas, pode auxiliar na elaboração de planejamentos terapêuticos mais adequados e, aumentar a eficácia da terapia de linguagem.

Descritores: Afasia - Transtornos cognitivos - Acidente cerebral vascularLinguagem - Cognição 
Bonini MV. The relationship between language disorders and non-linguistic cognitive deficits in aphasic individuals post-stroke [dissertation]. Faculty of Medicine, University of Sao Paulo, SP (Brazil); 2010.

The interface between language and other cognitive functions has been studied and the broad and extensive distribution of neural circuits has made the theme become very complex. The difficulty in assessing cognitive performance in aphasic patients excludes these patients from studies describing post-stroke cognitive deficits. Language assessment itself does not allow predicting the performance in other cognitive skills. Furthermore, language processing is supported by other cognitve abilities such as attention, memory, and executive functions. The literature about this theme in Brazil is scarce. This study aimed to evaluate the performance of aphasic patients in non-linguistic cognitive tasks (attention, verbal memory, non-verbal memory, executive functions and visuospatial skills), to compare the performance of aphasic and non-aphasic patients in non-linguistic cognitive tasks, and to correlate the performance of aphasic patients in nonlinguistic cognitive tasks and the aphasia severity. Forty seven individuals over 18 years old were enrolled in this research, both male and female, with minimum schooling level of two years, and diagnosis of first episode of stroke confirmed by CT brain scan. The following battery of tests was applied: Gesture Praxis Protocol (BDAE), Semantic (animals) and Phonemic (FAS) 
verbal fluency, Trail Making Test A and B, Cancellation Test, Word List Memory (CERAD), Figure Learning (BCB-Edu), Constructional Praxis (CERAD), Digit Span (DS) and Clock Drawing Test (CDT). The sample was divided in three groups: aphasic (AP, $n=21)$, non-aphasic with left hemisphere lesion (NAP E, $n=17$ ), and non-aphasic with right hemisphere lesion (NAP $D, n=9$ ). The group of aphasic patients was also subdivided in severe (APs) and mild (APm). There was no significant statistical difference between the groups in the Cancellation Test, in the Trail Making test, and in the Constructional Praxis. The aphasic presented worse performance in comparison to groups NAP E and NAP D in Semantic fluency task, gesture praxis, DS (forward and backward), Word List Memory, Constructional Praxis recall (total score), Figure Learning, and CDT. In the Digit Span test, forward order, it was observed worse performance of group APs, in comparison to APm. It was verified a correlation between the aphasia severity and the performance in the DS test, forward order ( $\mathrm{rho}=0,860, \mathrm{p}=0,0001)$ and backward order ( $r h o=0,543, p=0,0152$ ), and in the Gesture Praxis test mainly in bucco-facial and respiratory praxis (rho $=0,708, p=0,016$ ). It was observed worse performance of groups AP and NAP E, in comparison to group NAP D, in the Word Recognition task, Figure Learning and CDT. The impairment of oral expression and hemiparesis interfered in the performance of aphasic patients. Literature points, and the study confirms, that aphasic patients show great variability in the performance. More adequate instruments for the assessment of non-linguistic skills in aphasic patients are necessary, besides studies that may be replicated in different populations. The assessment of 
aphasic patients considering not only linguistic skills, but also other cognitive functions may help in the elaboration of more appropriate therapeutic planning and increase the efficacy of language therapy.

Descriptors: Aphasia - Cognitive disorders - Stroke - Language - Cognition 


\section{1- INTRODUÇÃO}

A interface entre a linguagem e demais funções cognitivas tem sido objeto de estudo. A ampla e extensa distribuição dos circuitos neuronais relacionados às funções cognitivas torna o tema bastante complexo. $O$ processamento da linguagem depende de habilidades como atenção, memória e funções executivas, para que seja garantido um bom desempenho linguístico.

Os estudos na área buscam evidenciar se alterações de linguagem tem impacto no desempenho em habilidades cognitivas não linguísticas, se são os déficits não linguísticos que interferem na linguagem e ainda, se ambos os processos ocorrem.

Os achados na literatura são bastante variáveis e a dificuldade em avaliar o desempenho cognitivo de certas populações, tais como a de afásicos é descrita, motivo pelo qual muitas vezes estes são excluídos da amostra em estudos que buscam descrever alterações cognitivas após AVE.

Uma série de estudos relata a associação entre a afasia e o prejuízo em outras habilidades cognitivas, tais como memória ${ }^{1,2}$, atenção ${ }^{3}$, raciocínio ${ }^{4}$, funções executivas ${ }^{5}$ e habilidades visuoespaciais ${ }^{6}$.

Recentemente, tem sido estudada a possível influência de déficits cognitivos não linguísticos na eficácia da terapia de linguagem ${ }^{7,8}$.

Acredita-se que a avaliação do afásico que não considere somente as 
habilidades linguísticas, mas também outras funções cognitivas, pode auxiliar na elaboração de planejamentos terapêuticos mais adequados e, dessa forma, aumentar a eficácia da terapia de linguagem.

A literatura nacional mostra-se bastante escassa na apresentação de dados e de discussão sobre todos os pontos supracitados. E esta constatação despertou ainda maior motivação para que fosse realizado o estudo que apresentamos a seguir. 


\section{2- REVISÃO DE LITERATURA}

\section{1- Acidente Vascular Encefálico}

Acidente vascular encefálico (AVE) é o termo usado para designar o déficit neurológico (transitório ou definitivo), secundário à lesão vascular em uma área cerebral. Representa um grupo de doenças com manifestações clínicas semelhantes, mas que possuem etiologias diversas. Os AVEs podem ser classificados em ${ }^{9}$ :

- AVE hemorrágico (AVEh), o qual compreende a hemorragia subaracnóide (HSA), em geral, decorrente da ruptura de aneurismas saculares congênitos localizados nas artérias do polígono de Willis, e a hemorragia intraparenquimatosa (HIP), cujo mecanismo causal básico é a degeneração hialina de artérias intraparenquimatosas cerebrais. Além disso, podem ocorrer a partir de outros mecanismos, como a ruptura de malformações artério-venosas, discrasias sanguíneas, tromboses venosas, complicações do uso de agentes anticoagulantes ou antiagregantes plaquetários, alcoolismo e neoplasias;

- AVE isquêmico (AVEi), déficit neurológico resultante da insuficiência de suprimento sanguíneo cerebral, podendo ser temporário (episódio isquêmico transitório) ou permanente. Tal insuficiência de suprimento sanguíneo pode ser decorrente de processo trombótico ou aterotrombótico por aterosclerose ou dissecção arterial (espontânea ou traumática), embólico (embolias de 
origem cardíaca ou arterial) ou hemodinâmico, por choque ou parada cardiorrespiratória.

Doenças como hipertensão, diabetes e as cardiopatias são fatores que aumentam a probabilidade de um indivíduo apresentar um quadro de AVE, assim como tabagismo, estresse, hipercolesterolemia, sedentarismo e consumo excessivo de álcool ${ }^{10,11,12,13}$. O acesso ao sistema de saúde mostra-se fator crítico na prevenção, assim como na recuperação e reabilitação, uma vez ocorrido o AVE $^{14}$.

As doenças vasculares encefálicas constituem a terceira causa de morte em vários países desenvolvidos, perdendo apenas para as cardiopatias e câncer ${ }^{15}$. De acordo com estimativa recente, o número anual de óbitos decorrentes de AVE no mundo, chega a 5 milhões e 540 mil $^{16}$.

No Brasil, atualmente, o AVE é considerado a primeira causa de morte em adultos. As elevadas taxas de mortalidade decorrentes de AVE no Brasil, bem como a constatação destas como sendo as mais altas em comparação aos demais países latino-americanos, encontram-se descritas

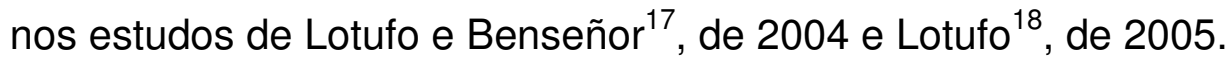

O AVE causa grande impacto sobre a saúde populacional, além dos impactos social, econômico e psicológico ${ }^{15}$. Com o crescimento da população idosa, tal impacto deve tornar-se ainda maior nas próximas décadas ${ }^{19}$.

Dentre as possíveis complicações e sequelas do AVE, podem ser destacados déficits motores, sensitivos e visuais, crises epilépticas, 
infecções, depressão, disfagia e alterações de comunicação e linguagem, tais como as afasias, todos levando a incapacidades funcionais.

Qualidade de vida relacionada à saúde pode ser conceituada como os aspectos físicos, psicológicos e sociais da vida do indivíduo que podem ser afetados a partir de mudanças nas condições de saúde ${ }^{20}$. Como exemplo, Mayo et al. ${ }^{21}$, em estudo no qual foram entrevistados 434 pacientes cerca de seis meses após a ocorrência de AVE, descreveram que 39\% dos entrevistados relataram limitações em atividades funcionais, 54\%, limitações em atividades como o cuidar da casa e fazer compras, e $65 \%$ relataram restrições na reintegração em atividades da comunidade.

\section{2- Linguagem e Afasia}

De acordo com a American Speech and Hearing Association $(\mathrm{ASHA})^{22}$

linguagem é um complexo e dinâmico sistema de símbolos convencionais que é utilizado de vários modos para 0 pensamento e a comunicação. Visões contemporâneas da linguagem sustentam que ela evolve no âmbito de contextos históricos, sociais e culturais específicos; é um comportamento governado por regras, descrito por pelo menos cinco parâmetros - fonológico, morfológico, sintático, semântico e pragmático; seu aprendizado e seu uso são determinados pela interação de fatores biológicos, cognitivos, psicossociais e ambientais; seu uso efetivo para comunicação requer um largo entendimento da interação humana incluindo fatores associados, tais como pistas não verbais, motivação e papéis sociais. 
Quanto às alterações relacionadas à linguagem, o estudo das afasias, iniciado há mais de 100 anos, é um dos mais instigantes. Este se mostra complexo, devido à variedade de suas manifestações, heterogeneidade de seus substratos neurológicos, e à sofisticação necessária à compreensão dos mecanismos envolvidos na sintomatologia apresentada ${ }^{23}$.

A afasia pode ser definida como uma alteração no conteúdo, forma e/ou uso da linguagem e de seus processos subjacentes, tais como percepção e memória. É caracterizada por redução e disfunção, que se manifestam tanto no aspecto expressivo quanto no receptivo da linguagem oral e escrita, embora em diferentes graus em cada uma dessas modalidades $^{23}$.

O grande número de trabalhos em Afasiologia e, consequentemente, a variedade de síndromes presentes na literatura tornaram a afasia uma das sequelas neurológicas com maior número de classificações. Historicamente, as afasias foram classificadas como "emissivas", "receptivas" e "mistas", considerando-se como áreas de comprometimento a emissão, a recepção ou ambas, em grau equivalente, respectivamente ${ }^{24}$.

O modelo Wernicke-Geschwind acrescentou grande valor às pesquisas desta área, formando a base para a classificação das afasias, mais utilizada na prática clínica. Segundo esse modelo, a área de Wernicke realizaria o processamento das imagens acústicas das palavras e a área de Broca seria responsável pela articulação da fala. O fascículo arqueado foi descrito como uma via unidirecional, a qual transmitiria a informação da área 
de Wernicke para a área de Broca. Essas áreas, por sua vez, interagiriam com as de associação polimodais ${ }^{25}$.

A classificação das afasias é realizada considerando-se o desempenho nos seguintes parâmetros clássicos:

- Fluência - parâmetro utilizado para dividir os quadros de afasia em fluentes e não fluentes. Considera o número de palavras no tempo, prosódia, articulação, esforço inicial para a produção oral, extensão das frases e o conteúdo das palavras;

- Compreensão Auditiva - função complexa decorrente do processamento dos sons da fala na área de Wernicke, e ocorre quando os conceitos associados à palavra registrada são ativados e selecionados. Esse processo envolve várias áreas de diferentes modalidades e hierarquias distribuídas por todo o cérebro ${ }^{26}$;

- Repetição - um dos mecanismos mais elementares da linguagem humana. Envolve a transcodificação audiofonatória, sem acesso ao significado para a repetição de não palavras e com o acesso em questão para a repetição de palavras ${ }^{27}$.

A avaliação dos parâmetros definidos acima permite a descrição das seguintes manifestações, as quais podem ser encontradas nos diferentes quadros de afasia ${ }^{28}$ :

- parafasias: fonética - caracterizada por uma distorção dos fonemas, sendo estes mal pronunciados; fonêmica - inadequação na seleção dos fonemas ou na combinação destes na cadeia da fala, manifestando-se como 
trocas, omissões, acréscimos de fonemas ou sílabas; morfêmica substituição dos morfemas gramaticais das palavras (amigo por amiga, falamos por falar); formal - troca, substituição, omissão ou acréscimo que originam outra palavra da língua, mas não se trata de troca semântica (emissão de "marmelo" para "martelo"); verbal - emissão de palavra existente na língua, mas que não apresenta relação com o vocábulo-alvo (emissão de "cadeira" para "maçã"); semântica - troca de um vocábulo por outro, sendo que ambos estão relacionados semanticamente (emissão de "caneta” para "lápis"). Paralexias - alterações semelhantes às descritas, observadas na leitura em voz alta - paralexias fonêmicas, formais, verbais, semânticas e literais; paragrafias - alterações semelhantes, observadas na emissão gráfica;

- paráfrase - substituição do vocábulo-alvo por uma frase ("aquilo que serve para pentear" para "pente");

- anomias - dificuldade em nomear o estímulo alvo. Pode estar relacionada à dificuldade no acesso fonológico, lexical ou semântico ou na passagem da informação entre alguns dos subsistemas;

- circunlóquio - manifestação que evidencia a dificuldade no acesso ao tema principal da enunciação;

- agramatismo - alteração na estrutura sintática, caracterizada pela omissão de elementos da frase, podendo ocorrer nas emissões oral e gráfica;

- redução - diminuição do número de enunciados numa unidade de tempo. Também podem ocorrer nas emissões oral e gráfica; 
- neologismos - sequências fonêmicas ou grafêmicas que obedecem às regras da língua e que se assemelham a palavras, mas que não existem na língua;

- estereotipias - repetições perseverantes e involuntárias de um determinado comportamento, podendo ocorrer nas emissões oral e gráfica;

- perseveração - manutenção da mesma resposta para estímulos distintos;

- supressão - ausência total de emissão oral ou gráfica; tal termo pode ser considerado sinônimo de mutismo, quando utilizado em relação à emissão oral.

Goodglass e Kaplan ${ }^{29}$, em 1972, atribuíram à afasia os termos fluente e não fluente, respectivamente, para afasias sensoriais e motoras. Desse modo, lesões na parte anterior do cérebro (anteriores à fissura Sylviana) causariam afasias não fluentes (predominando dificuldades de expressão da linguagem), enquanto as lesões posteriores causariam afasias fluentes (predominando dificuldades de compreensão de linguagem). A partir desta divisão, os autores classificaram as afasias e as correlacionaram às lesões responsáveis, conforme ilustram os quadros 1,2 e 3. 
Quadro 1 - Lesões anteriores (frontais) e sintomatologia:

\begin{tabular}{|c|c|c|}
\hline SINTOMA / AFASIA & BROCA & $\begin{array}{l}\text { TRANSCORTICAL } \\
\text { MOTORA }\end{array}$ \\
\hline FLUÊNCIA & não fluente & não fluente \\
\hline CARACTERÍSTICA TÍPICA & agramatismo (fala e escrita) & $\begin{array}{c}\text { simplificação gramatical } \\
\text { ecolalia } \\
\text { dificuldade de iniciação } \\
\text { da fala }\end{array}$ \\
\hline COMPREENSÃO & $\begin{array}{c}\text { variável (oral e escrita) em função } \\
\text { do grau de agramatismo }\end{array}$ & $\begin{array}{l}\text { compreensão boa (oral e } \\
\text { escrita), podendo haver } \\
\text { prejuízo em função de } \\
\text { perdas cognitivas } \\
\text { relativas à lesão frontal }\end{array}$ \\
\hline REPETIÇÃO & Ruim & Boa \\
\hline NOMEAÇÃO & ruim (erros semânticos) & $\begin{array}{l}\text { prejudicada (parafasias, } \\
\text { perseverações) }\end{array}$ \\
\hline ESCRITA & proporcional à fala & proporcional à fala \\
\hline $\begin{array}{l}\text { LOCAL DA LESÃo (SEMPRE } \\
\text { HEMISFÉRIO DOMINANTE) }\end{array}$ & $\begin{array}{l}\text { frontal dorso-lateral + substância } \\
\text { branca periventricular (SBPV) } \\
\text { frontal + núcleos da base }\end{array}$ & $\begin{array}{c}\text { frontal dorso-lateral + } \\
\text { SBPV } \\
\text { área motora suplementar } \\
\text { frontal mesial }\end{array}$ \\
\hline SINAIS ASSOCIADOS & $\begin{array}{l}\text { hemiparesia } \mathrm{D} \text {, apraxia oro-facial, } \\
\text { depressão }\end{array}$ & $\begin{array}{l}\text { hemiparesia } D \text {, grasping, } \\
\text { apraxia oro-facial }\end{array}$ \\
\hline FISIOPATOLOGIA & $\begin{array}{c}\text { rede fronto-estriatal: produção } \\
\text { complexa (sintaxe e discurso } \\
\text { narrativo) }\end{array}$ & $\begin{array}{l}\text { déficit gerativo e da } \\
\text { iniciação da fala (ativação } \\
\text { frontal por vias } \\
\text { ascendentes } \\
\text { dopaminérgicas) }\end{array}$ \\
\hline SíNDROMES FRACIONADAS & $\begin{array}{l}\text { afemia (alteração residual da } \\
\text { articulação e prosódia) }\end{array}$ & \\
\hline
\end{tabular}

FONTE: Mansur LL, Radanovic M. Neurolingüística: Princípios para a prática clínica. $2004 ; 131$.

Quadro 2 - Lesões posteriores (temporais / parietais) e sintomatologia:

\begin{tabular}{|c|c|c|c|}
\hline $\begin{array}{l}\text { SINTOMA / } \\
\text { AFASIA }\end{array}$ & WERNICKE & $\begin{array}{l}\text { TRANSCORTICAL } \\
\text { SENSORIAL }\end{array}$ & CONDUÇÃO \\
\hline FLUÊNCIA & $\begin{array}{l}\text { fluente, porém vazia } \\
\text { (parafasias, } \\
\text { circunlóquios) }\end{array}$ & Fluente & Fluente \\
\hline $\begin{array}{l}\text { CARACTERÍSTICA } \\
\text { TÍPICA }\end{array}$ & $\begin{array}{l}\text { jargonafasia } \\
\text { dissintaxia }\end{array}$ & $\begin{array}{c}\text { parafasias } \\
\text { semânticas } \\
\text { circunlóquios }\end{array}$ & parafasias fonêmicas \\
\hline COMPREENSÃo & $\begin{array}{l}\text { Ruim (oral e escrita), } \\
\text { desde o nível de } \\
\text { discriminação de } \\
\text { palavras a material } \\
\text { complexo }\end{array}$ & ruim (oral e escrita) & Boa (oral e escrita) \\
\hline REPETIÇÃO & Ruim & Boa & $\begin{array}{l}\text { Desproporcionalmente } \\
\text { ruim }\end{array}$ \\
\hline NOMEAÇÃo & $\begin{array}{l}\text { ruim (parafasias, } \\
\text { circunlóquios, } \\
\text { ausência de } \\
\text { resposta) }\end{array}$ & Prejudicada & $\begin{array}{c}\text { prejudicada de forma } \\
\text { variável }\end{array}$ \\
\hline ESCRITA & proporcional à fala & proporcional à fala & $\begin{array}{c}\text { pior que a fala, } \\
\text { podendo ocorrer alexia } \\
\text { com agrafia }\end{array}$ \\
\hline
\end{tabular}

continua 
continuação

Quadro 2 - Lesões posteriores (temporais / parietais) e sintomatologia:

\begin{tabular}{|c|c|c|c|}
\hline $\begin{array}{l}\text { SINTOMA / } \\
\text { AFASIA }\end{array}$ & WERNICKE & $\begin{array}{l}\text { TRANSCORTICAL } \\
\text { SENSORIAL }\end{array}$ & CONDUÇÃO \\
\hline $\begin{array}{l}\text { LOCAL DA LESÃO } \\
\text { (SEMPRE } \\
\text { HEMISFÉRIO } \\
\text { DOMINANTE) }\end{array}$ & $\begin{array}{c}\text { giro temporal } \\
\text { superior } \\
\text { área têmporo- } \\
\text { parieto-occipital: } \\
\text { predomina alexia }\end{array}$ & $\begin{array}{l}\text { giro temporal médio e } \\
\text { inferior } \\
\text { área têmporo-parieto- } \\
\text { occipital: predomina } \\
\text { alexia }\end{array}$ & $\begin{array}{l}\text { Giro supramarginal } \\
\text { (parietal inferior) }\end{array}$ \\
\hline $\begin{array}{c}\text { SINAIS } \\
\text { ASSOCIADOS }\end{array}$ & $\begin{array}{l}\text { hemianopsia D, } \\
\text { anosognosia, } \\
\text { agitação }\end{array}$ & Agnosias & $\begin{array}{l}\text { hipoestesia } D \text {, } \\
\text { quadrantanopsia }\end{array}$ \\
\hline FISIOPATOLOGIA & & $\begin{array}{c}\text { desordem do } \\
\text { processamento } \\
\text { semântico (interface } \\
\text { linguagem / memória } \\
\text { semântica) }\end{array}$ & $\begin{array}{c}\text { Desordem do } \\
\text { processamento } \\
\text { fonológico (vias curtas } \\
\text { de associação } \\
\text { têmporo-parietais) } \\
\text { alteração da memória } \\
\text { verbal de curto prazo }\end{array}$ \\
\hline $\begin{array}{l}\text { SíNDROMES } \\
\text { FRACIONADAS }\end{array}$ & $\begin{array}{c}\text { surdez verbal pura } \\
\text { (agnosia auditiva } \\
\text { para palavras) } \\
\text { em geral, lesões } \\
\text { bilaterais }\end{array}$ & & \\
\hline
\end{tabular}

FONTE: Mansur LL, Radanovic M. Neurolingüística: Princípios para a prática clínica. $2004 ; 132$.

Quadro 3 - Lesões combinadas (fronto-parieto-temporais) e sintomatologia:

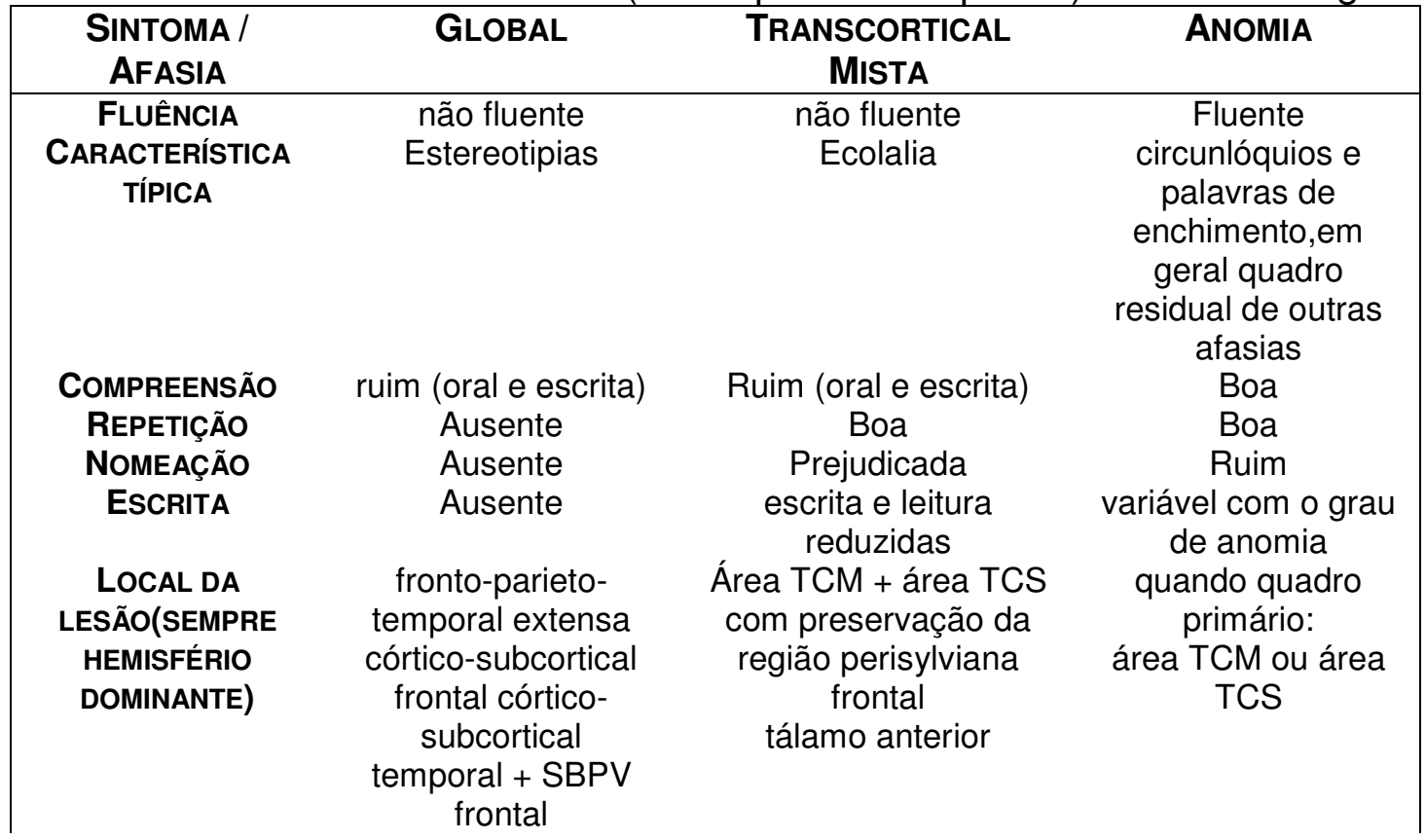


Quadro 3 - Lesões combinadas (fronto-parieto-temporais) e sintomatologia:

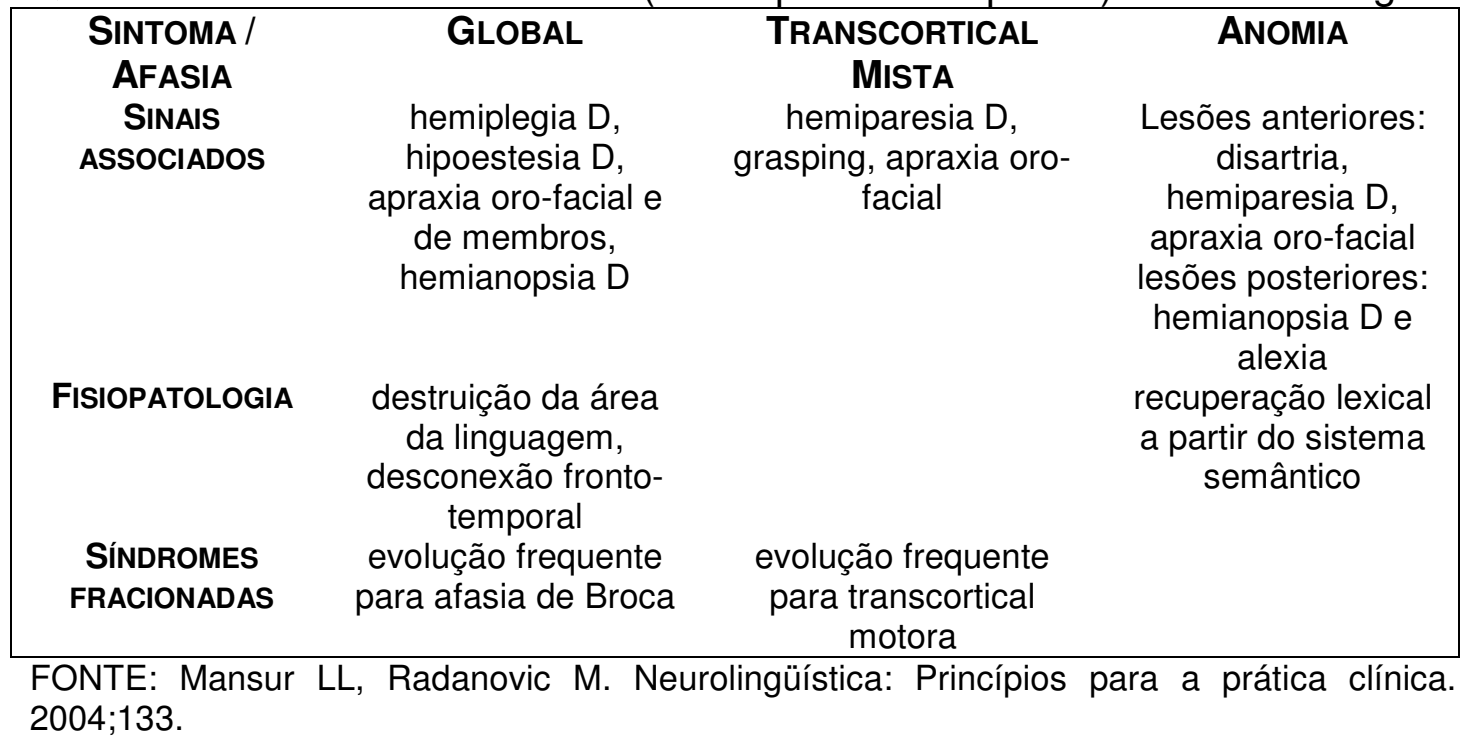

Lesões subcorticais, as quais passaram a ser melhor estudadas com o advento da neuroimagem, podem produzir enorme variedade de alterações de fala e linguagem, quanto ao tipo e à gravidade. De forma bastante sucinta, estudos descrevem que, nas lesões de núcleos da base, predominam as alterações motoras-articulatórias e dificuldades lexicais. Nas lesões acometendo o tálamo, podem ser observadas anomia, alterações de repetição e compreensão ${ }^{30,31}$. Os estudos sugerem que as alterações de linguagem decorrentes de lesões subcorticais são multifatoriais e não estão relacionadas apenas ao processamento linguístico em si, mas também a outros processos cognitivos ${ }^{32,33}$. Estes fatores incluem: interrupção das vias de conexão entre as áreas clássicas da linguagem; mecanismo de diásquise; lesão direta de estruturas subcorticais envolvidas primariamente na linguagem; fatores hemodinâmicos, em que a dinâmica circulatória 
desempenha papel crucial na manifestação dos sintomas de linguagem e no grau de recuperação após lesões; papel do tálamo no alerta e na ativação cortical e atenção, bem como na monitoração da produção verbal e liberação de segmentos de linguagem formulados para as áreas de programação motora da fala.

Os estudos quanto à incidência e prevalência da afasia e de seus subtipos oferecem estimativas bastante variáveis, de acordo com a amostragem e a descrição dos métodos. Estimativa realizada por Marquardsen ${ }^{34}$ menciona que aproximadamente um terço dos pacientes que sobrevivem à primeira semana após o AVE apresenta quadro de afasia. Scarpa et al. ${ }^{35}$ estimaram que $55 \%$ dos pacientes com lesão em hemisfério esquerdo decorrente de AVE apresentam quadro de afasia 15 a 30 dias após o icto.

Kauhanen et al. ${ }^{36}$, Viúde ${ }^{37}$ e Wade et al. ${ }^{38}$ constataram variação entre $21 \%$ e $38 \%$ na prevalência de afasia em seus estudos. Pedersen et al. ${ }^{39}$ demonstram prevalência de afasia maior que $40 \%$ em pacientes avaliados nos primeiros três dias após o AVE.

De acordo com o National Institute for Deafness and Other Communication Disorders ${ }^{40}$, são constatados cerca de 80.000 novos casos de afasia, anualmente.

A afasia decorrente de AVE está associada a aumento da mortalidade $^{41}$, a piores condições de recuperação funcional ${ }^{42,43}$ e a uma menor probabilidade de retorno às atividades ocupacionais ${ }^{44}$, em comparação aos indivíduos não afásicos. Fatores como idade, gênero, 
comorbidades, gravidade e localização do AVE podem influenciar o prognóstico do quadro de afasia, mas os resultados dos estudos que buscaram descrever 0 real impacto dessas variáveis não são consistentes ${ }^{45,46,47}$.

Os efeitos da alteração brusca nos casos de afasia decorrente de AVE podem ser estimados a partir da constatação do papel que a comunicação desempenha para 0 indivíduo, proporcionando o desenvolvimento e a manutenção de sua identidade, garantindo a transmissão e recepção de informações vitais sobre o autocuidado e o cuidado realizado por outros, amenizando sua solidão, depressão e ansiedade, favorecendo o exercício de poder e de influências sociais, permitindo a reflexão sobre a própria vida, estimulando o funcionamento cognitivo pela possibilidade de interação com diversos e constantes estímulos sensoriais e interpessoais, além de receber os benefícios estéticos e lúdicos do ambiente ${ }^{48}$.

Apesar dos esforços no mundo todo, com o objetivo de melhorar o modo como os indivíduos com desvantagem são tratados, sérias atitudes negativas permanecem. Indivíduos com sequelas de AVE e que apresentam afasia podem enfrentar barreiras "de atitude", tais como rejeição, desconfiança e estigmatização $0^{49}$.

Em resumo, o quadro de afasia pode provocar alterações na construção de redes sociais, gerar dependência e excluir o indivíduo do exercício do papel de adulto ativo no ambiente familiar e em outros ambientes sociais ${ }^{50}$. 


\title{
2.3- Afasia e Funções Cognitivas Não Linguísticas
}

\author{
Segundo Bayles ${ }^{51}$, a cognição \\ se refere ao que conhecemos e aos processos \\ que nos permitem adquirir e manipular \\ informações.
}

De acordo com Lezak ${ }^{52}$, a cognição pode ser dividida em domínios, como percepção, linguagem, memória, habilidades visuoespaciais, praxias, e pensamento (abstração, julgamento, análise e síntese). A atividade cognitiva depende e está estreitamente ligada a outras funções mentais, entre as quais se destacam a atenção e funções executivas. $O$ processamento da linguagem depende de outras habilidades cognitivas como atenção, memória, funções executivas e habilidades visuoespaciais, as quais atuam como sistemas de suporte.

A existência de inter-relação entre a linguagem e outras funções cognitivas é bem estabelecida; porém, os esforços dos estudiosos da área estão voltados para a busca de evidências sobre como e em qual grau os diferentes domínios cognitivos são recrutados para interagir entre si e ainda, sobre o impacto da alteração de uma determinada função cognitiva nas demais.

Com relação à afasia, a literatura aponta que o olhar para além da linguagem foi inicialmente considerado por Luria ${ }^{53}$ em suas abordagens terapêuticas. Recentemente, muitos autores tem ressaltado a importância da avaliação das funções cognitivas não linguísticas em afásicos, e da 
abordagem destas em terapia, para que seja alcançada maior eficácia na reabilitação.

Algumas pesquisas tem buscado descrever a ocorrência de prejuízo no desempenho de indivíduos após AVE, especialmente de afásicos, em tarefas não linguísticas ${ }^{36,54,55,56,57}$. Estudo de Kalbe et al. ${ }^{1}$, em que buscou validar um determinado instrumento para a avaliação de linguagem e de funções cognitivas não linguísticas (memória, atenção e raciocínio), descreve que os afásicos apresentaram prejuízo em pelo menos uma das três funções cognitivas testadas, sendo que 76\% destes apresentaram déficit de memória, 77\% de atenção e $73 \%$ na prova de raciocínio.

Burgio e Basso $^{58}$, ao investigarem o desempenho em tarefas de memória operacional e de longo prazo em lesados de HE (fase aguda e pósaguda), concluíram que essa população apresentou prejuízo importante nas tarefas, em comparação aos controles, mas descreveu que a presença de afasia não interferiu no desempenho.

Seniów, Litwin e Lésniak $^{59}$ avaliaram a memória visuoespacial e o pensamento abstrato de afásicos e controles normais e descreveram prejuízo dos afásicos em ambas as habilidades cognitivas. Os autores ressaltam a heterogeneidade dos resultados. De Renzi e Nichelli ${ }^{60}$, ao avaliarem o desempenho de 125 indivíduos com lesão cerebral unilateral após AVE em tarefas de memória verbal e não verbal de curto prazo, constataram prejuízo no desempenho dos indivíduos lesados de HE para ambas as tarefas. Neste estudo, os indivíduos afásicos apresentaram maior 
prejuízo nas tarefas de memória verbal em comparação aos não afásicos, lesados de HE.

Grande parte dos testes neuropsicológicos utilizados pela literatura para a avaliação do desempenho de afásicos em tarefas não linguísticas dependem do processamento verbal e por esta razão, mostram-se inadequados para aplicação em afásicos, principalmente nos casos graves $^{1,61,62}$.

Diante desta questão, foram elaborados instrumentos específicos de avaliação das funções cognitivas não linguísticas para afásicos, tais como o Cognitive Linguistic Quick-Test (CLQT) ${ }^{63}$, o Aphasia Check List $(A C L)^{1}$ e o Global Aphasic Neuropsychological Battery $(G A N B A)^{61}$, este último desenvolvido especificamente para pacientes com afasia grave.

Alguns pesquisadores questionaram a variabilidade no desempenho de pacientes com o mesmo grau de afasia, submetidos a um mesmo planejamento terapêutico. Deste questionamento, surgiu a suposição de que outras funções cognitivas, que não a linguagem, estariam relacionadas a esta variabilidade ou mesmo a um pior desempenho.

No estudo de Hinckley et al. ${ }^{64}$, os autores descreveram a habilidade de pensamento abstrato como um preditor para a eficácia da terapia de afasia.

Nicholas $^{65}$, por sua vez, constatou pior desempenho no treinamento de comunicação alternativa, em afásicos que apresentaram déficit na habilidade de função executiva e Fillingham et al. ${ }^{66}$ relataram que o prejuízo 
nas habilidades de memória episódica e de trabalho e no raciocínio afetaram o desempenho de afásicos durante terapia de anomia.

A partir destes estudos, fica comprovada a importância da avaliação das funções cognitivas não linguísticas em pacientes afásicos, para que a abordagem terapêutica mais apropriada seja estabelecida. 
3- OBJETIVOS

Os objetivos do presente estudo foram:

1) Avaliar o desempenho dos indivíduos afásicos em tarefas cognitivas não linguísticas (atenção, memória verbal e não verbal, funções executivas e habilidades visuoespaciais);

2) Comparar o desempenho dos indivíduos afásicos e não afásicos em tarefas cognitivas não linguísticas (atenção, memória verbal e não verbal, funções executivas e habilidades visuoespaciais);

3) Relacionar o desempenho dos sujetos afásicos nas tarefas cogntivas não linguísticas com a gravidade da afasia. 


\section{4- MÉTODOS}

Trata-se de estudo transversal, analítico-descritivo, realizado no Hospital Universitário da Universidade de São Paulo (HU / USP).

A pesquisa foi aprovada pelo Comitê de Ética da Faculdade de Medicina da Universidade de São Paulo - CAPPesq - protocolo de pesquisa n ${ }^{\circ}$ 0595/07 (Anexo A) e pelo Comitê de Ética em Pesquisa do Hospital Universitário da Universidade de São Paulo - CEP HU/USP - protocolo de pesquisa $n^{\circ} 734 / 07$ (Anexo B).

Foram incluídos na pesquisa quarenta e nove (49) indivíduos que receberam diagnóstico de primeiro episódio de AVE (hemorrágico ou isquêmico), com confirmação através de exame de neuroimagem (tomografia de crânio), convocados para a participação no estudo após a fase aguda (a partir do $31^{\circ}$ dia após o icto). Dois (2) participantes faleceram antes do término da avaliação. Dessa forma, foram considerados os dados de 47 participantes.

\section{1 - Captação dos sujeitos}

A captação de 40 sujeitos foi realizada a partir da análise do banco de dados elaborado para o Projeto EMMA - Estudo da Morbidade e Mortalidade do Acidente Vascular Encefálico -, estudo de vigilância epidemiológica da doença cerebrovascular em andamento no HU / USP. A partir do banco de dados em questão, foi possível obter informações tais como idade, 
escolaridade, data e confirmação do AVE, número de registro no hospital para acesso ao laudo da tomografia de crânio e ocorrência prévia de AVE.

Sete sujeitos foram selecionados a partir da análise da lista de pacientes em acompanhamento no Laboratório de Investigação Fonoaudiológica em Distúrbios Neurológicos no Adulto e Idoso do Curso de Fonoaudiologia da Faculdade de Medicina da USP.

O convite para participação na pesquisa foi realizado a partir de contato telefônico.

\section{2 - Critérios de Inclusão e Exclusão}

Foram considerados aptos a participarem do estudo indivíduos maiores de 18 anos de idade, de ambos os gêneros, com escolaridade mínima de dois (2) anos. Não houve restrições quanto à dominância manual. Foram excluídos do estudo os sujeitos que apresentassem quadro de afasia e / ou demais alterações de linguagem, ou de outras funções cognitivas, decorrentes de AVE prévio ou de outras etiologias, história pregressa ou atual de uso de drogas com efeito no Sistema Nervoso Central, em doses que pudessem comprometer o desempenho cognitivo, antecedentes de doenças neurológicas, e/ou psiquiátricas, que pudessem ter impacto no desempenho cognitivo ou de comunicação (como epilepsia, esquizofrenia, etc) e déficits visuais / auditivos não passíveis de correção, que pudessem prejudicar a realização do exame. 


\section{3 - Materiais e Procedimentos}

Após a apresentação e assinatura do Termo de Consentimento Livre e Esclarecido (Anexo C), foi iniciado o protocolo de pesquisa, do qual constam a bateria de testes e os questionários que seguem:

- Avaliação neurológica - foram registrados os resultados das avaliações neurológicas realizadas pela equipe de neurologistas do HU / USP e descritos nos prontuários dos sujeitos durante a internação ou a passagem no pronto-socorro, que mencionassem os seguintes aspectos: presença / ausência de hemiparesia, hipoestesia, movimentos involuntários, hemianopsia, hipoacusia, alterações da coordenação motora e alterações de nervos cranianos. Estes dados foram extraídos dos prontuários dos participantes em acompanhamento no LIF em Distúrbios Neurológicos no Adulto e Idoso.

- Teste de Boston para o Diagnóstico de Afasia (TBDA) ${ }^{67}$ (Anexo D) - avalia a compreensão e expressão das modalidades oral e escrita e rastreia aspectos motores correlatos. Aplicado em sua versão reduzida, da qual constam as seguintes provas: Conversação e Narração, Compreensão de Palavras, Ordens, Material Ideacional Complexo, Sequências Automatizadas, Repetição, Denominação Responsiva, Varredura para Categorias Específicas, Reconhecimento de Símbolos Básicos, Emparelhamento de Números, Emparelhamento Palavra-Figura, Leitura Oral de Palavras, Leitura 
Oral de Sentenças com Compreensão, Compreensão de Leitura, Mecânica da Escrita, Habilidade Básica de Codificação, Denominação Escrita e Narrativa Escrita. Nestas provas, cada resposta correta equivale a um ponto e, portanto, quanto maior a pontuação, melhor o desempenho. A pontuação total é calculada a partir da soma dos escores dos subitens. Para cada indivíduo afásico, foi atribuída uma pontuação, correspondente à Escala de Gravidade da Afasia no TDBA. Trata-se de escala com pontuação de 0 a 5 , na qual a pontuação 0 corresponde à fala ou compreensão auditiva não funcionais e a pontuação 5, à mínimos prejuízos de fala;

- Teste de Nomeação de Boston (TNB) ${ }^{67}$ (Anexo E) - teste de nomeação por confrontação visual, no qual são apresentados 60 estímulos visuais de alta, média e baixa frequências, com oferta de pistas semântica e fonológica, quando necessárias. Cada estímulo nomeado corretamente equivale a um ponto;

- Protocolo de Praxias Gestuais ${ }^{67}$ (subteste do TBDA, versão extensa) (Anexo F) - avalia o desempenho para a realização de gestos naturais, gestos convencionais, movimentos bucofaciais e respiratórios e para a utilização de objetos fictícios. A resposta correta recebe pontuação 3, quando o gesto é reconhecível a pontuação é 2 , para a tentativa sem sucesso é pontuado 1 e a resposta não reconhecível ou a ausência de resposta recebem pontuação 0 . A pontuação total é calculada a partir da soma dos escores dos subitens; 
- Fluência Verbal Semântica (categoria Animais) - geração do número máximo de nomes de animais que o indivíduo conseguir, em 60 segundos;

- Fluência Verbal Fonológica (FAS) - geração, no período de 60 segundos, do número máximo de palavras que se iniciem com as letras, A, F e S, respectivamente;

- Escala de Depressão de Hamilton ${ }^{68}$ (Anexo G) - escala construída com o objetivo de detectar sintomas depressivos. Pontuação maior do que sete é indicativa de depressão;

- Escala de Qualidade de Vida específica para sujeitos afásicos pós-AVE (SAQOL-39) $^{69}$ (Anexo H) - escala construída com o objetivo de possibilitar a aplicação em indivíduos afásicos, é administrada por meio de entrevista, e busca mensurar a percepção de qualidade de vida do indivíduo após o AVE, em relação a quatro domínios: Físico, Psicossocial, Comunicação, Energia. Traduzida e adaptada para o português por Ribeiro ${ }^{41}$, em 2008;

- Exame complementar da função cognitiva - testes selecionados para avaliação da atenção, memória verbal e não verbal, das funções executivas e das habilidades visuoespaciais:

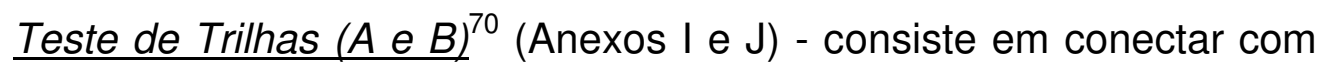
lápis, no menor tempo possível e em ordem crescente, 25 números (forma A) e números alternados com letras (forma B), avaliando atenção seletiva, velocidade de processamento perceptual e flexibilidade mental. Para análise dos resultados, foi considerado o 
tempo transcorrido até o participante finalizar cada uma das partes do teste;

$\underline{\text { Teste de Cancelamento }}^{71}$ (Anexo K) - teste utilizado para avaliação da vigilância. Examina a habilidade de focar e manter a atenção. Trata-se de tarefa que requer rápida seletividade visual para uma resposta motora repetitiva, avaliando a capacidade de atenção sustentada. Foi contabilizado o número de omissões e se estas predominavam à direita ou à esquerda da folha de aplicação do teste;

Aprendizado de palavras $^{72}$ (Anexos L,M e N) - dez palavras são apresentadas, um estímulo por segundo, para memorização, recordação imediata e tardia e posterior reconhecimento, dentre 20 estímulos. Foi contabilizado o número de palavras evocadas / reconhecidas corretamente, no tempo estabelecido. Para a pontuação total considera-se o número de respostas corretas, descontando-se o número de intrusões, quando realizadas;

Praxias construtivas e Evocação $^{72}$ (Anexos O e P)-são apresentados quatro desenhos para avaliação das habilidades visuoespaciais, um estímulo por vez, e o indivíduo é solicitado a copiá-los e, após a realização de outra tarefa (distrator), é solicitado a reproduzi-las espontaneamente. A pontuação para cada figura é dividida em subitens e para cada acerto, é somado um ponto;

Extensão de dígitos $^{73}$ (Anexo Q) - teste dividido em duas etapas, nas quais são lidas séries de números que aumentam gradativamente em extensão. O indivíduo é solicitado a repetir as séries, primeiramente 
na ordem direta, e, posteriormente, na ordem inversa. A sequência direta avalia a atenção e a capacidade de armazenamento de informações de uma só vez; a sequência invertida avalia memória operacional e o controle mental para a operacionalização de informações. Cada acerto equivale a um ponto, sendo somado o número de acertos para cada ordem, separadamente, ao final;

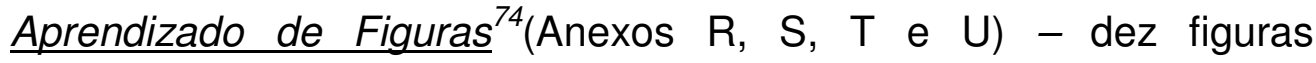
representando objetos são oferecidas para memorização, recordação imediata e tardia e posterior reconhecimento dentre 20 estímulos, com o objetivo de avaliar a memória não-verbal. Foi contabilizado o número de figuras evocadas / reconhecidas corretamente, no tempo estabelecido. Para a pontuação total considera-se o número de respostas corretas, descontando-se o número de intrusões, quando realizadas;

$\underline{\text { Desenho do Relógio }}^{74}$ (Anexo V) - teste de avaliação do funcionamento executivo e da praxia construtiva. Solicita-se ao indivíduo o desenho espontâneo de um mostrador de relógio com todos os números e com os ponteiros mostrando horário previamente estabelecido. Neste protocolo, foi utilizado o método de pontuação de Sunderland ${ }^{75}$.

Os valores de referência para a normalidade, considerados para cada prova cognitiva não linguística e mencionados na Discussão, encontram-se no Apêndice A.. 
A dominância manual foi confirmada a partir da aplicação do Inventário de Edinburgh ${ }^{76}$.

De acordo com o resultado obtido no Teste de Boston para o Diagnóstico de Afasia $^{67}$, os participantes foram divididos em dois grupos: afásicos ( $n=21)$ e não afásicos ( $n=26)$.

A constatação da afasia foi estabelecida a partir de critérios clínicos dificuldade em expressar-se verbalmente não decorrente de disartria, prejuízo na compreensão auditiva e dificuldade no acesso lexical perceptíveis já no momento da entrevista inicial; e do desempenho no TDBA.

A aplicação dos testes e questionários descritos acima foi realizada pela pesquisadora executante do estudo e teve a duração, em média, de duas horas. Mais de uma data foi agendada quando o participante da pesquisa demonstrava ou referia cansaço, para que fosse obtido seu melhor desempenho.

As tarefas de emissão oral foram registradas em gravador digital Panasonic® RR-US 395 e durante as tarefas de fluência verbal semântica e fonológica, Teste de Trilhas A e B, Aprendizado de Palavras e Aprendizado de Figuras, foi utilizado cronômetro Profesional Timer Quartz®.

Para documentação, foram fotocopiados os laudos dos exames de neuroimagem dos sujeitos da pesquisa e registrados, em câmera digital SONY Cyber-shot 7.2 mega pixels, os cortes dos exames que melhor ilustravam a lesão existente. Os dados obtidos foram tabulados em planilha do programa Microsoftß Office Excel 2003. 


\section{4 - Análise Estatística dos Dados}

A composição da amostra foi determinada a partir da comparação das médias de idade, escolaridade, tempo decorrido entre o icto e a avaliação fonoaudiológica, escore na Escala de Depressão de Hamilton, escore na escala SAQOL e distribuição quanto à frequência por gênero, tipo e localização do AVE (isquêmico e hemorrágico) entre os grupos de afásicos ( $n=21)$ e não-afásicos $(n=26)$.

Foi realizada a comparação de médias de desempenho nas provas de linguagem e testes cognitivos, dividindo-se a amostra em 3 (três) grupos: afásicos ( $n=21)$, não afásicos com lesão em hemisfério esquerdo $(n=17)$ e não afásicos com lesão em hemisfério direito $(n=9)$. Esta comparação teve como objetivo isolar os efeitos da lateralidade da lesão e da presença de afasia no desempenho dos sujeitos. Variáveis contínuas foram comparadas entre os 3 grupos através do teste de Kruskall-Wallis, e, quando pertinente, realizada comparação múltipla entre os grupos através do teste post-hoc de Dunn. Para comparação da distribuição entre as variáveis categóricas (gênero, tipo e distribuição do AVE, presença de alterações neurológicas e local de lesão), foram utilizados o teste exato de Fisher e o teste do Quiquadrado para amostras independentes.

Nas provas cognitivas em que foi constatada diferença significativa de desempenho entre os afásicos e não afásicos, foi realizada a comparação entre os grupos, considerando-se a gravidade da afasia, a fim de verificar se as dificuldades de expressão verbal poderiam interferir com o desempenho 
no grupo mais grave. Assim, o grupo de afásicos foi dividido em grupo grave (escore de gravidade de afasia de 0 a 2 - 14 sujeitos) e leve (escore 3 a 5 7 sujeitos) e comparado aos grupos de não afásicos. Nestas provas e nas provas de Praxias Gestuais, a possível associação entre o escore de gravidade da afasia e o desempenho foi analisada através do teste de correlação de Spearman.

As análises foram realizadas utilizando-se o programa estatístico MedCalc® para Windows versão 10.0. Foi considerado um nível de significância (p) de 0,05 em todas as análises. 


\section{5- RESULTADOS}

Os grupos foram equiparados quanto às variáveis idade, escolaridade e tempo entre o icto e a avaliação, sendo que a homogeneidade da amostra é apresentada na Tabela 1.

Tabela 1 - Caracterização da amostra, segundo dados demográficos, tempo transcorrido entre o icto e a avaliação, escores nas escalas de Hamilton e SAQOL-39, tipo de AVE e lateralidade da lesão

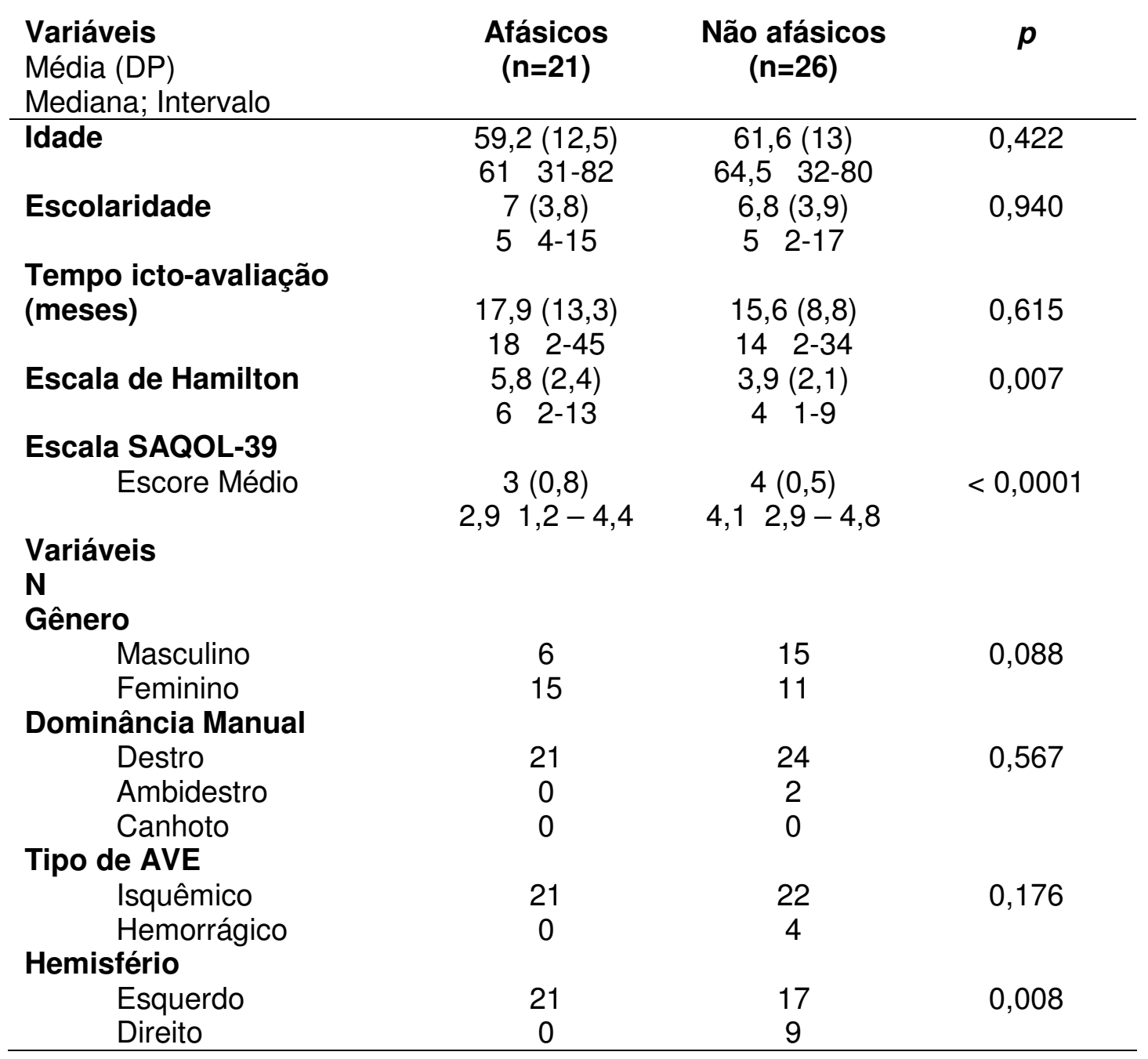

Houve diferença estatisticamente significante entre os grupos na pontuação da Escala de Hamilton e no escore médio da Escala SAQOL-39, 
havendo maior ocorrência de sintomas depressivos e piores índices de qualidade de vida entre os afásicos. Quanto à distribuição das lesões por hemisfério, houve predominância de lesões de HE entre os afásicos. Todos os casos de afasia foram decorrentes de AVE isquêmico.

As alterações neurológicas presentes nos dois grupos são apresentadas na Tabela 2.

Tabela 2 - Alterações neurológicas nos grupos

\begin{tabular}{lccc}
\hline Alterações & $\begin{array}{c}\text { Afásicos } \\
(\mathbf{n}=\mathbf{2 1})\end{array}$ & $\begin{array}{c}\text { Não Afásicos } \\
(\mathbf{n}=\mathbf{2 6})\end{array}$ & $\boldsymbol{p}$ bicaudal \\
\hline Hemiparesia & 16 & 12 & 0,0715 \\
Hipoestesia & 11 & 5 & 0,0293 \\
Hemianopsia & 2 & 4 & 0,6779 \\
Hipoacusia & 1 & 2 & 1,0000 \\
Disartria & - & 3 & 0,2423 \\
Disfagia & 3 & 1 & 0,3112 \\
Disfonia & 2 & 5 & 0,4364 \\
\hline
\end{tabular}

A sequela neurológica mais frequente na amostra foi a hemiparesia, evidenciada em $76 \%$ dos afásicos e em $46 \%$ dos não afásicos, seguida pela hipoestesia, presente em $52 \%$ dos afásicos e em 19\% dos não afásicos. Não houve diferença estatisticamente significante na distribuição das alterações neurológicas entre os grupos, com exceção da hipoestesia, mais frequente nos afásicos. 
A Tabela 3 apresenta a distribuição dos grupos de afásicos e não afásicos, de acordo o local da lesão (lesões corticais anteriores, posteriores e ântero-posteriores, e lesões subcorticais).

Tabela 3 - Distribuição da localização da lesão nos grupos de afásicos e não afásicos

\begin{tabular}{|c|c|c|}
\hline Local da lesão & $\begin{array}{c}\text { Afásicos } \\
(\mathrm{n}=21)\end{array}$ & $\begin{array}{c}\text { Não afásicos } \\
(\mathrm{n}=26)\end{array}$ \\
\hline \multicolumn{3}{|l|}{ Corticais } \\
\hline \multicolumn{3}{|l|}{ Anteriores } \\
\hline$E$ & 1 & 1 \\
\hline D & 0 & 1 \\
\hline Total & 1 & 2 \\
\hline \multicolumn{3}{|l|}{ Posteriores } \\
\hline 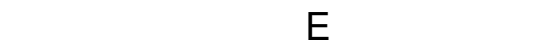 & 10 & 10 \\
\hline D & 0 & 2 \\
\hline Total & 10 & 12 \\
\hline \multicolumn{3}{|l|}{$A+P$} \\
\hline$E$ & 8 & 3 \\
\hline D & 0 & 4 \\
\hline Total & 8 & 7 \\
\hline \multicolumn{3}{|l|}{ Subcorticais } \\
\hline$E$ & 2 & 3 \\
\hline D & 0 & 2 \\
\hline Total & 2 & 5 \\
\hline
\end{tabular}

$A+P$ - lesões ântero-posteriores

Não houve diferença estatisticamente significante quanto à distribuição do local de lesão em HE entre os grupos de afásicos e não afásicos $(p=0,557)$.

A Tabela 4 apresenta a distribuição da amostra de afásicos, de acordo com a classificação das afasias, sua gravidade da afasia e localização da lesão. 
Tabela 4 - Distribuição da amostra de afásicos, segundo a classificação das afasias, gravidade e localização da lesão

\begin{tabular}{|c|c|c|c|}
\hline $\begin{array}{c}\text { Afásicos } \\
\text { graves }(n=14)\end{array}$ & Local da lesão & $\begin{array}{c}\text { Afásicos } \\
\text { leves }(n=7)\end{array}$ & Local da lesão \\
\hline \multirow[t]{6}{*}{ Global (5) } & Parietal & - & - \\
\hline & Parietal & - & - \\
\hline & Fronto-têmporo-parieto- & - & - \\
\hline & occipital & & \\
\hline & Fronto-parietal & - & - \\
\hline & Fronto-têmporo-parietal & - & - \\
\hline \multirow[t]{3}{*}{ Broca (3) } & Fronto-têmporo-parietal & - & - \\
\hline & Parietal & - & - \\
\hline & Fronto-têmporo-parietal & - & - \\
\hline \multirow[t]{2}{*}{ Wernicke (2) } & Núcleos da base & Wernicke (1) & Fronto-parietal \\
\hline & Têmporo-parietal & & - \\
\hline Transcortical & Têmporo-parietal & & - \\
\hline \multicolumn{4}{|l|}{ Motora (1) } \\
\hline \multirow[t]{2}{*}{-} & - & Transcortical & Têmporo-parietal \\
\hline & & Sensorial (3) & \\
\hline- & - & & Temporal \\
\hline- & - & & Parietal e coroa \\
\hline & & & radiada \\
\hline Transcortical & Parietal & Transcortical & Frontal + SBPV \\
\hline \multirow[t]{2}{*}{ Mista (2) } & & Mista (1) & \\
\hline & Fronto-têmporo-parietal & - & - \\
\hline Condução (1) & Têmporo-parietal & - & - \\
\hline \multirow[t]{2}{*}{-} & - & Anômica (2) & Núcleos da base \\
\hline & & & e cápsula interna \\
\hline \multirow[t]{2}{*}{-} & - & & Núcleos da base \\
\hline & & & e cápsula interna \\
\hline
\end{tabular}

Com relação à distribuição das lesões de acordo com a gravidade da afasia (Tabela 5), no grupo de afásicos graves encontramos 5 em região FTP (37\%), 4 parietais (28\%), 3 em região TP (21\%), e 1 (7\%) em região FP 
e núcleos da base, respectivamente. No grupo de afásicos leves, houve grande heterogeneidade da distribuição, não sendo possível o agrupamento por região. No grupo de não afásicos com lesão à $E$, a maior frequência foi de lesões parietais (5 ou 29\%) e de tálamo (5 ou 29\%).

Tabela 5 - Distribuição da localização das lesões segundo a gravidade da afasia

\begin{tabular}{lccc}
\hline \multicolumn{1}{c}{ Lesão (\%) } & Afásicos graves & Afásicos leves & Não afásicos \\
& & & \\
\hline FTP & $5(37 \%)$ & 0 & 0 \\
FT & 0 & $1(14,2 \%)$ & 0 \\
FP & $1(7 \%)$ & $1(14,2 \%)$ & $3(18 \%)$ \\
TP & $3(21 \%)$ & $1(14,2 \%)$ & $1(6 \%)$ \\
F & 0 & $1(14,2 \%)$ & 0 \\
T & 0 & $1(14,2 \%)$ & 0 \\
P & $4(28 \%)$ & $1(14,2 \%)$ & $5(29 \%)$ \\
O & 0 & 0 & $1(6 \%)$ \\
NB & $1(7 \%)$ & $1(14,2 \%)$ & $1(6 \%)$ \\
tálamo & 0 & 0 & $5(29 \%)$ \\
SBPV & 0 & 0 & $1(6 \%)$ \\
TOTAL & $14(100 \%)$ & $7(100 \%)$ & $17(100 \%)$
\end{tabular}

FTP - fronto-têmporo parietal, FT - fronto-temporal, FP - fronto-parietal, TP - têmporoparietal, F-frontal, T-temporal, P-parietal, O-occipital, NB-núcleos da base, SBPV-substância branca periventricular

Quanto ao desempenho nos testes de linguagem, houve diferença estatisticamente significante entre os grupos de afásicos, não afásicos com lesão à $E$, e não afásicos com lesão à $D$ em todas as provas, evidenciando pior desempenho dos afásicos (Tabela 6). Os três grupos eram equiparáveis quanto à idade $(p=0,3699)$ e à escolaridade $(p=0,6144)$. 
Tabela 6 - Desempenho dos afásicos e não afásicos no Teste de Boston para Diagnóstico da Afasia, Teste de Nomeação de Boston e nas provas de Fluência Verbal

\begin{tabular}{|c|c|c|c|c|c|}
\hline $\begin{array}{c}\text { PROVA } \\
\text { Média (DP) } \\
\text { Mediana; } \\
\text { Intervalo }\end{array}$ & $\begin{array}{l}\text { Afásicos } \\
(\mathrm{N}=21)\end{array}$ & $\begin{array}{c}\text { Não } \\
\text { Afásicos } \mathrm{E} \\
(\mathrm{N}=17)\end{array}$ & $\begin{array}{c}\text { Não } \\
\text { Afásicos } D \\
(\mathrm{~N}=9)\end{array}$ & $p$ bicaudal & $\begin{array}{c}\text { Comparação } \\
\text { múltipla } \\
(p<0,05)\end{array}$ \\
\hline $\begin{array}{l}\text { CONVERSAÇÃO } \\
\text { E NARRATIVA }\end{array}$ & & & & & \\
\hline $\begin{array}{l}\text { Respostas sociais } \\
\text { simples }\end{array}$ & $\begin{array}{c}3(2,6) \\
2 \\
0-7\end{array}$ & $\begin{array}{c}6,9(0,24) \\
7 \\
6-7\end{array}$ & $\begin{array}{l}7(0) \\
7 \\
7-7\end{array}$ & $<0,0001$ & $\begin{array}{c}\text { AF } \neq \text { NAF E e } \\
\text { NAF D }\end{array}$ \\
\hline Conversação Livre & $\begin{array}{c}1,5(1,3) \\
2 \\
0-3\end{array}$ & $\begin{array}{c}5(0) \\
5 \\
5-5\end{array}$ & $\begin{array}{c}5(0) \\
5 \\
5-5\end{array}$ & $<0,0001$ & $\begin{array}{c}A F \neq N A F E \text { e } \\
\text { NAF D }\end{array}$ \\
\hline $\begin{array}{l}\text { Prancha Roubo } \\
\text { dos Biscoitos }\end{array}$ & $\begin{array}{c}1,5(1,4) \\
2 \\
0-4\end{array}$ & $\begin{array}{c}4,6(0,5) \\
5 \\
4-5\end{array}$ & $\begin{array}{c}4,9(0,3) \\
5 \\
4-5\end{array}$ & $<0,0001$ & $\begin{array}{c}A F \neq N A F E \text { e } \\
\text { NAF D }\end{array}$ \\
\hline $\begin{array}{l}\text { COMPREENSÃO } \\
\text { AUDITIVA }\end{array}$ & & & & & \\
\hline $\begin{array}{l}\text { Compreensão de } \\
\text { palavras }\end{array}$ & $\begin{array}{c}11,4(4,3) \\
12,5 \\
1-16\end{array}$ & $\begin{array}{c}14,9(1) \\
15 \\
13-16\end{array}$ & $\begin{array}{c}15,1(0,7) \\
15 \\
14-16\end{array}$ & 0,0020 & $\begin{aligned} A F & \neq \text { NAF E e } \\
& \text { NAF D }\end{aligned}$ \\
\hline Ordens & $\begin{array}{c}5(2,9) \\
5 \\
0-9\end{array}$ & $\begin{array}{c}9,6(0,6) \\
10 \\
8-10\end{array}$ & $\begin{array}{c}9,5(0,5) \\
10 \\
9-10\end{array}$ & $<0,0001$ & $\begin{array}{c}A F \neq N A F E e \\
\text { NAF D }\end{array}$ \\
\hline $\begin{array}{l}\text { Material ideacional } \\
\text { complexo }\end{array}$ & $\begin{array}{c}2,2(1,9) \\
2 \\
0-5\end{array}$ & $\begin{array}{c}4,8(0,6) \\
5 \\
4-6\end{array}$ & $\begin{array}{c}5,1(0,6) \\
5 \\
4-6\end{array}$ & $<0,0001$ & $\begin{array}{c}A F \neq N A F E \text { e } \\
\text { NAF D }\end{array}$ \\
\hline $\begin{array}{l}\text { EXPRESSÃO } \\
\text { ORAL }\end{array}$ & & & & & \\
\hline $\begin{array}{l}\text { Sequências } \\
\text { automatizadas }\end{array}$ & $\begin{array}{c}2(1,5) \\
3 \\
0-4\end{array}$ & $\begin{array}{c}4(0) \\
4 \\
4-4\end{array}$ & $\begin{array}{c}4(0) \\
4 \\
4-4\end{array}$ & $<0,0001$ & $\begin{array}{c}\text { AF } \neq \text { NAF E e } \\
\text { NAF D }\end{array}$ \\
\hline $\begin{array}{l}\text { Repetição de } \\
\text { palavras }\end{array}$ & $\begin{array}{c}2,7(2,2) \\
3 \\
0-5\end{array}$ & $\begin{array}{c}5(0) \\
5 \\
5-5\end{array}$ & $\begin{array}{c}5(0) \\
5 \\
5-5\end{array}$ & 0,0001 & $\begin{array}{c}A F \neq N A F E \text { e } \\
\text { NAF D }\end{array}$ \\
\hline $\begin{array}{l}\text { Repetição de } \\
\text { sentenças }\end{array}$ & $\begin{array}{c}0,7(0,9) \\
0 \\
0-2\end{array}$ & $\begin{array}{c}2(0) \\
2 \\
2-2\end{array}$ & $\begin{array}{c}2(0) \\
2 \\
2-2\end{array}$ & $<0,0001$ & $\begin{array}{c}A F \neq N A F E \text { e } \\
\text { NAF D }\end{array}$ \\
\hline $\begin{array}{l}\text { Denominação } \\
\text { responsiva }\end{array}$ & $\begin{array}{c}3,7(4,1) \\
1 \\
0-10\end{array}$ & $\begin{array}{c}9,8(0,3) \\
10 \\
9-10\end{array}$ & $\begin{array}{c}9,8(0,4) \\
10 \\
9-10\end{array}$ & $<0,0001$ & $\begin{array}{c}A F \neq N A F E e \\
\text { NAF D }\end{array}$ \\
\hline $\begin{array}{l}\text { Varredura } \\
\text { categorias } \\
\text { específicas } \\
\text { LEITURA }\end{array}$ & $\begin{array}{c}5,7(5,3) \\
7 \\
0-12\end{array}$ & $\begin{array}{c}11,9(0,2) \\
12 \\
11-12\end{array}$ & $\begin{array}{c}11,9(0,3) \\
12 \\
11-12\end{array}$ & $<0,0001$ & $\begin{array}{c}A F \neq N A F E e \\
\text { NAF D }\end{array}$ \\
\hline Emparelhamento & $\begin{array}{c}2,9(1,5) \\
4\end{array}$ & $4(0)$ & $4(0)$ & 0,0005 & $\begin{array}{c}A F \neq \text { NAF E e } \\
\text { NAF D }\end{array}$ \\
\hline letra-palavra & $\begin{array}{c}0-4 \\
3,2(1,2)\end{array}$ & $\begin{array}{c}4-4 \\
3,8(0,33)\end{array}$ & $\begin{array}{l}4-4 \\
4(0)\end{array}$ & 0,0275 & $\mathrm{AF} \neq \mathrm{NAF} \mathrm{E}$ e \\
\hline $\begin{array}{l}\text { Emparelhamento } \\
\text { números }\end{array}$ & $\begin{array}{c}4 \\
0-4\end{array}$ & $\begin{array}{c}4 \\
3-4\end{array}$ & $\begin{array}{c}4 \\
4-4\end{array}$ & & NAF D \\
\hline $\begin{array}{l}\text { Emparelhamento } \\
\text { palavra-figura }\end{array}$ & $\begin{array}{c}2,7(1,1) \\
3 \\
0-4\end{array}$ & $\begin{array}{c}3,8(0,3) \\
4 \\
3-4\end{array}$ & $\begin{array}{c}3,9(0,3) \\
4 \\
3-4\end{array}$ & 0,0001 & $\begin{array}{c}A F \neq N A F E \text { e } \\
\text { NAF D }\end{array}$ \\
\hline
\end{tabular}


continuação

Tabela 6 - Desempenho dos afásicos e não afásicos no Teste de Boston para Diagnóstico da Afasia, Teste de Nomeação de Boston e nas provas de Fluência Verbal



continua 
conclusão

Tabela 6 - Desempenho dos afásicos e não afásicos no Teste de Boston para Diagnóstico da Afasia, Teste de Nomeação de Boston e nas provas de Fluência Verbal

\begin{tabular}{|c|c|c|c|c|c|}
\hline $\begin{array}{c}\text { PROVA } \\
\text { Média (DP) } \\
\text { Mediana; } \\
\text { Intervalo }\end{array}$ & $\begin{array}{c}\text { Afásicos } \\
(\mathrm{N}=21)\end{array}$ & $\begin{array}{c}\text { Não } \\
\text { Afásicos } E \\
(\mathrm{~N}=17)\end{array}$ & $\begin{array}{c}\text { Não } \\
\text { Afásicos } D \\
(\mathrm{~N}=9)\end{array}$ & $p$ bicaudal & $\begin{array}{c}\text { Comparação } \\
\text { múltipla } \\
(p<0,05)\end{array}$ \\
\hline $\begin{array}{l}\text { TESTE DE } \\
\text { NOMEAÇÃO DE } \\
\text { BOSTON }\end{array}$ & $\begin{array}{c}17,5(16,8) \\
10 \\
0-45\end{array}$ & $\begin{array}{c}46,2(8,5) \\
46 \\
33-58\end{array}$ & $\begin{array}{c}48,9(5,9) \\
50 \\
40-59\end{array}$ & $<0,0001$ & 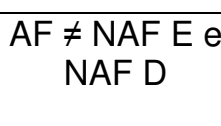 \\
\hline FLUÊNCIA & $3(3,2)$ & $12,5(3,2)$ & $13,4(3,2)$ & $<0,0001$ & $\mathrm{AF} \neq \mathrm{NAF} \mathrm{E} \mathrm{e}$ \\
\hline $\begin{array}{l}\text { SEMÂNTICA } \\
\text { (ANIMAIS) }\end{array}$ & $\begin{array}{c}2 \\
0-10\end{array}$ & $\begin{array}{c}13 \\
6-19\end{array}$ & $\begin{array}{c}13 \\
8-19\end{array}$ & & NAF D \\
\hline FLUÉNCIA & $3,2(4,5)$ & $20,3(8,9)$ & $27,1(7,7)$ & $<0,0001$ & Todos se \\
\hline $\begin{array}{l}\text { FONOLÓGICA } \\
\text { (FAS) }\end{array}$ & $\begin{array}{c}1 \\
0-16\end{array}$ & $\begin{array}{c}19 \\
6-40\end{array}$ & $\begin{array}{c}25 \\
17-41\end{array}$ & & diferenciam \\
\hline
\end{tabular}

$\mathrm{AF}$ - afásicos; NAF E - não afásicos com lesão em hemisfério esquerdo; NAF D - não afásicos com lesão em hemisfério direito

Com relação à prova de Praxias Gestuais, houve diferença estatisticamente significante entre os grupos de afásicos e não afásicos, com pior desempenho dos afásicos (Tabela 7).

Tabela 7 - Desempenho dos afásicos e não afásicos nas provas de Praxias Gestuais

\begin{tabular}{|c|c|c|c|c|c|}
\hline $\begin{array}{c}\text { Prova } \\
\text { Média (DP) } \\
\text { Mediana; } \\
\text { Intervalo }\end{array}$ & $\begin{array}{l}\text { Afásicos } \\
(n=21)\end{array}$ & $\begin{array}{c}\text { Não } \\
\text { afásicos E } \\
(n=17)\end{array}$ & $\begin{array}{c}\text { Não } \\
\text { afásicos D } \\
(n=9)\end{array}$ & $\begin{array}{c}p \\
\text { bicaudal }\end{array}$ & $\begin{array}{c}\text { Comparação } \\
\text { múltipla } \\
(p<0,05)\end{array}$ \\
\hline Gestos & $6,4(3,5)$ & $11,4(0,7)$ & $11,4(1)$ & $<0,0001$ & $\mathrm{AF} \neq \mathrm{NAF} E$ \\
\hline naturais & $60-12$ & $1210-12$ & $129-12$ & & e NAF D \\
\hline Gestos & $7,5(3,6)$ & $11,4(0,9)$ & $11,6(0,5)$ & $<0,0001$ & $\mathrm{AF} \neq \mathrm{NAF} \mathrm{E}$ \\
\hline convencionais & $90-12$ & $129-12$ & $1211-12$ & & e NAF D \\
\hline Uso de & $16,8(7)$ & $23,4(1,3)$ & $23,9(0,3)$ & $<0,0001$ & $A F \neq N A F E$ \\
\hline $\begin{array}{l}\text { objetos } \\
\text { fictícios }\end{array}$ & $200-24$ & $2419-24$ & $2423-24$ & & e NAF D \\
\hline Praxia & $6,7(4,5)$ & $11,9(0,3)$ & $12(0)$ & $<0,0001$ & $A F \neq N A F E$ \\
\hline $\begin{array}{l}\text { Bucofacial e } \\
\text { Respiratória }\end{array}$ & $60-12$ & $1211-12$ & $1212-12$ & & \\
\hline Total & $\begin{array}{r}34,5(16,5) \\
37 \quad 2-57\end{array}$ & $\begin{array}{c}58,2(2,4) \\
5950-60\end{array}$ & $\begin{array}{c}59(1,6) \\
2423-24\end{array}$ & $<0,0001$ & $\begin{array}{c}A F \neq N A F E \\
\text { e NAF D }\end{array}$ \\
\hline
\end{tabular}


Foi constatada diferença estatisticamente significante entre os grupos de afásicos graves e leves para todos os subtestes da prova de Praxias Gestuais, conforme apresentado na Tabela 8.

Tabela 8 - Desempenho dos afásicos e não afásicos nas provas de Praxias Gestuais, segundo a gravidade da afasia

\begin{tabular}{|c|c|c|c|c|c|c|}
\hline $\begin{array}{l}\text { Prova } \\
\text { Média (DP) } \\
\text { Mediana; } \\
\text { Intervalo }\end{array}$ & $\begin{array}{l}\text { Afásicos } \\
\text { graves } \\
(\mathrm{N}=14)\end{array}$ & $\begin{array}{l}\text { Afásicos } \\
\text { leves } \\
(\mathrm{N}=7)\end{array}$ & $\begin{array}{c}\text { Não } \\
\text { afásicos } \\
E \\
(n=17)\end{array}$ & $\begin{array}{c}\text { Não } \\
\text { afásicos } \\
\text { D } \\
(n=9)\end{array}$ & $\begin{array}{c}p \\
\text { bicaudal }\end{array}$ & $\begin{array}{c}\text { Comparação } \\
\text { múltipla } \\
(p<0,05)\end{array}$ \\
\hline Gestos & $5,2(3)$ & $8,7(3,3)$ & $11,4(0,7)$ & $11,4(1)$ & $<0,0001$ & $\mathrm{AFg} \neq \mathrm{AFI}$ \\
\hline \multirow[t]{2}{*}{ naturais } & 4,5 & 9 & 12 & 12 & & $A F \neq N A F E$ \\
\hline & $0-12$ & $3-12$ & $10-12$ & $9-12$ & & e NAF D \\
\hline Gestos & $6,1(3,4)$ & $10,3(1,8)$ & $11,4(0,9)$ & $11,6(0,5)$ & $<0,0001$ & $\mathrm{AFg} \neq \mathrm{AFI}$ \\
\hline \multirow[t]{2}{*}{ convencionais } & 6 & 11 & 12 & 12 & & $\mathrm{AF} \neq \mathrm{NAF} E$ \\
\hline & $0-11$ & $7-12$ & $9-12$ & $11-12$ & & e NAF D \\
\hline Uso de objetos & $15,3(7,6)$ & $19,8(4,7)$ & $23,4(1,3)$ & $23,9(0,3)$ & $<0,0001$ & $\mathrm{AF} \neq \mathrm{NAF} E$ \\
\hline \multirow[t]{2}{*}{ fictícios } & 17,5 & 22 & 24 & 24 & & e NAF D \\
\hline & $0-23$ & $11-24$ & $19-24$ & $23-24$ & & \\
\hline Praxia & $5(4,3)$ & $10,1(2,5)$ & $11,9(0,3)$ & $12(0)$ & $<0,0001$ & $\mathrm{AFg} \neq \mathrm{AFI}$ \\
\hline Bucofacial e & 3,5 & 11 & 12 & 12 & & $\mathrm{AF} \neq \mathrm{NAF} E$ \\
\hline Respiratória & $0-12$ & $5-12$ & $11-12$ & $12-12$ & & e NAF D \\
\hline \multirow[t]{3}{*}{ TOTAL } & $31,7(16,3)$ & $49(10,2)$ & $58,2(2,4)$ & $59(1,6)$ & $<0,0001$ & $\mathrm{AFg} \neq \mathrm{AFI}$ \\
\hline & 31 & 54 & 59 & 24 & & $\mathrm{AF} \neq \mathrm{NAF} \mathrm{E}$ \\
\hline & $2-53$ & $33-57$ & $50-60$ & $23-24$ & & e NAF D \\
\hline
\end{tabular}

AF - afásicos; NAF E - não afásicos com lesão em hemisfério esquerdo; NAF D - não afásicos com lesão em hemisfério direito; AFg - afásicos graves; AFI - afásicos leves

Quanto à bateria de testes cognitivos, a comparação entre os três grupos (AF, NAF E e NAF D), apresentada na Tabela 9, evidencia pior desempenho dos indivíduos afásicos nas provas de Extensão de Dígitos (ordem direta e inversa), Aprendizado de Palavras e Figuras, Evocação de Praxias Construtivas e Desenho do Relógio. Na prova de reconhecimento de 
palavras, os sujeitos com lesão de hemisfério $E$ (afásicos e não afásicos) tiveram pior desempenho que os sujeitos com lesão à D.

Tabela 9 - Desempenho dos afásicos e não afásicos nas provas cognitivas

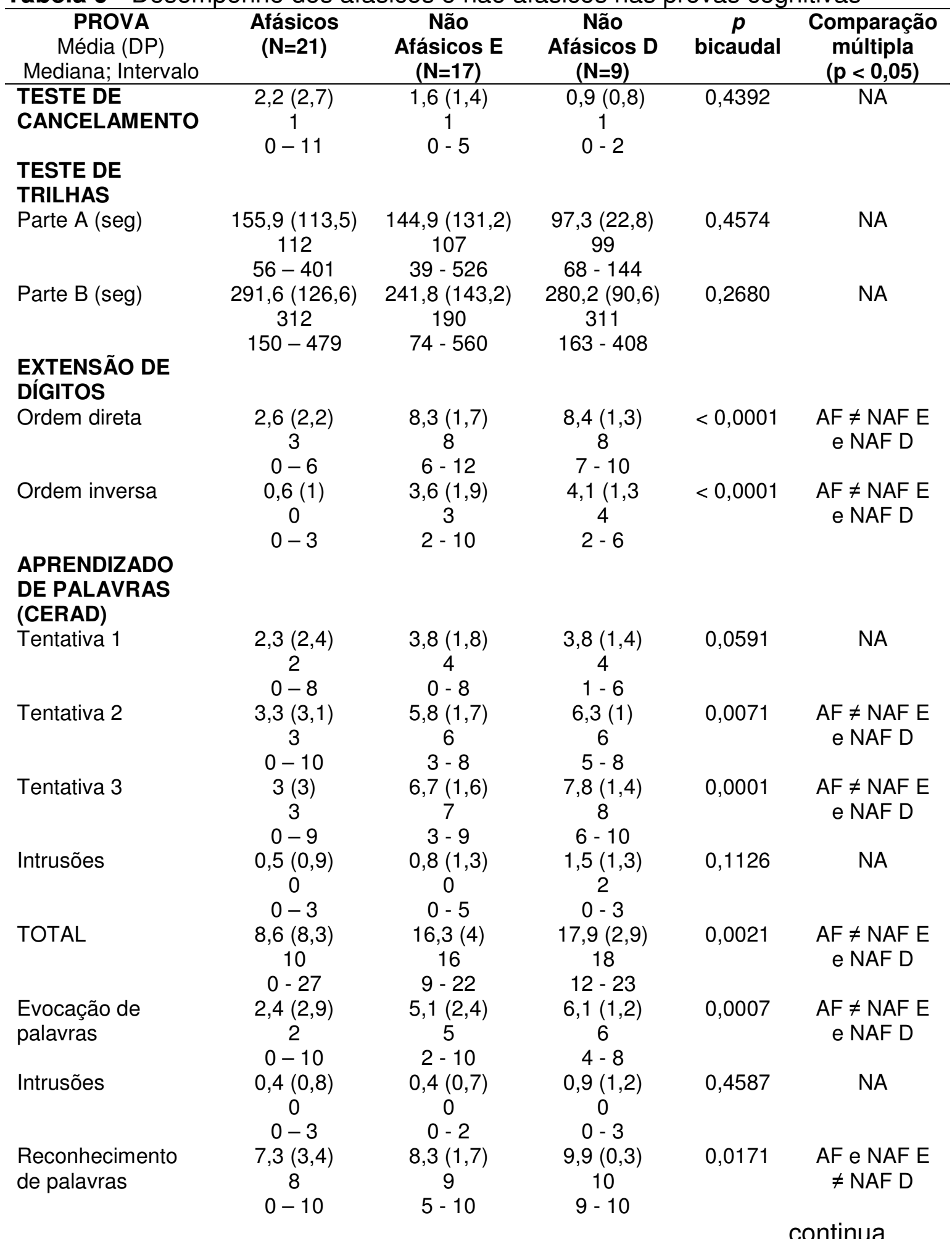


continuação

Tabela 9 - Desempenho dos afásicos e não afásicos nas provas cognitivas

\begin{tabular}{|c|c|c|c|c|c|}
\hline $\begin{array}{c}\text { PROVA } \\
\text { Média (DP) } \\
\text { Mediana; Intervalo }\end{array}$ & $\begin{array}{l}\text { Afásicos } \\
(\mathrm{N}=21)\end{array}$ & $\begin{array}{c}\text { Não } \\
\text { Afásicos } E \\
(\mathrm{~N}=17)\end{array}$ & $\begin{array}{c}\text { Não } \\
\text { Afásicos D } \\
(\mathrm{N}=9)\end{array}$ & $\begin{array}{c}p \\
\text { bicaudal }\end{array}$ & $\begin{array}{c}\text { Comparação } \\
\text { múltipla } \\
(p<0,05) \\
\end{array}$ \\
\hline $\begin{array}{l}\text { PRAXIAS } \\
\text { CONSTRUTIVAS } \\
\text { (CERAD) }\end{array}$ & & & & & \\
\hline Círculo & $\begin{array}{c}1,9(0,4) \\
2 \\
0-2\end{array}$ & $\begin{array}{c}1,9(0,2) \\
2 \\
1-2\end{array}$ & $\begin{array}{l}2(0) \\
2 \\
2-2\end{array}$ & 0,7780 & NA \\
\hline Losango & $\begin{array}{c}1,5(0,8) \\
2 \\
0-2\end{array}$ & $\begin{array}{c}1,9(0,3) \\
2 \\
1-2\end{array}$ & $\begin{array}{c}1,8(0,4) \\
2 \\
1-2\end{array}$ & 0,3588 & NA \\
\hline Retângulo & $\begin{array}{c}1,4(0,9) \\
2 \\
0-2\end{array}$ & $\begin{array}{c}1,9(0,3) \\
2 \\
1-2\end{array}$ & $\begin{array}{c}1,9(0,3) \\
2 \\
1-2\end{array}$ & 0,1332 & NA \\
\hline Cubo & $\begin{array}{c}1(1,4) \\
0 \\
0-4\end{array}$ & $\begin{array}{c}2(1,8) \\
3 \\
0-4\end{array}$ & $\begin{array}{c}1,6(1,5) \\
2 \\
0-4\end{array}$ & 0,2446 & NA \\
\hline TOTAL & $\begin{array}{c}5,9(2,7) \\
6 \\
0-10\end{array}$ & $\begin{array}{c}7,7(2,1) \\
8 \\
4-10\end{array}$ & $\begin{array}{c}7,3(1,7) \\
7 \\
5-10\end{array}$ & 0,0926 & NA \\
\hline $\begin{array}{l}\text { EVOCAÇÃO } \\
\text { PRAXIAS } \\
\text { (CERAD) }\end{array}$ & & & & & \\
\hline Círculo & $\begin{array}{c}1(1) \\
2 \\
0-2\end{array}$ & $\begin{array}{c}1,7(0,6) \\
2 \\
0-2\end{array}$ & $\begin{array}{c}1,5(0,9) \\
2 \\
0-2\end{array}$ & 0,0590 & NA \\
\hline Losango & $\begin{array}{c}1,3(0,9) \\
2 \\
0-2\end{array}$ & $\begin{array}{c}1,4(0,8) \\
2 \\
0-2\end{array}$ & $\begin{array}{c}1,5(0,7) \\
2 \\
0-2\end{array}$ & 0,8335 & NA \\
\hline Retângulo & $\begin{array}{c}1(1) \\
1 \\
0-2\end{array}$ & $\begin{array}{c}1,8(0,5) \\
2 \\
0-2\end{array}$ & $\begin{array}{c}1,8(0,6) \\
2 \\
0-2\end{array}$ & 0,0083 & $\begin{array}{c}\text { AF } \neq \text { NAF E } \\
\text { e NAF D }\end{array}$ \\
\hline Cubo & $\begin{array}{c}0,6(1,2) \\
0 \\
0-4\end{array}$ & $\begin{array}{c}1,7(1,9) \\
1 \\
0-4\end{array}$ & $\begin{array}{c}1,4(1,7) \\
0 \\
0-4\end{array}$ & 0,0914 & NA \\
\hline TOTAL & $\begin{array}{c}3,9(3,1) \\
4 \\
0-10\end{array}$ & $\begin{array}{c}6,7(2,7) \\
6 \\
2-10\end{array}$ & $\begin{array}{c}6,3(2,4) \\
6 \\
3-10\end{array}$ & 0,0162 & $\begin{array}{c}\text { AF } \neq \text { NAF E } \\
\text { e NAF D }\end{array}$ \\
\hline $\begin{array}{l}\text { APRENDIZADO } \\
\text { DE FIGURAS } \\
\text { (BBRC-edu) }\end{array}$ & & & & & \\
\hline $\begin{array}{l}\text { Percepção / } \\
\text { Nomeação }\end{array}$ & $\begin{array}{c}8,5(2,9) \\
10 \\
0-10\end{array}$ & $\begin{array}{c}10(0) \\
10 \\
10-10\end{array}$ & $\begin{array}{c}10(0) \\
10 \\
10-10\end{array}$ & 0,0013 & $\begin{array}{c}\text { AF } \neq \text { N NAF E } \\
\text { e NAF D }\end{array}$ \\
\hline Memória incidental & $\begin{array}{c}3,7(2,7) \\
4 \\
0-9\end{array}$ & $\begin{array}{c}5,2(1,6) \\
5 \\
2-8\end{array}$ & $\begin{array}{c}5,6(1,4) \\
5 \\
4-8\end{array}$ & 0,0756 & NA \\
\hline Memória imediata 1 & $\begin{array}{c}4,8(3,4) \\
5 \\
0-10\end{array}$ & $\begin{array}{c}7,4(1,7) \\
8 \\
5-10\end{array}$ & $\begin{array}{l}8,3(1) \\
8 \\
7-10\end{array}$ & 0,0063 & $\begin{array}{c}\text { AF } \neq \text { NAF E } \\
\text { e NAF D }\end{array}$ \\
\hline
\end{tabular}

continua 
conclusão

Tabela 9 - Desempenho dos afásicos e não afásicos nas provas cognitivas

\begin{tabular}{|c|c|c|c|c|c|}
\hline $\begin{array}{c}\text { PROVA } \\
\text { Média (DP) } \\
\text { Mediana; Intervalo }\end{array}$ & $\begin{array}{c}\text { Afásicos } \\
(\mathrm{N}=21)\end{array}$ & $\begin{array}{c}\text { Não } \\
\text { Afásicos E } \\
(\mathrm{N}=17)\end{array}$ & $\begin{array}{c}\text { Não } \\
\text { Afásicos D } \\
(\mathrm{N}=9)\end{array}$ & $\begin{array}{c}p \\
\text { bicaudal }\end{array}$ & $\begin{array}{c}\text { Comparação } \\
\text { múltipla } \\
(p<0,05)\end{array}$ \\
\hline Memória imediata 2 & $\begin{array}{c}5(3,5) \\
5 \\
0-10\end{array}$ & $\begin{array}{c}8,3(1,5) \\
8 \\
6-10\end{array}$ & $\begin{array}{c}8,9(0,9) \\
9 \\
7-10\end{array}$ & 0,0013 & $\begin{array}{c}\text { AF } \neq \text { NAF E } \\
\text { e NAF D }\end{array}$ \\
\hline Evocação & $\begin{array}{c}4(3,8) \\
3 \\
0-10\end{array}$ & $\begin{array}{c}7,4(1,9) \\
8 \\
4-10\end{array}$ & $\begin{array}{c}8,4(1,2) \\
9 \\
7-10\end{array}$ & 0,0042 & $\begin{array}{c}\text { AF } \neq \text { NAF E } \\
\text { e NAF D }\end{array}$ \\
\hline Reconhecimento & $\begin{array}{c}9,2(2,2) \\
10 \\
0-10\end{array}$ & $\begin{array}{c}10(0) \\
10 \\
10-10\end{array}$ & $\begin{array}{c}9,5(1,3) \\
10 \\
6-10\end{array}$ & 0,1031 & NA \\
\hline $\begin{array}{l}\text { DESENHO DO } \\
\text { RELÓGIO }\end{array}$ & $\begin{array}{c}5,5(3) \\
7 \\
0-9\end{array}$ & $\begin{array}{l}7,9(2) \\
9 \\
2-10\end{array}$ & $\begin{array}{c}8,2(0,8) \\
8 \\
7-9\end{array}$ & 0,0068 & $\begin{array}{c}\text { AF } \neq \text { N NAF E } \\
\text { e NAF D }\end{array}$ \\
\hline
\end{tabular}

AF - afásicos; NAF E - não afásicos com lesão em hemisfério esquerdo; NAF D - não afásicos com lesão em hemisfério direito; NA - não se aplica

A comparação entre o desempenho dos grupos nas provas cognitivas, considerando-se a gravidade da afasia, evidenciou diferença estatisticamente significante nas provas de Extensão de Dígitos (ordem direta), Aprendizado de Palavras (tentativa 2), evocação das Praxias Construtivas (retângulo e pontuação total) e Aprendizado de Figuras (percepção / nomeação) e memória imediata 1), conforme ilustra a Tabela 10. 
Tabela 10 - Comparação entre afásicos e não afásicos nas provas cognitivas, segundo a gravidade da afasia

\begin{tabular}{|c|c|c|c|c|c|c|}
\hline $\begin{array}{l}\text { PROVA } \\
\text { Média (DP) } \\
\text { Mediana; } \\
\text { Intervalo }\end{array}$ & $\begin{array}{l}\text { Afásicos } \\
\text { graves } \\
(\mathrm{N}=14)\end{array}$ & $\begin{array}{l}\text { Afásicos } \\
\text { leves } \\
(\mathrm{N}=7)\end{array}$ & $\begin{array}{c}\text { Não } \\
\text { afásicos } \\
D \\
(n=17)\end{array}$ & $\begin{array}{c}\text { Não } \\
\text { afásicos } \\
E \\
(n=9)\end{array}$ & $\begin{array}{c}p \\
\text { bicaudal }\end{array}$ & $\begin{array}{c}\text { Comparação } \\
\text { múltipla } \\
(p<0,05)\end{array}$ \\
\hline \multicolumn{7}{|l|}{$\begin{array}{l}\text { Extensão de } \\
\text { Dígitos }\end{array}$} \\
\hline Ordem direta & $\begin{array}{c}1,4(1,6) \\
1 \\
0-5\end{array}$ & $\begin{array}{c}5(1) \\
5 \\
4-6\end{array}$ & $\begin{array}{c}8,3(1,7) \\
8 \\
6-12\end{array}$ & $\begin{array}{c}8,4(1,3) \\
8 \\
7-10\end{array}$ & $<0,0001$ & $\begin{array}{c}A F g \neq A F I \\
A F \neq N A F E \\
\text { e NAF D }\end{array}$ \\
\hline Ordem inversa & $\begin{array}{c}0,3(0,8) \\
0 \\
0-3\end{array}$ & $\begin{array}{c}1,3(1,2) \\
2 \\
0-3\end{array}$ & $\begin{array}{c}3,6(1,9) \\
3 \\
2-10\end{array}$ & $\begin{array}{c}4,1(1,3 \\
4 \\
2-6\end{array}$ & $<0,0001$ & $\begin{array}{c}\text { AF } \neq \text { NAF E } \\
\text { e NAF D }\end{array}$ \\
\hline $\begin{array}{l}\text { Aprendizado de } \\
\text { Palavras } \\
\text { (CERAD) }\end{array}$ & & & & & & \\
\hline Tentativa 2 & $\begin{array}{c}2,8(3,2) \\
2 \\
0-10\end{array}$ & $\begin{array}{c}4,3(3) \\
5 \\
1-8\end{array}$ & $\begin{array}{c}5,8(1,7) \\
6 \\
3-8\end{array}$ & $\begin{array}{c}6,3(1) \\
6 \\
5-8\end{array}$ & 0,0098 & $\begin{array}{c}\text { AFg } \neq \text { NAF E } \\
\text { e NAF D }\end{array}$ \\
\hline Tentativa 3 & $\begin{array}{c}2,7(3) \\
2 \\
0-9\end{array}$ & $\begin{array}{c}3,5(3,3) \\
3 \\
0-8\end{array}$ & $\begin{array}{c}6,7(1,6) \\
7 \\
3-9\end{array}$ & $\begin{array}{c}7,8(1,4) \\
8 \\
6-10\end{array}$ & 0,0004 & $\begin{array}{c}\text { AF } \neq \text { NAF E } \\
\text { e NAF D }\end{array}$ \\
\hline TOTAL & $\begin{array}{c}7,8(8,7) \\
6,5 \\
0-27\end{array}$ & $\begin{array}{c}10,4(7,9) \\
10 \\
1-21\end{array}$ & $\begin{array}{c}16,3(4) \\
16 \\
9-22\end{array}$ & $\begin{array}{c}17,9(2,9) \\
18 \\
12-23\end{array}$ & 0,0042 & $\begin{array}{c}\mathrm{AFg} \neq \mathrm{NAF} E \\
\text { e NAF D }\end{array}$ \\
\hline $\begin{array}{l}\text { Evocação de } \\
\text { palavras }\end{array}$ & $\begin{array}{c}2,4(3,1) \\
1 \\
0-10\end{array}$ & $\begin{array}{c}2,4(2,5) \\
2 \\
0-6\end{array}$ & $\begin{array}{c}5,1(2,4) \\
5 \\
2-10\end{array}$ & $\begin{array}{c}6,1(1,2) \\
6 \\
4-8\end{array}$ & 0,0023 & $\begin{array}{c}\text { AF } \neq \text { NAF E } \\
\text { e NAF D }\end{array}$ \\
\hline $\begin{array}{l}\text { Reconhecimento } \\
\text { de palavras }\end{array}$ & $\begin{array}{c}6,8(4) \\
8,5 \\
0-10\end{array}$ & $\begin{array}{c}8,3(1,4) \\
8 \\
7-10\end{array}$ & $\begin{array}{c}8,3(1,7) \\
9 \\
5-10\end{array}$ & $\begin{array}{c}9,9(0,3) \\
10 \\
9-10\end{array}$ & 0,0431 & $\begin{array}{l}\text { AF e NAF E } \\
\quad \neq \text { NAF D }\end{array}$ \\
\hline $\begin{array}{l}\text { Evocação } \\
\text { Praxia } \\
\text { Construtiva } \\
\text { (CERAD) }\end{array}$ & & & & & & \\
\hline Retângulo & $\begin{array}{c}0,8(1) \\
0 \\
0-2\end{array}$ & $\begin{array}{c}1,3(0,9) \\
2 \\
0-2\end{array}$ & $\begin{array}{c}1,8(0,5) \\
2 \\
0-2\end{array}$ & $\begin{array}{c}1,8(0,6) \\
2 \\
0-2\end{array}$ & 0,0156 & $\begin{array}{c}\text { AFg } \neq \text { NAF E } \\
\text { e NAF D }\end{array}$ \\
\hline Total & $\begin{array}{c}3,8(3,3) \\
4 \\
0-10\end{array}$ & $\begin{array}{c}4,3(2,8) \\
4 \\
1-9\end{array}$ & $\begin{array}{c}6,7(2,7) \\
6 \\
2-10\end{array}$ & $\begin{array}{c}6,3(2,4) \\
6 \\
3-10\end{array}$ & 0,0400 & $\begin{array}{c}\text { AFg } \neq \text { NAF E } \\
\text { e NAF D }\end{array}$ \\
\hline $\begin{array}{l}\text { Aprendizado de } \\
\text { Figuras (BBRC } \\
\text { - Edu) }\end{array}$ & & & & & & \\
\hline $\begin{array}{l}\text { Percepção / } \\
\text { Nomeação }\end{array}$ & $\begin{array}{c}7,9(3,5) \\
9,5 \\
0-10\end{array}$ & $\begin{array}{c}9,7(0,5) \\
10 \\
9-10\end{array}$ & $\begin{array}{c}10(0) \\
10 \\
10-10\end{array}$ & $\begin{array}{c}10(0) \\
10 \\
10-10\end{array}$ & 0,0016 & $\begin{array}{c}\text { AFg } \neq \text { NAF E } \\
\text { e NAF D }\end{array}$ \\
\hline $\begin{array}{l}\text { Memória } \\
\text { imediata } 1\end{array}$ & $\begin{array}{c}4,6(3,8) \\
5 \\
0-10\end{array}$ & $\begin{array}{c}5,1(2,5) \\
6 \\
1-9\end{array}$ & $\begin{array}{c}7,4(1,7) \\
8 \\
5-10\end{array}$ & $\begin{array}{c}8,3(1) \\
8 \\
7-10\end{array}$ & 0,0175 & $\begin{array}{c}\text { AFg } \neq \text { NAF E } \\
\text { e NAF D } \\
\text { AFI } \neq \text { NAF D }\end{array}$ \\
\hline
\end{tabular}


continuação

Tabela 10 - Comparação entre afásicos e não afásicos nas provas cognitivas, segundo a gravidade da afasia

\begin{tabular}{lcccccc}
\hline $\begin{array}{c}\text { PROVA } \\
\text { Média (DP) } \\
\text { Mediana; } \\
\text { Intervalo }\end{array}$ & $\begin{array}{c}\text { Afásicos } \\
\text { graves } \\
(\mathbf{N}=14)\end{array}$ & $\begin{array}{c}\text { Afásicos } \\
\text { leves } \\
\mathbf{( N = 7 )}\end{array}$ & $\begin{array}{c}\text { Não } \\
\text { afásicos } \\
\mathbf{D} \\
(\mathbf{n = 1 7})\end{array}$ & $\begin{array}{c}\text { Não } \\
\text { afásicos } \\
\mathbf{E} \\
(\mathbf{n}=\mathbf{9})\end{array}$ & $\begin{array}{c}\boldsymbol{p} \\
\text { bicaudal }\end{array}$ & $\begin{array}{c}\text { Comparação } \\
\text { múltipla } \\
(\mathbf{p}<\mathbf{0 , 0 5})\end{array}$ \\
\hline Memória & $4,8(3,9)$ & $5,4(2,5)$ & $8,3(1,5)$ & $8,9(0,9)$ & 0,0040 & AF e NAF E \\
imediata 2 & 5,5 & 5 & 8 & 9 & & fNAF D \\
& $0-10$ & $2-10$ & $6-10$ & $7-10$ & & \\
Evocação & $4,2(4)$ & $3,6(3,7)$ & $7,4(1,9)$ & $8,4(1,2)$ & 0,0110 & AF e NAF E \\
& 3,5 & 3 & 8 & 9 & & $\neq$ NAF D \\
Desenho do & $0-10$ & $0-10$ & $4-10$ & $7-10$ & & AF e NAF E \\
relógio & $5,5(3,3)$ & $5,6(2,7)$ & $7,9(2)$ & $8,2(0,8)$ & 0,0183 & $\neq$ NAF D \\
& 7 & 5 & 9 & 8 & & \\
\hline
\end{tabular}

Mais especificamente, houve diferença estatisticamente significante entre os afásicos graves e leves na prova de Extensão de Dígitos (ordem direta), entre os afásicos graves e os não afásicos na tentativa 2 da prova de Aprendizado de Palavras, na prova de evocação das Praxias Construtivas (retângulo e pontuação total) e nas tarefas de percepção / nomeação e memória imediata 1 da prova de Aprendizado de Figuras. Nesta última tarefa também foi constatada diferença entre o desempenho dos afásicos leves e os sujeitos do grupo NAF D.

Tabela 11 - Correlações entre as provas de praxias gestuais e a gravidade da afasia

\begin{tabular}{lcc}
\hline Praxia & $\begin{array}{c}\text { Coeficiente rho de } \\
\text { Spearman }\end{array}$ & $\boldsymbol{p}$ bicaudal \\
\hline Gestos naturais & 0,477 & 0,0329 \\
Gestos convencionais & 0,653 & 0,0035 \\
Uso de objetos fictícios & 0,465 & 0,0377 \\
Praxia Bucofacial e & 0,708 & 0,0016 \\
Respiratória & & \\
TOTAL & 0,668 & 0,0028 \\
\hline
\end{tabular}


Foi encontrada correlação positiva entre o escore de gravidade da afasia e o desempenho no teste de extensão de dígitos em ordem direta (rho $=0,860, p=0,0001)$ e em ordem inversa (rho=0,543, $p=0,0152)$. Nas provas de praxias gestuais, houve correlação positiva entre todas as modalidades e a gravidade da afasia, com destaque para a forte correlação no caso das praxias buco-faciais ( $\mathrm{rho}=0,708, \mathrm{p}=0,016)$, conforme apresentado na Tabela 11. 


\section{6- DISCUSSÃO}

O presente estudo teve como principais objetivos avaliar 0 desempenho de indivíduos afásicos em tarefas cognitivas não linguísticas, abrangendo as habilidades de atenção, memória verbal e não verbal, funções executivas e visuoespaciais, assim como comparar tal desempenho ao de indivíduos não afásicos, sendo que em ambos os grupos os pacientes apresentavam lesão cerebral única decorrente de AVE.

A comparação entre os grupos AF, NAF E e NAF D nas tarefas de linguagem do TBDA e TNB evidenciou pior desempenho dos afásicos em todas as provas, como esperado. De acordo com o Perfil Resumido dos Subtestes do TBDA, a maioria dos não afásicos (70\%) apresentou desempenho igual ou superior a percentil 80 em 14 das 21 tarefas realizadas. Nas provas de compreensão de palavras, material ideacional complexo e compreensão de leitura, o desempenho foi igual ou superior a percentil 70. Cerca de metade da amostra de não afásicos apresentou desempenho inferior a percentil 70 em tarefas relacionadas à habilidade de escrita (forma da escrita, escolha da letra, habilidade motora e narrativa escrita), prejudicada principalmente em decorrência da hemiparesia e com a possibilidade de interferência da escolaridade no desempenho. A maioria dos afásicos apresentou desempenho igual ou inferior a percentil 50 em 19 das 21 tarefas. Nas tarefas de emparelhamento letra-palavra e emparelhamento de números, 11 e 13 afásicos atingiram percentil 100, respectivamente. 
No exame complementar da função cognitiva, inicialmente foi aplicado o Teste de Cancelamento, que avalia a atenção sustentada. Nesta prova, não foi constatada diferença estatisticamente significante entre os grupos AF, NAF E e NAF D, evidenciando que todos os grupos apresentaram desempenho semelhante. Apesar de os afásicos terem apresentado, em média, número de omissões discretamente maior $(2,2)$ que o valor para normalidade $(2,0)$, em nossa amostra o quadro de afasia não parece ter interferido na habilidade de atenção sustentada. Tal achado é corroborado pelo estudo de Korda e Douglas ${ }^{77}$, no qual foi comparado o desempenho entre afásicos e normais (não cérebro-lesados) em tarefa de atenção sustentada e não foi constatada diferença entre os grupos, somente aumento equivalente no tempo de reação no decorrer do tempo. Também está em concordância com o estudo de Helm-Estabrooks ${ }^{62}$, no qual a autora descreveu que as habilidades de discriminação visual e atenção se mostraram preservadas em sua amostra de afásicos.

Considerando-se os participantes do estudo que apresentaram número de omissões do estímulo-alvo maior que dois (2) no Teste de Cancelamento, encontramos seis afásicos e três não afásicos lesados de HE. Dentre os afásicos, cinco apresentaram maior número de omissões à direita, achado que sugere que os mesmos apresentavam pelo menos certo grau de inatenção sensorial visual. Todos os componentes do grupo NAF D apresentaram desempenho dentro da normalidade. Vale ressaltar que um afásico e um não afásico lesado de HE apresentavam hemianopsia à direita. Embora seja mais frequente e mais grave nas lesões à $D$, negligência ou 
inatenção pode ocorrer também após lesões em hemisfério $E$, mais usualmente na fase aguda do $\operatorname{AVE}^{78}$. No grupo de pacientes com inatenção, porém sem hemianopsia (seis sujeitos), 4 (quatro) apresentavam lesão parietal, 1 (um) lesão frontal e 1 (um) lesão talâmica.

No Teste de Trilhas, partes A e B, para avaliação da atenção seletiva, bem como da velocidade do processamento perceptual e da flexibilidade mental, foi constatado desempenho abaixo do normal para todos os grupos (AF, NAF E e NAF D), em especial na parte B do teste. Apesar de os indivíduos afásicos terem apresentado, em média, maior tempo para realizarem a tarefa, os achados não permitem confirmar a desvantagem decorrente da afasia nas habilidades cognitivas não linguísticas avaliadas no teste em questão, considerando-se a alteração na função motora, no caso dos afásicos e não afásicos hemiparéticos à direita. Dentre os 14 afásicos que não finalizaram a parte $B$ do teste, 11 apresentavam hemiparesia à $D$ e seis não compreenderam a tarefa, três apresentando também hemiparesia. Já dentre os não afásicos, apenas três não finalizaram a parte B e destes, um apresentava hemiparesia.

Ainda abordando as provas e/ou tarefas nas quais não houve diferença entre o desempenho dos grupos, encontramos a prova de Praxias Construtivas. Nesta, todos os grupos apresentaram desempenho inferior ao descrito na normalidade, com relação à pontuação total. A literatura descreve a ocorrência de alterações nas habilidades visuoespaciais em lesões de ambos os hemisférios, ainda que a caracterização destas alterações seja diferente. Tal afirmação pode justificar os achados de nossa 
amostra. De modo geral, pacientes com lesão à $D$ tendem a produzir desenhos com erros de orientação espacial e desorganizados, enquanto pacientes com lesão à $E$ frequentemente geram desenhos simplificados e com omissão de detalhes, porém com preservação das relações espaciais entre as partes ${ }^{79}$.

Em comparação aos grupos NAF E e NAF D, os afásicos apresentaram pior desempenho na tarefa de fluência verbal semântica. Tarefas de fluência verbal tem sido amplamente utilizadas para avaliar processamentos de linguagem e função executiva. Alteração nesta habilidade pode ser o resultado de dificuldades articulatórias e nos mecanismos de iniciação da fala ou de empobrecimento semântico ${ }^{18}$. Tais funções estão organizadas nos lobos frontais, temporais e parietais, e alterações também são descritas em lesões subcorticais. Como todos os afásicos apresentaram lesão em pelo menos uma das regiões citadas, justifica-se a alteração de fluência verbal semântica encontrada no estudo.

Além disso, os grupos NAF E e NAF D também apresentaram desempenho ruim nesta tarefa. O prejuízo no processamento léxicosemântico nas lesões de HE é bem descrito, mas, atualmente, alguns autores tem encontrado evidências de alterações neste processamento também em lesões de HD, sustentando o achado do presente estudo. Estudos sugerem, inclusive, que o desempenho de pacientes com lesão em HD é pior, quando comparados aos controles, quando o critério de produção é semântico e não fonológico, resultado também obtido em nossa amostra $^{80,81,82}$. 
Esperava-se encontrar resultado semelhante ao da prova de fluência verbal semântica na prova de fluência verbal fonológica (FAS), ou seja, que houvesse diferença estatisticamente significante somente entre afásicos e não afásicos, evidenciando pior desempenho dos afásicos na tarefa. Porém, foi constatada diferença estatisticamente significante entre os três grupos, sendo que o desempenho dos afásicos e dos não afásicos com lesão em HE foi pior em comparação ao dos não afásicos com lesão em HD. O grupo com lesão em HD apresentou desempenho próximo ao normal, o que mostra que a lesão de HD prejudica de forma mais intensa a fluência semântica, como já apontado. Ambas as tarefas de fluência verbal (semântica e fonológica) envolvem principalmente a ativação dos lobos frontal e temporal ${ }^{83}$.

Nas provas de Praxias Gestuais, também foi constatado pior desempenho dos afásicos, quando comparados aos NAF E e NAF D, em todos os subtestes (praxia de mão / membros, gestos convencionais, uso de objetos fictícios e praxia buco-facial / respiratória). A associação entre a afasia e a apraxia pode ser explicada pela lesão de estruturas contíguas em hemisfério dominante, especializadas nas habilidades de linguagem e $\operatorname{praxia}^{84}$

Quando solicitados a imitar os movimentos, uma vez não respondendo ao comando verbal ou errando a resposta, os afásicos apresentaram melhora significativa no desempenho - 14 dentre 18 afásicos na tarefa de gestos naturais, 13 dentre 19 na de gestos convencionais, 13 dentre 20 na de uso de objetos fictícios e oito dentre 16 na de praxia bucofacial e respiratória. Acredita-se que esta melhora no desempenho 
esteja relacionada à presença de apraxia dissociativa. Neste caso, baseando-se no modelo de praxia que descreve seu processamento por dois sistemas - conceitual para ação, relacionado ao conhecimento de ferramentas / objetos e suas ações e sistema de produção da ação (habilidade de executar programas motores) - ambos estariam preservados, mas não poderiam ser acessados pelo comando verbal ${ }^{85}$.

Os afásicos também apresentaram pior desempenho na prova de Extensão de Dígitos, a qual avalia atenção, memória operacional e o controle mental para operacionalização de informações, em ambas as etapas: ordem direta e ordem inversa, em comparação aos grupos NAF E, NAF D e às normas de referência. O mesmo achado foi descrito em estudo de De Renzi e Nichelli ${ }^{60}$.

Na prova de Aprendizado de Palavras, a qual avalia a memória verbal, os afásicos apresentaram desempenho abaixo da normalidade, nas tarefas de evocação imediata e tardia, enquanto os indivíduos dos grupos NAF E e NAF D apresentaram desempenho correspondente à normalidade. Um dos fatores a serem considerados com relação ao pior desempenho dos afásicos é a necessidade de resposta verbal, prejudicada principalmente nos casos de afasia mais grave. Por outro lado, o prejuízo da memória verbal em afásicos, independentemente do prejuízo na expressão oral é descrito em vários estudos $2,86,87$, o que nos permite sugerir a presença de prejuízo na memória verbal dos afásicos da nossa amostra. No entanto, os pacientes afásicos apresentaram melhora do desempenho na prova de reconhecimento das palavras o que mostra uma capacidade de codificação 
de informação relativamente preservada em relação à recordação espontânea, sugerindo a interferência do prejuízo da produção verbal para a resposta, ou de dificuldades de organização de estratégias de busca espontânea das informações armazenadas (disfunção executiva).

Na prova de Evocação de Praxias Construtivas, tarefa de evocação, os afásicos apresentaram pior desempenho, em relação aos não afásicos, cujo desempenho foi normal. Quanto à prova de Aprendizado de Figuras, que também avalia a memória não verbal, os resultados evidenciaram pior desempenho dos afásicos, em comparação aos não afásicos, nas tarefas de percepção / nomeação, memória imediata 1 e 2 e de evocação. Considerando-se as normas de referência para a prova em questão, foi constatado pior desempenho dos afásicos em todas as tarefas, com exceção da de reconhecimento, achado em concordância com alguns estudos ${ }^{88,89,90}$. A literatura aponta que indivíduos normais utilizam o código verbal mesmo para o armazenamento de informação visual ${ }^{60}$. Este argumento explicaria 0 prejuízo de afásicos em tarefas de memória não verbal. Porém, nota-se melhora no desempenho (dentro da normalidade) na prova de reconhecimento das figuras, mostrando preservação da codificação do material não verbal, semelhante ao observado na tarefa de Aprendizado de Palavras.

A prova do Desenho do Relógio buscou avaliar o funcionamento executivo, bem como a habilidade visuoespacial (praxia construtiva). Nesta prova, os resultados do estudo evidenciaram pior desempenho dos afásicos, quando comparados aos NAF E e NAF D e não houve diferença entre os 
afásicos, de acordo com a gravidade da afasia. Em estudo mencionado anteriormente, Helm-Estabrooks ${ }^{62}$ descreveu maior dificuldade na realização das tarefas propostas no CLQT, quanto maior a demanda destas para as funções executivas. A autora conclui que, além da linguagem, as funções executivas seriam as habilidades cognitivas mais vulneráveis aos efeitos da lesão cerebral associada à afasia. Hincley et al. $^{64}$, buscando evidências quanto à interferência das funções executivas na terapia de afasia, descreveram uma demora maior dos indivíduos até preencherem os critérios para o início da terapia de linguagem formal, quanto pior o desempenho nos teste aplicados.

Em comparação com as normas de referência consideradas, todos os grupos apresentaram desempenho abaixo do normal no TDR, sugerindo prejuízo das funções executivas independentemente da ocorrência da afasia e da lateralidade da lesão.

A subdivisão do grupo de afásicos de acordo com a gravidade da afasia em $\mathrm{AFg}$ e $\mathrm{AFI}$, mostrou pior desempenho dos afásicos graves em relação aos afásicos leves e aos não afásicos nas provas de Extensão de Dígitos, Aprendizado de Palavras, Aprendizado de Figuras e Evocação de Praxias Construtivas. Este achado sugere a interferência do prejuízo na expressão oral no desempenho de indivíduos afásicos. O relativo melhor desempenho dos afásicos na tarefa de reconhecimento de palavras e figuras reforça nossa suposição, uma vez que não exigia resposta a partir de expressão oral ou escrita. 
Finalmente, as únicas provas em que encontramos correlação direta entre a gravidade da afasia e o desempenho dos pacientes foram Extensão de Dígitos (ordem direta e inversa) e Praxias Gestuais. Nestas provas, o desempenho foi inversamente proporcional à gravidade da afasia. Pode-se argumentar que essas provas avaliam de forma mais direta e pontual habilidades altamente dependentes da linguagem, como a tarefa de Extensão de Dígitos que se apóia em mecanismos de memória operacional (alça fonológica), ou que, além disso, compartilhem as mesmas redes neurais, como já descrito anteriormente com relação às Praxias Gestuais.

A literatura aponta e o presente estudo confirma que os afásicos demonstram grande variabilidade no desempenho ${ }^{62}$. Para diferentes tarefas que avaliam uma mesma função cognitiva, ocorre diferença no desempenho, o que dificulta afirmar em quais provas cognitivas não linguísticas o prejuízo existe, efetivamente. Não obstante, vários fatores não relacionados à lesão ou ao processamento de determinada função cognitiva, tais como o prejuízo na expressão oral e a ocorrência de hemiparesia, podem interferir no desempenho e não devem ser desconsideradas.

Uma das dificuldades práticas encontradas por profissionais de reabilitação que trabalham com afásicos é executar uma avaliação cognitiva confiável que permita identificar quais funções não linguísticas estão preservadas e quais estão prejudicadas, o que pode influenciar diretamente na escolha da linha de intervenção terapêutica mais adequada para cada paciente. Dessa forma, este estudo reforça a necessidade de construção e validação de instrumentos específicos para a avaliação das habilidades não 
linguísticas em afásicos, para que os fatores acima mencionados não interfiram ou interfiram minimamente no desempenho.

Nossos resultados mostram que a interferência do déficit motor (paresia da mão dominante) e das dificuldades de produção verbal são fatores que prejudicam a execução de algumas provas e a interpretação dos resultados. Provas com menor demanda relativa na habilidade motora como o Teste de Cancelamento e as provas de Praxias Construtivas permitem um melhor desempenho dos sujeitos afásicos. Provas que demandam maior destreza manual, como o Teste de Trilhas, que depende de velocidade manual para sua execução, impõem um obstáculo adicional a esses indivíduos. O mesmo ocorre com tarefas em que a entrada e saída dos estímulos é feita verbalmente.

Sugere-se, para pesquisas futuras, que a relação entre a afasia e cada habilidade cognitiva não linguística seja analisada separadamente, dada a complexidade do tema.

Se o desempenho nas tarefas de linguagem é prejudicado pelos déficits cognitivos não linguísticos (função cognitiva como base para o processamento lingüístico) ou se os déficits cognitivos ocorrem como consequência do prejuízo da linguagem (funções cognitivas regidas pela linguagem), ou ambos, o estudo em questão não permite ou teve a intenção de comprovar, permanecendo o questionamento para pesquisas futuras. Um fator que permeia esta inter-relação entre funções cognitivas é a sobreposição dos sítios anatômicos acometidos nas lesões vasculares, pois uma mesma região cerebral (por exemplo, o lobo temporal), participa 
simultaneamente de diversas funções ${ }^{71}$. Esta é uma dificuldade metodológica que dificilmente será superada quando se estudam populações com lesões vasculares corticais, pois as lesões se distribuem em função da anatomia vascular e não de acordo com os circuitos cognitivos subjacentes. No entanto, acreditamos que um número maior de casos, que permita a comparação dos grupos segundo os locais de lesão pode permitir avanços no entendimento da co-dependência entre a linguagem e outras funções cognitivas. Da mesma forma, a análise e comparação de grupos de acordo com tipo clínico de afasia permitiria um melhor entendimento do peso específico que as alterações de produção verbal e de compreensão exercem no desempenho dos sujeitos afásicos, especialmente naqueles com afasia mais grave.

Dentre as limitações do estudo, destacamos o número reduzido de sujeitos da amostra, a ausência de controles normais para a comparação do desempenho dos demais grupos, a heterogeneidade das lesões vasculares e dos tipos clínicos de afasia, assim como a necessidade de resposta verbal em praticamente todas as provas cognitivas não linguísticas, fator que prejudicou o desempenho dos afásicos, em especial dos graves, de forma significativa. O número pequeno de estudos com desenho semelhante existentes na literatura internacional, e ausência de dados para comparação na literatura nacional também constituíram um fator limitante para a nossa discussão. 


\section{7- CONCLUSÕES}

Os indivíduos afásicos não apresentaram prejuízo no desempenho em atenção sustentada (Teste de Cancelamento) e nas tarefas de reconhecimento de palavras e figuras. Apresentaram prejuízo no Teste de Trilhas (partes A e B), Extensão de Dígitos, Praxias Construtivas, Desenho do Relógio, Aprendizado de Palavras e Figuras, e Praxias Gestuais mostrando comprometimento em funções executivas, memória verbal e não verbal, habilidades visuoespacias e praxias.

Os sujeitos afásicos apresentaram pior desempenho em comparação aos não afásicos nas provas de Praxias Gestuais, Extensão de Dígitos, Aprendizado de Palavras, Aprendizado de Figuras, Evocação de Praxias e Desenho do Relógio.

Foi constatada interferência da gravidade da afasia nas provas de Extensão de Dígitos (ordem direta), Aprendizado de Palavras e Figuras, e Evocação das Praxias Construtivas. Foi encontrada correlação positiva entre o escore de gravidade da afasia e o desempenho no teste de Extensão de Dígitos (ordens direta e inversa) e nas provas de Praxias Gestuais. 
8- ANEXOS

Anexo A

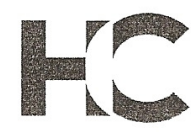

\title{
APROVAÇÃO
}

A Comissão de Ética para Análise de Projetos de Pesquisa - CAPPesq da Diretoria Clínica do Hospital das Clínicas e da Faculdade de Medicina da Universidade de São Paulo, em sessão de 01/08/2007, APROVOU o Protocolo de Pesquisa n 0595/07, intitulado: "AFASIAS PÓS ACIDENTE VASCULAR ENCEFÁlICO: ASPECTOS EPIDEMIOLÓGICOS E IMPACTO NA QUALIDADE DE VIDA" apresentado pelo DEPARTAMENTO DE NEUROLOGIA, inclusive O Termo de Consentimento Livre e Esclarecido.

Cabe ao pesquisador elaborar e apresentar à CAPPesq, os relatórios parciais e final sobre a pesquisa (Resolução do Conselho Nacional de Saúde $n^{\circ}$ 196, de 10/10/1996, inciso IX.2, letra "c").

Pesquisador (a) Responsável: Marcia Radanovic

Pesquisador (a) Executante: Milena Vaz Bonini

CAPPesq, 07 de Agosto de 2007

\begin{abstract}
Prof. Dr. Eduardo Massad Presidente da Comissão de Ética para Análise de Projelos de Pesquisa
\end{abstract}

Comissão de Ética para Análise de Projetos de Pesquisa do HCFMUSP e da FMUSP Diretoria Clínica do Hospital das Clínicas da Faculdade de Medicina da Universidade de Säo Paulo Rua Ovídio Pires de Campos, 255, $5^{\circ}$ andar - CEP 05403010 - São Paulo - SP Fone: 01130696442 Fax: 01130696492 e-mail: cappesq@hcnet.usp.br / secretariacappesq@hcnet.usp.br 
Anexo B

São Paulo, 4 de junho de 2007.

$I l^{m o(a)} \cdot S^{r(a)}$

Dra. Márcia Radanovic

Hospital das Clínicas

Faculdade de Medicina

UNIVERSIDADE DE SÃO PAULO

REFERENTE: Projeto de Pesquisa "Afasias pós acidente vascular encefálico: aspectos epidemiológicos e impacto na qualidade de vida" - Co-Autor(es): Milena Vaz Bonini - Registro CEP-HU/USP: 734/07 - SISNEP CAAE: 0016.0.198.015-07

Prezado(a) Senhor(a)

O Comitê de Ética em Pesquisa do Hospital Universitário da Universidade de São Paulo, em reunião ordinária realizada no dia $1^{\circ}$ de junho de 2007 , analisou o projeto de pesquisa acima citado, considerando-o como APROVADO, bem como, seu Termo de Consentimento Livre e Esclarecido.

Lembramos que cabe ao pesquisador elaborar e apresentar a este Comitê, relatórios anuais (parciais ou final, em função da duração da pesquisa), de acordo com a Resolução 196/96 do Conselho Nacional de Saúde, item IX.2 letra c.

O primeiro relatório está previsto para $1^{\circ}$ de junho de 2008 .

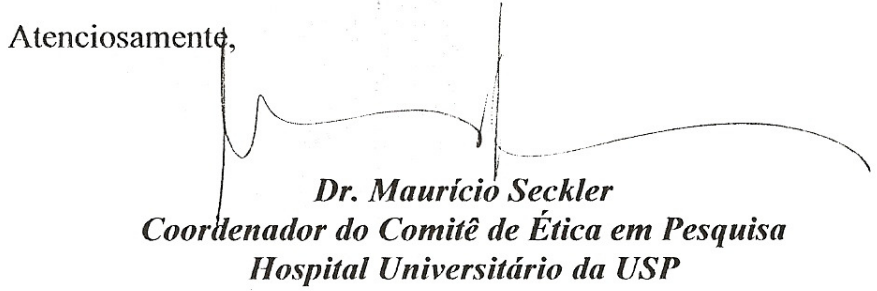


Avenida Profescor I inew Prestes. 2565 - Cidade I niversitaria - 05508-900 San Paulo - SP Tels.: (11) 3039-9457 ou 9479 - lax: (11) 30.39-9452 - V-mail: cepahu.usph.hr 
Anexo C

\section{TERMO DE CONSENTIMENTO LIVRE E ESCLARECIDO}

1.NOME DO PACIENTE .:

DOCUMENTO DE IDENTIDADE № :

SEXO:.$M \quad F$

DATA NASCIMENTO: ........................

ENDEREÇO

№

APTO:

BAIRRO: CIDADE

CEP:.

TELEFONE: DDD (

..)

2.RESPONSÁVEL LEGAL

NATUREZA (grau de parentesco, tutor, curador etc.)

DOCUMENTO DE IDENTIDADE :

DATA NASCIMENTO.: ......................

ENDEREÇO:

No. APTO:

BAIRRO: CIDADE:

CEP:.

TELEFONE: $(\ldots \ldots \ldots \ldots)$

1. TÍTULO DO PROTOCOLO DE PESQUISA: RELAÇÃO ENTRE ALTERAÇÕES DE LINGUAGEM E DÉFICITS COGNITIVOS NÃO LINGUíSTICOS EM INDIVÍDUOS AFÁSICOS APÓS ACIDENTE VASCULAR ENCEFÁLICO.

PESQUISADOR: MILENA VAZ BONINI

2.FUNÇÃO: Fonoaudióloga INSCRIÇÃO CONSELHO REGIONAL (Fonoaudiologia): № 13992/SP

3. AVALIAÇÃO DO RISCO DA PESQUISA:

$\begin{array}{lll}\text { SEM RISCO } & X & \text { RISCO MÍNIMO } \\ \text { RISCO BAIXO } & \text { RISCO MAIOR }\end{array}$

4.DURAÇÃO DA PESQUISA : 3 anos

Estamos realizando um estudo para conhecermos alguns aspectos da linguagem $\mathrm{e}$ o impacto na qualidade de vida de pessoas que sofreram um "derrame" (acidente vascular encefálico), para assim podermos ajudar a estas e outras pessoas que têm dificuldades para se comunicar de maneira eficaz ou para realizar as atividades de todos os dias. Sabemos que os hábitos de uma pessoa, o tempo que freqüentou escola e as ocupações que exerceu durante a vida podem fazer com que ela realize melhor algumas tarefas relacionadas à comunicação e à linguagem do que outras, mesmo após terem sofrido um "derrame".

Faremos ao (à) senhor(a) algumas perguntas sobre sua idade, tempo de estudo, ocupações e hábitos. Também questionaremos o (a) senhor(a) sobre as condições atuais de saúde, visão e audição e sobre o que mudou em sua vida após ter sofrido o "derrame".

Pediremos que o(a) senhor(a) realize tarefas que avaliarão a linguagem, tais como dizer nomes de objetos e desenhos, repetir frases, memorizar histórias e frases, escrever, ler palavras e frases, contar e recontar pequenas histórias.

Essas atividades serão interrompidas se o(a) senhor(a) ficar cansado (a) ou indisposto (a). A aplicação total dura, em média, 2 horas. Faremos intervalos e, se houver necessidade, poderemos realizá-las em duas ou mais sessões.

$\mathrm{O}$ (A) senhor(a) receberá orientações gerais sobre como estimular hábitos saudáveis de comunicação. Além disso, se for necessário, será oferecido acompanhamento 
fonoaudiológico a ser realizado no Hospital Universitário, para tratamento de possíveis alterações constatadas nas tarefas propostas.

$\mathrm{O}$ (A) senhor (a) terá acesso, a qualquer tempo, às informações sobre procedimentos e benefícios relacionados à pesquisa, inclusive para solucionar eventuais dúvidas. Se percebermos algum risco, não previsto até o momento, o(a) senhor (a) será informado.

$\mathrm{O}$ (A) senhor (a) terá liberdade de retirar seu consentimento a qualquer momento e de deixar de participar do estudo, sem que isto traga prejuízo à continuidade da assistência à sua saúde nessa instituição.

Não divulgaremos em nenhum momento sua identidade e todos os dados obtidos serão mantidos em lugar seguro. Se for necessário mencionar algum dado seu, utilizaremos iniciais falsas, por exemplo, J.P para indicar seu nome.

Até o momento, não sabemos de ninguém que apresentasse qualquer problema ao realizar esses testes e questionários, mas se por acaso ocorrer algum problema com o(a) senhor(a) que possa estar relacionado ao estudo realizado, o(a) senhor(a) terá a possibilidade de ser atendido(a) no Hospital Universitário da USP, sendo respeitado o critério de assistência (hospital de atendimento secundário) ou ser encaminhado(a) ao SUS. Não há previsão de ressarcimento das despesas de transporte, nem ocorreu contratação de seguro, visto não haver risco no projeto.

\section{EM CASO DE DÚVIDAS:}

\section{MILENA VAZ BONINI}

Telefone: (0XX11) 9241-1685 - E-mail: mili_bonini@uol.com.br

Declaro que, após convenientemente esclarecido pelo pesquisador e ter entendido o que me foi explicado, consinto em participar do presente Protocolo de Pesquisa.

São Paulo, de de 20

assinatura do sujeito da pesquisa ou responsável legal

\footnotetext{
* Comissão de Ética para Análise de Projetos de Pesquisa do HCFMUSP e da FMUSP. Diretoria Clínica do Hospital das Clínicas das Faculdade de Medicina da Universidade de São Paulo. Rua Ovídio Pires de Campo, 255, 5은 andar - CEP: 05403-010 - São Paulo - SP Fone: 11 3069-6442 - E-mail: cappesq@hcnet.usp.br

- Comitê de Ética em Pesquisa do Hospital Universitário da USP (CEP) - Endereço: Avenida Professor Lineu Prestes, 2565 - Cidade Universitária - CEP: 05508-900 - Telefones: 3039-9457 / 3039-9479 - E-mail: cep@hu.usp.br
} 
TESTE DE BOSTON PARA O DIAGNÓSTICO DE AFASIA

Anexo D

(Goodglass, Kaplan e Barresi, 2001)

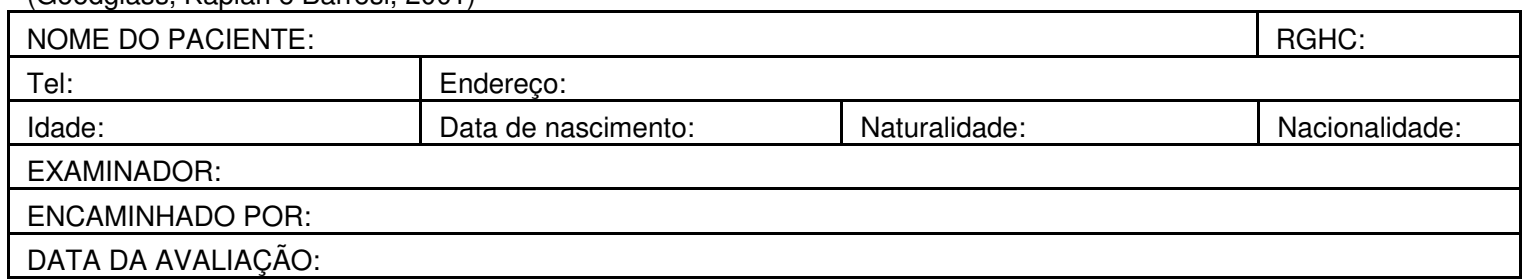

\begin{tabular}{|c|c|}
\hline Locais onde morou por mais de 15 anos: & $\begin{array}{l}\text { Idiomas: somente português: } \\
\text { bilingüe: } \\
\text { Se bilingüe breve relato sobre aquisição: } \\
\text { Língua falada em casa }\end{array}$ \\
\hline $\begin{array}{l}\text { Escolaridade (número de anos): } \\
\text { Completados aos........ anos }\end{array}$ & Histórico profissional: \\
\hline Natureza e duração da doença atual: & Informação sobre localização da lesão: \\
\hline EEG - Foco: & Informações sobre cirurgias: \\
\hline \multicolumn{2}{|c|}{ Outras informações sobre localização ex.: Tomografía, Ressonância, Angiografia, etc. } \\
\hline $\begin{array}{l}\text { Hemiplegia: direita esquerda recuperada ausente } \\
\text { (circule a condição do paciente) }\end{array}$ & $\begin{array}{l}\text { Hemianopsia: direita esquerda recuperada } \\
\text { ausente }\end{array}$ \\
\hline
\end{tabular}

\section{*DOMINÂNCIA MANUAL- EDINBURGH}

Instruções: você é destro ou canhoto? Você tem tendência a realizar atividades com sua outra mão? Com que mão você............ (enumerar diversas atividades). Algumas vezes você usa a outra mão?

\begin{tabular}{|l|l|l|l|l|}
\hline Atividade & Mão esquerda & & Mão direita & \\
\hline $\begin{array}{l}\text { escrever ou distribuir as cartas de um } \\
\text { baralho. }\end{array}$ & & & & \\
\hline desenhar ou encher de água um copo & & & & \\
\hline jogar uma bola & & & & \\
\hline utilizar um cinzeiro & & & & \\
\hline utilizar uma escova de dentes & & & & \\
\hline comer com um garfo & & & & \\
\hline segurar uma vassoura (mão do alto) & & & & \\
\hline acender um fósforo & & & & \\
\hline segurar uma colher de sopa & & & & \\
\hline abrir um pote (mão que segura a tampa & & & & \\
\hline
\end{tabular}

Cotação: mão preferencial: (+)

Quociente de lateralidade

$[($ total $D$ - total E) / total D + total E) $\times 100$

(-100) canhoto absoluto ; ( 0 ) ambidextro; (100) destro absoluto

História da Dominância Manual (pai, mãe, irmão, descendente)

Canhotismo familiar: (1) presente (2) ausente (pai, mãe, irmão, descendente)

I. Conversação e fala espontânea

A. Respostas sociais simples: Conduzir um diálogo informal, incorporando as questões sugeridas, para induzir tanto quanto for possível as respostas desejadas. Gravar.

1. "Como está você hoje?" (Ok, bem, ou outra resposta apropriada)

2. "Você já esteve aqui antes? Ou "Eu já avaliei você antes?" (Sim, não ou outra resposta relevante) 
3. "Você acha que nós podemos ajudá-lo?" (ou que nós o temos ajudado)? (Eu acho que sim, talvez, ou equivalente)

4. "Você acha que pode melhorar?" (Eu não sei, vou melhorar logo, etc)

5. "Quando você vai sair daqui? /ou quando você acha que vai receber alta do hospital?" (Eu não sei, logo, etc)

6. "Qual é o seu nome completo"?

7. "Qual é o seu endereço completo?" (Número, rua, cidade. Pergunte pelos elementos omitidos) Número de respostas socialmente apropriadas (máximo 7).

B. Conversação livre: A fim de induzir maior tempo de conversação, sugere-se que o examinador inicie com um tópico familiar, como "Que tipo de trabalho você fazia antes de ficar doente?" ou "Conte-me o que aconteceu com você". Encoraje pelo menos 3 minutos de conversação, se possível. Evite questões fechadas que levem a respostas do tipo SIM/NÂO. Registre, em gravação, o diálogo.

C. Descrição de prancha: Figura: ROUBO DOS BISCOITOS. Mostre a figura e diga ao paciente: "Diga-me tudo o que está acontecendo nesta figura ". Apontar características negligenciadas da figura e solicitar a elaboração, se a resposta do paciente estiver mais reduzida do que seu potencial aparente. Registre, em gravação.

ROUBO DOS BISCOITOS (Cartão 01) (transcrever abaixo, utilizando as convenções de análise de conversação)

\section{PERFIL DAS CARACTERÍSTICAS DA GRAVIDADE E DA PRODUÇÃO DA LINGUAGEM}

\section{Escala para pontuação da gravidade da afasia}

0. Não utiliza fala funcional ou compreensão auditiva.

1. Toda a comunicação é através de expressão fragmentada; grande necessidade de inferência, questionamento ou adivinhação por parte do interlocutor. A informação possível de ser intercambiada é limitada e o ouvinte assume a responsabilidade pela comunicação.

2. A conversação sobre temas familiares é possível com ajuda do interlocutor. Ocorrem freqüentes falhas para veicular a idéia, mas o paciente é capaz de compartilhar a responsabilidade pela comunicação.

3. O paciente pode discutir quase todos os problemas da vida cotidiana com pouca ou nenhuma assistência. A redução da fala e/ou compreensão, entretanto, torna a conversação sobre determinados temas impossível.

4. Ocorre perda óbvia da fluência na fala ou há alguma dificuldade para compreensão, sem limitação significante nas idéias expressas ou forma de expressão.

5. Desvantagem mínima, perceptível; o paciente pode ter dificuldades subjetivas que não são óbvias para o ouvinte. 


\section{II - COMPREENSÃO AUDITIVA}

A - Compreensão de palavras

1. Discriminação básica de palavras. Instrua o paciente para apontar para a figura (cor, letra ou número) correspondente à que foi falada no teste. Pontue 1 ponto por item se a resposta estiver correta e for dada em 5 segundos, $1 / 2$ ponto se a resposta é correta em mais de 5 segundos e atribua 0 se for falha. Escreva as respostas erradas.

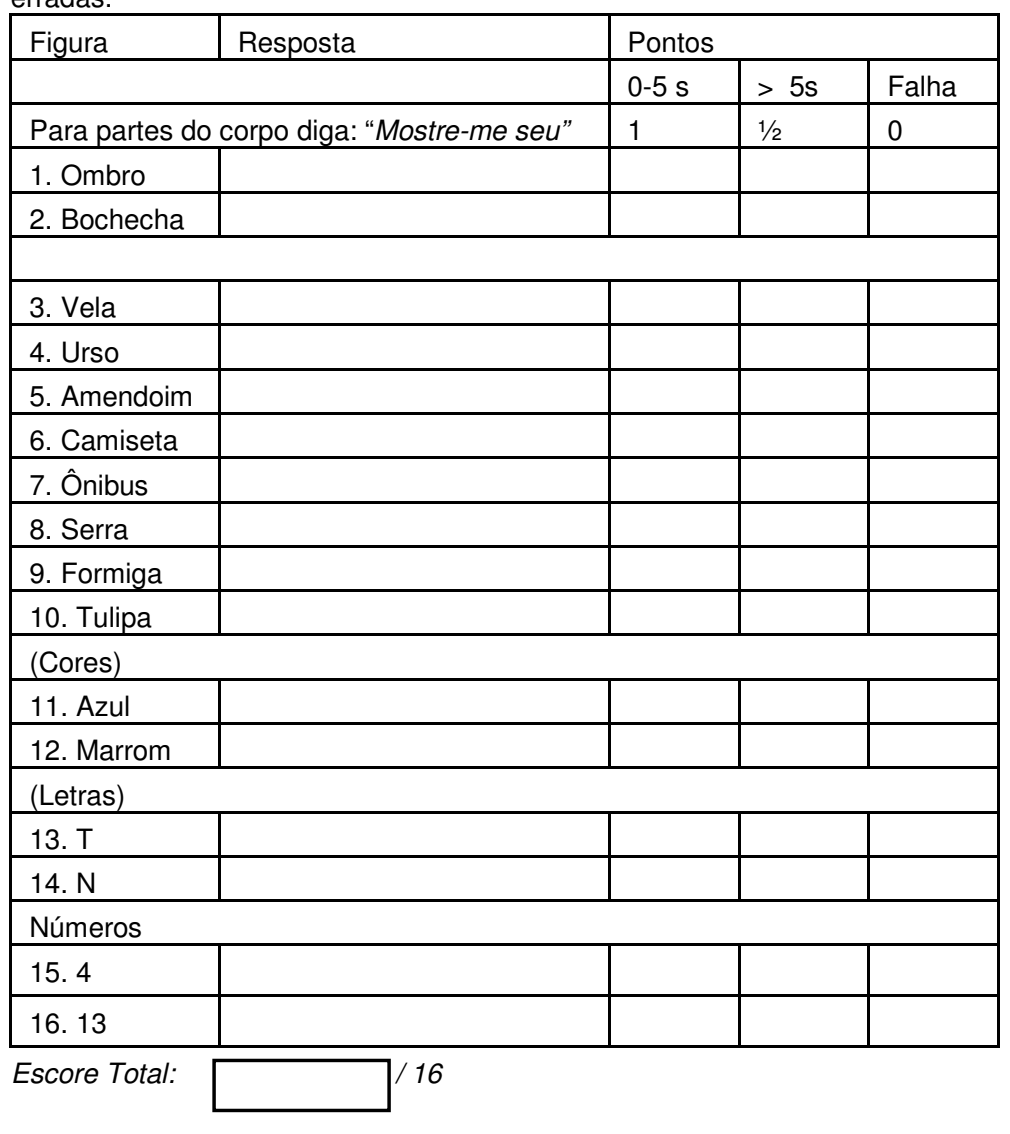

\section{B - Ordens}

Peça ao paciente para realizar as seguintes ordens, dando um ponto de crédito para cada elemento sublinhado que ele execute. Uma repetição é permitida, se solicitada, mas a ordem inteira deve ser repetida.

1- Aponte para o teto e depois para o chão.

\# Após dispor sobre a mesa um lápis, relógio, e um cartão, nesta ordem, diga ao paciente:

2- Ponha o lápis acima do cartão e então, ponha-o de volta no lugar.

3- Toque cada ombro duas vezes com dois dedos, mantendo os olhos fechados.

Escore Total: (1pt. p/ cada item correto)

C - Material Ideacional Complexo

6 pares de questões, cada par consistindo de um item SIM e um item NÂO. Ambas as questões, a e b, devem estar corretas para o indivíduo ganhar 1 ponto de crédito para cada par numerado. Observe que os itens desemparelhados e os que têm a correspondência numérica, estão misturados para evitar a alternância previsível de respostas SIM e NÃO. As questões 3 a 6 estão baseadas em curtos parágrafos para serem lidas para 0 paciente.

\begin{tabular}{|l|l|}
\hline \multicolumn{1}{|c|}{ Perguntas } & \\
\cline { 1 - 1 } 1a. Uma rolha de cortiça afunda na água? & \\
\cline { 1 - 1 } 2a. Você pode usar um martelo para bater pregos? & 2a_______ \\
\cline { 1 - 1 } 1b. Uma pedra afunda na água? & \\
\hline 2b. Um martelo é bom para cortar madeira? & \\
\hline
\end{tabular}


Vou ler uma pequena história e depois vou fazer algumas perguntas sobre ela. Você está pronto? (Leia com velocidade normal).

Sr. João tinha que ir para o Paraná. Ele decidiu pegar um avião. Sua esposa levou-o ao aeroporto, mas no caminho, o pneu furou. No entanto, eles chegaram ao aeroporto a tempo de pegar o avião.

\begin{tabular}{|l|l|}
\hline \multicolumn{1}{|c|}{ Perguntas } & \\
\cline { 1 - 1 } 3a. O Sr João perdeu o avião? & 3a_b___ \\
\hline 4a. O Sr João estava indo para o Paraná? & 4a_b___ \\
\hline 3b. Ele chegou ao aeroporto a tempo? & \\
\hline 4b. Ele estava voltando do Paraná? & \\
\hline
\end{tabular}

"Vou ler um outro parágrafo. Você está pronto?"

Carlos bateu à porta de uma casa grande para pedir dinheiro para dar aos pobres.

Um moço atendeu e Carlos pediu-lhe para dizer ao dono da casa que estava precisando de dinheiro para dar aos necessitados. O moço entrou em casa e voltou logo depois dizendo que o dono da casa havia saído. Então, digaIhe um conselho: "quando sair não deve deixar a cara na janela porque alguém pode roubá-la".

\begin{tabular}{|l|l|}
\hline \multicolumn{1}{|c|}{ Perguntas } \\
\hline 5a. Carlos queria dinheiro? \\
\hline 6a. Foi o dono da casa que atendeu a porta?
\end{tabular}

\section{III - EXPRESSÃO ORAL \\ A - SEQÜẾNCIAS AUTOMATIZADAS}

Faça o paciente recitar cada uma das seguintes 4 séries ajudando com a 1a palavra, se necessário. Dê ajuda adicional se necessário, mas interrompa as séries quando houver falha em 4 itens sucessivos. A pontuação é baseada no número de itens consecutivos realizados sem o auxílio do examinador.

\section{Código de erros:}

\begin{tabular}{|l|l|}
\hline Fn & Parafasia fonêmica, resultando em pseudopalavra. \\
\hline \multicolumn{1}{|c|}{$\mathrm{Fn} / \mathrm{v}$} & Parafasia fonêmica, resultando em palavra real. \\
\hline $\mathrm{V}$ & Parafasia verbal (semanticamente relacionada) \\
\hline $\mathrm{V} / \mathrm{nr}$ & Parafasia verbal (não relacionada) \\
\hline $\mathrm{N}$ & Neologismo \\
\hline $\mathrm{Mp}$ & Erro parafásico, utiliza múltiplas palavras, pseudo palavras, frases sem sentido / erro paragramático \\
\hline Out & Emissões ou comentários não relacionados ao alvo (não considerados parafasias) \\
\hline $\mathrm{Cl}$ & Circunlóquios \\
\hline $\mathrm{P}$ & Perseveração \\
\hline
\end{tabular}

\section{ARTICULAÇÃO (A): Normal; Rígida ; Distorcida; Falha}

PARAFASIA (P): Distorcida Neologística; Fonêmica; Verbal; Outras

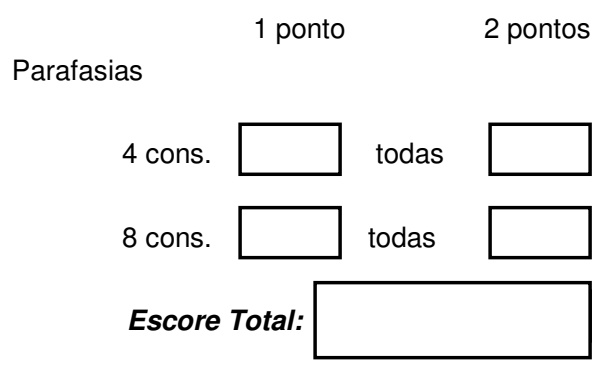

Código de erros:

\begin{tabular}{|l|l|}
\hline $\mathrm{Ph}$ & Erro parafásico, resultando em pseudo palavra fonemicamente similar \\
\hline \multicolumn{1}{|l|}{$\mathrm{Ph} / \mathrm{v}$} & Erro parafásico, resultando em palavra real fonemicamente similar. \\
\hline $\mathrm{V}$ & Parafasia verbal (semanticamente relacionada) \\
\hline
\end{tabular}




\begin{tabular}{|l|l|}
\hline $\mathrm{V} / \mathrm{u}$ & Parafasia verbal (não relacionada) \\
\hline $\mathrm{N}$ & Neologismo \\
\hline $\mathrm{Mw}$ & Erro parafásico múltiplas palavras /erro paragramático \\
\hline $\mathrm{Otu}$ & Emissões ou comentários (não considerados parafasias) \\
\hline $\mathrm{Cl}$ & Circunlocuções \\
\hline $\mathrm{P}$ & Perseveração \\
\hline
\end{tabular}

\section{B - REPETIÇÃo}

\section{PALAVRAS ISOLADAS}

Faça o paciente repetir cada uma das palavras seguintes. Uma repetição isolada pode ser feita pelo examinador, se solicitado. Para ser considerada correta, a palavra deve ser inteligível. Anote se houver prejuízo da articulação.

\begin{tabular}{|l|l|l|l|l|}
\hline Palavra & Acerto/Erro & Transcrição & Alteração da articulação & Código - erro \\
\hline 1. marrom & & & & \\
\hline 2. cadeira & & & & \\
\hline 3. que & & & & \\
\hline 4. enfatizar & & & & \\
\hline 5. Católico Apostólico & & & & \\
\hline
\end{tabular}

Escore Total:

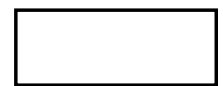

\section{SENTENÇAS}

A sentença inteira é apresentada para repetição. Marque (V) cada palavra correta e identifique as omissões ( / ), transcreva produções erradas e anote se houver prejuízo articulatório. Registre o tipo de erro na coluna código de erro, usando os códigos fornecidos na página 3. Um item está correto se todas as palavras estiverem certas e não houver acréscimos.

\begin{tabular}{|l|l|l|l|}
\hline \multicolumn{1}{|c|}{ Sentença alvo } & Resposta & Alteração da articulação & Código - erro \\
\hline 1. O pai chega a casa. & & & \\
\hline 2. Ele pega o jornal na mesa do café. & & & \\
\hline
\end{tabular}

\section{Escore -}

\section{C - DENOMINAÇÃO}

\section{1 - Denominação responsiva}

Faça o paciente fornecer a palavra-resposta que corresponde à questão. Marque, na coluna, o tempo aproximado para a resposta e se houve prejuízo na articulação. Use o código da página 3.

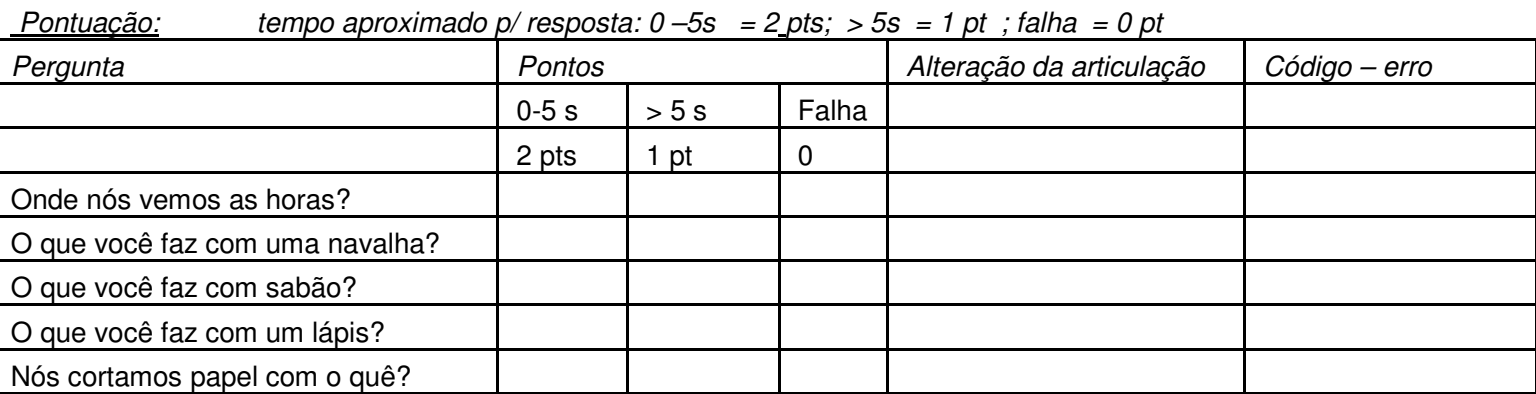

\section{Escore Total:}

110

2. Teste de nomeação - Boston (versão reduzida)

Escore (do manual do teste de nomeação - Boston): $/ 15$

Registro dos tipos de parafasia:

Conte o número de parafasias nas colunas de código de erro nos itens repetição de palavras, repetição de frases e nomeação responsiva, bem como no teste de nomeação de Boston. Anote esses totais aqui e nas linhas correspondentes da seção de parafasia no resumo do perfil dos subtestes 


\begin{tabular}{|l|l|}
\hline Fonológicas & Soma de Fn e Fn/V \\
\hline Verbal & Soma de $\mathrm{Ve} \mathrm{V/nr}$ \\
\hline Neologismos & $\mathrm{N}$ \\
\hline Múltiplas palavras & $\mathrm{MP}$ \\
\hline
\end{tabular}

3. Varredura para categorias específicas

Recomenda-se que este subteste não seja aplicado se o paciente obteve menos de 10 pontos no Teste de Nomeação Boston, versão extensa.

\begin{tabular}{|l|l|l|l|l|l|}
\hline a. Letras & resposta & pts & Letras & resposta & pts \\
\hline 1. S & & & 3. T & & \\
\hline 2. E & & & $4 . \mathrm{R}$ & & \\
\hline
\end{tabular}

\begin{tabular}{|l|l|l|l|l|l|}
\hline b. Números & resposta & pts & Números & resposta & pts \\
\hline 1.7 & & & 3.13 & & \\
\hline 2.9 & & & 4.200 & & \\
\hline
\end{tabular}

\begin{tabular}{|l|l|l|l|l|l|}
\hline c. Cores & resposta & pts & Cores & resposta & pts \\
\hline 1. Vermelho & & & 3. Azul & & \\
\hline 2. Verde & & & 4. Marrom & & \\
\hline
\end{tabular}

Escore Total:

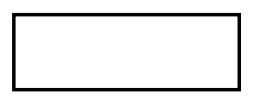

$/ 12$

\section{LEITURA}

\section{A. Reconhecimento de símbolos básicos}

\section{Emparelhar letras e palavras}

\begin{tabular}{|l|l|l|l|l|l|l|l|l|l|l|l|l|}
\hline Alvo & \multicolumn{3}{|l|}{ Resposta } & Pto & Alvo & \multicolumn{2}{|l|}{ Resposta } & Pto \\
\hline G & h & Q & g & S & & boi & boa & oba & Boi & doi & \\
\hline F & F & T & S & p & & de & se & de & Be & ei & \\
\hline
\end{tabular}

Escore Total: 14

\section{Emparelhamento de números}

a. Dedos e números arábicos

O examinador mostra o número de dedos e o paciente emparelha a quantidade correta de números arábicos na prancha 80. Circule a escolha do paciente.

\begin{tabular}{|l|l|l|l|l|l|l|}
\hline Dedos & \multicolumn{3}{|l|}{ Resposta } & Pto \\
\hline $\mathbf{5}$ & 6 & 4 & 5 & 3 & 2 & \\
\hline 4 & 5 & 1 & 7 & 4 & 6 & \\
\hline
\end{tabular}

\section{b. Números arábicos emparelhados com os dados}

\begin{tabular}{|l|l|l|l|l|l|}
\hline Número & \multicolumn{3}{|l|}{ Resposta } & \multicolumn{2}{l|}{ Pto } \\
\hline 3 & 3 & 4 & 7 & 5 & \\
\hline 7 & 5 & 4 & 7 & 8 & \\
\hline
\end{tabular}

Escore: 12 
Escore total: 14

B. Identificação de palavras - emparelhamento palavra-figura

O examinador aponta para a figura sem nomeá-la e pede ao paciente para encontrar seu nome entre as 4 palavras da direita.

Circule a escolha do paciente.

\begin{tabular}{|l|l|l|l|l|}
\hline Figura & \multicolumn{4}{|l|}{ Resposta } \\
\hline 1. bola & círculo & jogo & bola & bota \\
\hline 2. cama & cochilo & sono & cana & cama \\
\hline 3. seção & sessão & setor & divisão & senão \\
\hline 4. auxílio & auxílio & ajuda & exílio & esmola \\
\hline
\end{tabular}

Escore total: 14

\section{Leitura oral}

1. Leitura oral de palavras - nível básico

Faça o paciente ler as palavras do cartão de testes uma por vez. A pontuação é ajustada para permitir latência na resposta. Pode se fornecer auxílio, mas não se pontua palavras lidas com auxílio. Use o código de erros da página 3.

\begin{tabular}{|c|c|c|c|c|c|c|}
\hline \multirow{2}{*}{ Palavra-alvo } & \multicolumn{4}{|l|}{ Tempo } & \multirow[b]{2}{*}{$\begin{array}{l}\text { Alter. da } \\
\text { articul. }\end{array}$} & \multirow[b]{2}{*}{ Erro - código } \\
\hline & $0-3 s-3 p t s$ & $3-10 s-2 p t s$ & $10-30 \mathrm{~s}-1 \mathrm{pt}$ & Falha -0 & & \\
\hline \multicolumn{7}{|l|}{ Cadeira } \\
\hline \multicolumn{7}{|l|}{ Círculo } \\
\hline \multicolumn{7}{|l|}{ Rede } \\
\hline \multicolumn{7}{|l|}{ Roxo } \\
\hline Quinze & & & & & & \\
\hline
\end{tabular}

D - LEITURA ORAL DE SENTENÇAS com compreensão

O paciente deve ler em voz alta as sentenças do cartão 23 e responder questões relativas a seu conteúdo. Deve ser previamente informado de que irá responder a essas questões.

A sentença inteira deve ser lida sem erro para ser considerada correta.

Pontuação: correto $=1 \mathrm{pt} ;$ Falho $=0 \mathrm{pt}$

\begin{tabular}{|l|l|l|}
\hline \multicolumn{1}{|c|}{ Sentença a ser lida (cartão 23) } & Resposta & Pontuação \\
\hline 1. Um belo dia de praia. & & \\
\hline 2. João e Maria embrulham um lanche & & \\
\hline $\begin{array}{l}\text { 3. Depois de dirigir por quarenta e cinco minutos eles } \\
\text { chegaram até a praia. }\end{array}$ & & \\
\hline 4. Quando eles saem da água estão famintos. & & \\
\hline $\begin{array}{l}\text { 5. Felizmente, eles descobrem uma barraca com vários } \\
\text { salgadinhos (petiscos) para escolher. }\end{array}$ & & \\
\hline
\end{tabular}

Escore Total: 15

\section{Compreensão:}

O paciente é instruído a ler em voz alta cada uma das afirmações e então selecionar o complemento correto. 0 examinador pode apontar para cada uma das 4 palavras para o primeiro item e pedir ao paciente para selecionar 0 melhor complemento para aquele item. Não leia nenhuma das afirmações ou opções em voz alta para o paciente. O paciente pode apontar para sua seleção, dize-la em voz alta ou ambos. É considerada correta apenas a seleção do item. 
1. O tempo estava

$\begin{array}{lccc}\text { Frio } & \text { Ensolarado } & \text { Nublado } & \text { Chuvoso } \\ \text { 2. João e Maria viajaram em um } & \\ \text { Trem } \quad \text { Barco } & \text { Carro } & \text { Avião } \\ \text { 3. A viagem durou } & & \\ \text { Meio dia } 5 \text { minutos } & 45 \text { minutos } & 2 \text { horas } \\ \text { Escore: __ } / 3 & \end{array}$

\section{D - COMPREENSÃo DE LEITURA: PARÁGRAFOS E SENTENÇAS}

Mostra-se ao paciente a sentença-exemplo e as 4 opções para completá-la. O examinador pode ler a sentença e cada uma das opções em voz alta e selecionar o complemento correto. A segunda sentença exemplo também pode ser lida em voz alta pelo examinador. O paciente é então instruído a ler as sentenças testes silenciosamente e apontar o complemento correto sem ajuda adicional do examinador.
EXEMPLOS:
a) Água é
........(voar
molhada
seca
vermelha)
b) Crianças jogam (porta
sapato
moeda bola)

1- Um cachorro pode ............(falar latir cantar gato)

2- Sr. João lava e corta cabelos. Ele é um -..........(barbear menino açougueiro $\underline{\text { cabeleireiro) }}$

3- Escolas e estradas custam dinheiro. Nós pagamos esses gastos por meio de
(casas
país
impostos
polícia)

4- O alumínio antigamente era muito caro para ser refinado. Atualmente, a eletricidade resolveu o problema da refinação e o alumínio tornou-se

$$
\text { (Muito resistente }
$$

um minério

eletrônico

muito mais barato)

Escore: 14

\section{V- ESCRITA}

\section{A - MECÂNICA DA ESCRITA}

Instruir o paciente a realizar as sete tarefas de escrita listadas abaixo. Coloque o escore em cada coluna correspondente ao seu item. Nota: na pontuação (bem formado) desconsidere se a letra ou número produzidos estão corretos.

1. assinatura (letra cursiva)

2. nome (letra de fôrma)

3. ditado de letras (TGRSB)

4. copiar "A esperta raposa marrom..." (cursiva)

5. copiar mesma sentença em letra fôrma

6. números 1 a 10

7. ditado de números (2-12-9-11-16)

\begin{tabular}{|l|l|l|}
\hline Forma das letras & Escolha correta das letras & Habilidade motora \\
\hline $\begin{array}{l}\text { 2- todas as letras estão bem } \\
\text { formadas }\end{array}$ & 3- sem erros & 2- Sem prejuízo \\
\hline 1- parcialmente mal formadas & 2- mais da metade corretas & 1- Com dificuldade \\
\hline 0- ilegíveis & 1- menos do que a metade corretas & 0- Falha no controle motor \\
\hline & 0- menos do que 2 corretas & \\
\hline
\end{tabular}

Escore total: $/ 14$ 


\section{B - Habilidade básica de codificação}

1. Ditado de palavras simples

\begin{tabular}{|l|l|l|l|}
\hline 1. boi & & 3. pia & \\
\hline 2. ir & & 4. lua & \\
\hline
\end{tabular}

Escore

\section{Palavras regulares}

\begin{tabular}{|l|l|}
\hline 1. grupo & \\
\hline 2. apartamento & \\
\hline
\end{tabular}

Escore 12

3. Palavras irregulares freqüentes

\begin{tabular}{|l|l|}
\hline 1. lixo & \\
\hline 2. bolo & \\
\hline 3. fixo & \\
\hline
\end{tabular}

Escore 13

\section{A ESPERTA RAPOSA MARROM PULA SOBRE O CÃO PREGUIÇOSO.}

\section{C - Denominação escrita (figuras)}

O estímulo consiste de 4 objetos que aparecem num cartão. $O$ examinador aponta para cada figura e pede ao paciente para escrever o nome do item. Diga: "Você sabe o que é isto. Como você escreve? Escreva aqui."

\begin{tabular}{|l|l|l|l|}
\hline 1. árvore & & 3. canoa & \\
\hline 2. cabide & & 4. sanfona & \\
\hline
\end{tabular}

Escore 14

\section{NARRATIVA ESCRITA}

1- Narração escrita

Apresente a figura do Roubo dos Biscoitos do cartão 1. Diga: "Escreva tudo o que você pode sobre o que você vê acontecer nessa figura. Permita ao paciente aproximadamente 3 minutos para escrever. Se a produção do paciente é menor do que você julga ser seu potencial, use as questões seguintes para estimular escrita adicional.

1. Que tipo de parentesco têm as pessoas dessa figura?

2. O que está acontecendo atrás da mulher?

3. Por que a menininha está dizendo para ele não fazer barulho?

4. Por que você acha que o menino pode se machucar?

5. O que está acontecendo em frente à mãe?

\section{Pontuação:}

A produção escrita completa (espontânea e elicitada) é pontuada como um todo nas 4 categorias listadas abaixo. 0 escore numérico apresentado aqui gradua a presença ou ausência de traços relacionados ao alvo (Por exemplo, a mulher, o menino). Não tente levar em consideração produção que fuja ao alvo.

\begin{tabular}{|l|l|l|l|}
\hline Mecânica & $\begin{array}{l}\text { Acesso ao vocabulário } \\
\text { escrito }\end{array}$ & Sintaxe & Adequação de conteúdo \\
\hline & 3- Adequada & 3- Totalmente correta & 3- Adequação de conteúdo \\
\hline 2- Letras bem formadas & $\begin{array}{l}\text { 2- Algumas palavras } \\
\text { importantes foram omitidas }\end{array}$ & $\begin{array}{l}\text { 2- Algumas falhas na } \\
\text { estruturação da sentença }\end{array}$ & $\begin{array}{l}\text { 2- Relevante porém } \\
\text { incompleta }\end{array}$ \\
\hline
\end{tabular}




\begin{tabular}{|l|l|l|l|}
\hline 1- Legível com alterações & $\begin{array}{l}\text { 1- Menos do que 8 } \\
\text { palavras importantes }\end{array}$ & 1- Grupos sub-clausais & $\begin{array}{l}\text { 1- Informação } \\
\text { minimamente relevante }\end{array}$ \\
\hline 0- A maior parte é ilegível & $\begin{array}{l}\text { 0- Menos do que 2 } \\
\text { palavras importantes }\end{array}$ & $\begin{array}{l}\text { 0- Sem agrupamento de } \\
\text { palavras }\end{array}$ & $\begin{array}{l}\text { 0- Não há informações } \\
\text { relevantes. }\end{array}$ \\
\hline Total $=$ & Total= & Total= \\
\hline Total Geral = $/ 11$ & \multicolumn{2}{l|}{} \\
\hline
\end{tabular}

\section{Análise qualitativa}

\begin{tabular}{|l|l|l|l|}
\hline $\begin{array}{l}\text { Produz escrita de } \\
\text { múltiplas palavras } \\
\text { irrelevantes }\end{array}$ & Frequentemente & Raramente & Nunca \\
\hline $\begin{array}{l}\text { Substituições de palavras } \\
\text { isoladas }\end{array}$ & Frequentemente & Raramente & Nunca \\
\hline \multicolumn{2}{|l|}{ Outros comentários: } & & \\
\hline
\end{tabular}

\section{NARRAÇÃO ESCRITA}


Anexo E

\begin{tabular}{|c|c|c|c|c|c|c|c|}
\hline Boston Naming & & & & POSTA & & & \\
\hline Figura: & Transcrição & $\begin{array}{c}\text { Correta s/ } \\
\text { pistas }\end{array}$ & $\begin{array}{l}\text { Latência } \\
\text { (segundos) }\end{array}$ & $\begin{array}{c}\text { Pista } \\
\text { semantica }\end{array}$ & $\begin{array}{c}\text { Pista } \\
\text { fonológica }\end{array}$ & $\begin{array}{l}\text { Código do } \\
\text { erro }\end{array}$ & $\begin{array}{l}\text { Múltipla } \\
\text { escollha }\end{array}$ \\
\hline $\begin{array}{l}\text { 1. cama } \\
\text { (um móvel) }\end{array}$ & & & & & & & \\
\hline $\begin{array}{l}\text { 2. árvore } \\
\text { (algo que cresce na tern }\end{array}$ & & & & & & & \\
\hline $\begin{array}{l}\text { 3. lápis } \\
\text { (usado para escrever) }\end{array}$ & & & & & & & \\
\hline $\begin{array}{l}\text { 4. casa } \\
\text { (espécie de construção) }\end{array}$ & & & & & & & \\
\hline $\begin{array}{l}\text { 5. apito / assobio } \\
\text { (usado para soprar) }\end{array}$ & & & & & & & \\
\hline $\begin{array}{l}\text { 6. tesoura } \\
\text { (usada para cortar) }\end{array}$ & & & & & & & \\
\hline $\begin{array}{l}\text { 7. pente } \\
\text { (usado para endireitar o } \\
\text { cabelo) }\end{array}$ & & & & & & & \\
\hline $\begin{array}{l}\text { 8. flores } \\
\text { (crescem no jardim) }\end{array}$ & & & & & & & \\
\hline $\begin{array}{l}\text { 9.serrote } \\
\text { (usado pelos marceneir }\end{array}$ & & & & & & & \\
\hline $\begin{array}{l}\text { 10. escova de dentes } \\
\text { (usada na boca) }\end{array}$ & & & & & & & \\
\hline $\begin{array}{l}\text { 11. helicóptero } \\
\text { (usado para viagens } \\
\text { aéreas) }\end{array}$ & & & & & & & \\
\hline $\begin{array}{l}\text { 12. vassoura } \\
\text { (usada para limpar) }\end{array}$ & & & & & & & \\
\hline $\begin{array}{l}\text { 13. polvo / raia / luła } \\
\text { (animal do mar) }\end{array}$ & & & & & & & \\
\hline $\begin{array}{l}\text { 14. cogumelo } \\
\text { (algo para comer) } \\
\text { 15. cabide } \\
\text { (encontra-se no guarda- } \\
\text { roupa) }\end{array}$ & & & & & & & \\
\hline $\begin{array}{l}\text { 16. cadeira de rodas } \\
\text { (encontra-se no hospita }\end{array}$ & & & & & & & \\
\hline $\begin{array}{l}\text { 17. camelo } \\
\text { (animal) }\end{array}$ & & & & & & & \\
\hline $\begin{array}{l}\text { 18. máscara } \\
\text { (parte de um fantasma) }\end{array}$ & & & & & & & \\
\hline $\begin{array}{l}\text { 19.rosca / biscoito } \\
\text { (algo para comer) }\end{array}$ & & & & & & & \\
\hline $\begin{array}{l}\text { 20.banco } \\
\text { (usa-se para sentar) }\end{array}$ & & & & & & & \\
\hline $\begin{array}{l}\text { 21. raquete } \\
\text { (usada para esportes) }\end{array}$ & & & & & & & \\
\hline $\begin{array}{l}\text { 22. caracol / caramujo / } \\
\text { lesma } \\
\text { (um animal) }\end{array}$ & & & & & & & \\
\hline $\begin{array}{l}\text { 23. vulcão } \\
\text { (uma espécie de } \\
\text { montanha) }\end{array}$ & & & & & & & \\
\hline $\begin{array}{l}\text { 24. cavalo-marinho } \\
\text { (animal do mar) }\end{array}$ & & & & & & & \\
\hline $\begin{array}{l}\text { 25. dardo } \\
\text { (você joga) }\end{array}$ & & & & & & & \\
\hline $\begin{array}{l}\text { 26. canoa / barco } \\
\text { (usada na água) }\end{array}$ & & & & & & & \\
\hline $\begin{array}{l}\text { 27. globo } \\
\text { (uma espécie de mapa) }\end{array}$ & & & & & & & \\
\hline $\begin{array}{l}\text { 28.guirlanda / coroa/ } \\
\text { coroa de flores } \\
\text { (usa-se na decoração do } \\
\text { natal) } \\
\text { 29.castor } \\
\text { (um animal) }\end{array}$ & & & & & & & \\
\hline $\begin{array}{l}\text { 30. gaita / realejo } \\
\text { (instrumento musical) }\end{array}$ & & & & & & & \\
\hline
\end{tabular}




\begin{tabular}{|c|c|c|c|c|c|c|c|}
\hline Figura: & Transcrição & $\begin{array}{c}\text { Correta s/ } \\
\text { pistas }\end{array}$ & $\begin{array}{c}\text { Latência } \\
\text { (segundos) }\end{array}$ & $\begin{array}{c}\text { Pista } \\
\text { semantica }\end{array}$ & $\begin{array}{c}\text { Pista } \\
\text { fonologica }\end{array}$ & $\begin{array}{l}\text { Código do } \\
\text { erro }\end{array}$ & $\begin{array}{l}\text { Múltipla } \\
\text { escolha }\end{array}$ \\
\hline \multicolumn{8}{|l|}{$\begin{array}{l}\text { 31. rinoceronte (um } \\
\text { animal) }\end{array}$} \\
\hline \multicolumn{8}{|l|}{$\begin{array}{l}\text { 32. semente } \\
\text { (vem da árvore) }\end{array}$} \\
\hline \multicolumn{8}{|l|}{ 33.iglu (tipo de casa) } \\
\hline \multicolumn{8}{|l|}{$\begin{array}{l}\text { 34. perna de pau } \\
\text { (usa-se para ficar mais } \\
\text { alto) }\end{array}$} \\
\hline \multicolumn{8}{|l|}{ 35.dominós (um jogo) } \\
\hline \multicolumn{8}{|l|}{$\begin{array}{l}\text { 36. cactus / mandacaru } \\
\text { (algo que cresce) }\end{array}$} \\
\hline \multicolumn{8}{|c|}{$\begin{array}{l}\text { 37. escada-rolante (você } \\
\text { sobe por ela) }\end{array}$} \\
\hline \multicolumn{8}{|c|}{$\begin{array}{l}\text { 38. harpa (um instrumento } \\
\text { musical) }\end{array}$} \\
\hline \multicolumn{8}{|l|}{$\begin{array}{l}\text { 39.rede (você descansa } \\
\text { nela) }\end{array}$} \\
\hline \multicolumn{8}{|c|}{ 40. aldrava (está na porta) } \\
\hline \multicolumn{8}{|l|}{ 41. pelicano (uma ave) } \\
\hline \multicolumn{8}{|l|}{$\begin{array}{l}\text { 42. estetoscópio (usado } \\
\text { por médicos e } \\
\text { enfermeiras) }\end{array}$} \\
\hline \multicolumn{8}{|c|}{$\begin{array}{l}\text { 43. pirâmide (encontra-se } \\
\text { no Egito) }\end{array}$} \\
\hline \multicolumn{8}{|c|}{$\begin{array}{l}\text { 44. focinheira (usa-se nos } \\
\text { cachorros) }\end{array}$} \\
\hline \multicolumn{8}{|l|}{$\begin{array}{l}\text { 45. unicórnio (animal } \\
\text { mítico) }\end{array}$} \\
\hline \multicolumn{8}{|c|}{$\begin{array}{l}\text { 46. funil (usado para } \\
\text { derramar líquido de um } \\
\text { pote para outro) }\end{array}$} \\
\hline \multicolumn{8}{|c|}{$\begin{array}{l}\text { 47.acordeon / / sanfona } \\
\text { (um instrumento musical) }\end{array}$} \\
\hline \multicolumn{8}{|l|}{$\begin{array}{l}\text { 48. laço/torca (usado } \\
\text { para enforcar) }\end{array}$} \\
\hline \multicolumn{8}{|l|}{$\begin{array}{l}\text { 49. aspargos (algo de } \\
\text { comer) }\end{array}$} \\
\hline \multicolumn{8}{|l|}{ 50.compasso } \\
\hline \multicolumn{8}{|c|}{$\begin{array}{l}\text { 51. tranca (parte de uma } \\
\text { porta) }\end{array}$} \\
\hline \multicolumn{8}{|c|}{ 52. tripé (fotógrafos usam) } \\
\hline \multicolumn{8}{|l|}{$\begin{array}{l}\text { 53.pergaminho (um } \\
\text { documento) }\end{array}$} \\
\hline \multicolumn{8}{|c|}{$\begin{array}{l}\text { 54. pinça / peyadur de } \\
\text { geto (um utensílio) }\end{array}$} \\
\hline \multicolumn{8}{|c|}{$\begin{array}{l}\text { 55.esfinge (encontrada no } \\
\text { Egito) }\end{array}$} \\
\hline \multicolumn{8}{|l|}{$\begin{array}{l}\text { 56.canga (usada em } \\
\text { animais de fazenda) }\end{array}$} \\
\hline \multicolumn{8}{|l|}{$\begin{array}{l}\text { 57. treliça } \\
\text { (usada no jardim) }\end{array}$} \\
\hline \multicolumn{8}{|l|}{$\begin{array}{l}\text { 58.palheta / aquarela } \\
\text { (os artistas usam) }\end{array}$} \\
\hline \multicolumn{8}{|l|}{$\begin{array}{l}\text { 59. transferidor } \\
\text { (para medir ângulos) }\end{array}$} \\
\hline $\begin{array}{l}\text { 60.ábaco } \\
\text { (usado para contas) }\end{array}$ & & & & & & & \\
\hline TOTAL & & & & & & & \\
\hline
\end{tabular}


Anexo F

\section{PRAXIAS (Teste de Boston - Versão extensa)}

Administração Cada item é primeiramente elicitado por solicitação verbal. Registre a pontuação usando o código de pontuação abaixo, seguido por uma descrição do desempenho no espaço apropriado.

\section{Código de pontuação}

\section{3- Normal}

2- Reconhecível (incluindo parte do corpo como objeto)

1- Tentativa sem sucesso (paramimia; vocalização)

\section{0- Não reconhecível/ ausência de resposta}

Imitação: Após a realização de todo o teste sob solicitação verbal, volte ao começo e peça ao paciente para imitar seu desempenho em cada item para o qual ele(ela) tenha obtido pontuação menor do que 3 . Use o código modificado da imitação para indicar se o desempenho na imitação melhora $(m)$; fica inalterado (i); ou se piora $(p)$ em relação ao desempenho por solicitação verbal.

A. Praxia de mão / membros

1. Gestos naturais. Diga "COMO VOCÊ MOSTRARIA ..."

\begin{tabular}{|l|l|l|}
\hline Descrição & Pontuação & $\begin{array}{l}\text { Imitação } \\
(\mathrm{M}, \mathrm{I}, \mathrm{P})\end{array}$ \\
\hline a. que alguma coisa cheira muito mal & & \\
\hline b. que tem muito barulho & & \\
\hline c. que você está com muito frio & & \\
\hline d. que você está com muito calor & & \\
\hline & & \\
\hline
\end{tabular}

2. Gestos convencionais. Diga "COMO VOCÊ FINGIRIA QUE ..."

\begin{tabular}{|l|l|l|}
\hline Descrição & Pontuação & $\begin{array}{l}\text { Imitação } \\
(\mathrm{I}, \mathrm{U}, \mathrm{P})\end{array}$ \\
\hline a. abana para se despedir & & \\
\hline b. saúda como um soldado & & \\
\hline c. chama alguém para chegar até você & & \\
\hline d. pára o trânsito & & \\
\hline & & \\
\hline
\end{tabular}

3. Uso de objetos fictícios. Diga "MOSTRE-ME COMO VOCÊ USARIA ISSO E..." (Pranchas 105 e 106)

\begin{tabular}{|l|l|l|}
\hline Descrição & Pontuação & $\begin{array}{l}\text { Imitação } \\
(I, U, P)\end{array}$ \\
\hline a. escreva com isso (item 1. lápis) & & \\
\hline b. feche uma porta (item 2. chave) & & \\
\hline c. olhe através disso (item 3. binóculo) & & \\
\hline $\begin{array}{l}\text { d. encha um copo com água (item 4. } \\
\text { vasilha) }\end{array}$ & & \\
\hline $\begin{array}{l}\text { e. escove seus dentes (item 5. escova de } \\
\text { dentes) }\end{array}$ & & \\
\hline f. penteie seu cabelo (item 6. pente) & & \\
\hline g. bata um prego (item 7. martelo) & & \\
\hline $\begin{array}{l}\text { h. aperte um parafuso com isso (item 8. } \\
\text { chave de fenda) }\end{array}$ & & \\
\hline
\end{tabular}


B. Praxia Buco-facial/respiratória. Dê as seguintes ordens

\begin{tabular}{|l|l|l|}
\hline a. Deixe-me ouvi-lo tossir & & \\
\hline b. Finja estar apagando uma vela & & \\
\hline c. Finja estar cheirando uma flor & & \\
\hline d. Finja estar chupando um canudo & & \\
\hline & & \\
\hline
\end{tabular}

\begin{tabular}{|l|ll|}
\hline Pontuação & 1. Gestos naturais & $/ 12$ \\
\hline & 2. Gestos convencionais & $/ 12$ \\
\hline & 3. Uso simulado de objetos & $/ 12$ \\
\hline & 4. Movimentos Buco-faciais/ respiratórios & $/ 12$ \\
\hline & \multicolumn{1}{c|}{ TOTAL } & $/ 60$ \\
\hline Imitação & Melhora (M) \\
\hline & Inalterada (I) \\
\hline & Piora (P) \\
\hline
\end{tabular}


Anexo G

\section{ESCALA DEPRESSÃO DE HAMILTON}

Todos os ítens devem ser preenchidos. Assinalar o número apropriado.

1. HUMOR DEPRIMIDO (Tristeza, desesperança, desamparo, inutilidade)

0 . Ausente.

1.Sentimentos relatados apenas ao ser inquirido.

2.Sentimentos relatados espontaneamente com palavras.

3.Comunica os sentimentos não com palavras, isto é, com a expressão facial, a postura,

a voz e a tendência ao choro.

4. Sentimentos deduzidos da comunicação verbal e não-verbal do paciente.

\section{SENTIMENTOS DE CULPA}
0 . Ausente
1. Auto-recriminação; sente que decepcionou os outros.
2. Idéias de culpa ou ruminação sobre erros passados ou más ações.
3. A doença atual é um castigo.
4. Ouve vozes de acusação ou denúncia e/ou tem alucinações visuais ameaçadoras.

3. SUICÍDIO

0 . Ausente.

1. Sente que a vida não vale a pena.

2. Desejaria estar morto ou pensa na probabilidade de sua própria morte.

3. Idéias ou gestos suicidas.

4.Tentativa de suicídio ( qualquer tentativa séria, marcar 4).

4. INSÔNIA INICIAL

0 . Sem dificuldades para conciliar o sono.

1. Queixa-se de dificuldade ocasional para conciliar o sono, isto é, mais de meia hora.

2. Queixa-se de dificuldade para conciliar o sono todas as noites.

\section{INSÔNIA INTERMEDIÁRIA}

0 . Sem dificuldades.

1. O paciente se queixa de inquietude e perturbação durante a noite.

\section{INSÔNIA TARDIA}

2. Acorda à noite - qualquer saída da cama marcar 2( exceto $\mathrm{p} /$ urinar).

0 . Sem dificuldades.

1. Acorda de madrugada, mas volta a dormir

2. Incapaz de voltar a conciliar o sono se deixar a cama.

\section{TRABALHO E ATIVIDADES}

0 . Sem dificuldades.

1. Pensamento e sentimentos de incapacidade, fadiga ou fraqueza relacionada a atividades, trabalho ou passatempos.

2. Perda de interesse por atividades (passatempos ou trabalho) quer diretamente relatada pelo paciente, quer indiretamente por desatenção, indecisão e vacilação (sente que precisa esforçar-se para o trabalho ou atividade).

3. Diminuição do tempo gasto em atividades ou queda de produtividade. No hospital, marcar 3 se o paciente não passar ao menos 3 horas por dia em atividades externas (trabalho hospitalar ou passatempo).

4. Parou de trabalhar devido à doença atual. No hospital, marcar 4 se o paciente não se ocupar com outras atividades, além de pequenas tarefas do leito, ou for incapaz de realizá-las sem ajuda.

8. RETARDO (lentidão de idéias e fala; dificuldade de concentração; atividade motora diminuída)

0 . Pensamento e fala normais.

1. Leve retardo à entrevista.

2. Retardo óbvio à entrevista.

3. Entrevista difícil.

9. AGITAÇÃO

4. Estupor completo.

0. Nenhuma.

1. Inquietude.

2. Brinca com as mãos, com os cabelos,etc.

3. Mexe-se, não consegue sentar quieto.

4. Torce as mãos, rói as unhas, puxa os cabelos, morde os lábios. 
10. ANSIEDADE PSÍQUICA

0. Sem dificuldade.

1. Tensão e irritabilidade subjetivas.

2. Preocupação com trivialidades.

3. Atitude apreensiva aparente no rosto ou na fala.

4. Medos expressos sem serem inquiridos.

11.ANSIEDADE SOMÁTICA

Concomitantes fisiológicos de ansiedade, tais como:

Gastrointestinais: boca seca, flatulência, indisgestão, diarréia, cólicas, eructação;

Cardiovasculares: palpitações, cefaléia;

Respiratórios: hiperventilação, suspiros; Freqüência urinária; Sudorese

0 . Ausente :

1. Leve

2. Moderada

3. Grave

4. Incapacitante

12. SINTOMAS SOMÁTICOS GASTRINTESTINAIS

0 . Nenhum

1. Perda de apetite, mas alimenta-se voluntariamente. Sensações de peso no abdomen

2. Dificuldade de comer se não insistirem. Solicita ou exige laxativos ou medicações para os intestinos ou para sintomas digestivos.

13. SINTOMAS SOMÁTICOS EM GERAL

0 . Nenhum

1. Peso nos membros, nas costas ou na cabeça. Dores nas costas, cefaléia, mialgias.

Perda de energia e cansaço.

14. SINTOMAS GENITAIS

2. Qualquer sintoma bem caracterizado e nítido, marcar 2.

Sintomas como: perda da libido, distúrbios menstruais

0 . Ausentes

1. Leves

2. Intensos

15. HIPOCONDRIA

0 . Ausente

1. Auto-observação aumentada (com relação ao corpo)

2. Preocupação com a saúde

3. Queixas freqüentes, pedidos de ajuda,etc.

16. PERDA DE PESO (Marcar A ou B)

4. Idéias delirantes hipocondríacas.

A - Quando avaliada pela história clínica

0 . Sem perda de peso.

1. Provável perda de peso associada à moléstia atual.

2. Perda de peso definida ( de acordo com o paciente)

3. Não avaliada.

B - Avaliada semanalmente pelo psiquiatra responsável, quando são medidas alterações reais de peso

0 . Menos de $0,5 \mathrm{Kg}$ de perda por semana.

1. Mais de $0,5 \mathrm{Kg}$ de perda por semana.

2. Mais de $1 \mathrm{Kg}$ de perda por semana.

17. CONSCIÊNCIA

3. Não avaliada.

0 . Reconhece que está deprimido e doente.

1. Reconhece a doença mas atribui-Ihe a causa à má alimentação, ao clima, ao excesso de trabalho, a vírus, à necessidade de repouso, etc.

18. VARIAÇÃO DIURNA 2. Nega estar doente.

A - Observar se os sintomas são piores pela manhã ou à tarde. Caso NÃO haja variação, marcar "nenhuma".

0 . Nenhuma

1. Pior de manhã. 
2. Pior à tarde.

B - Quando presente, marcar a gravidade da variação. Marcar "nenhuma" caso NÃO haja variação.

0 . Nenhuma.

1. Leve

2. Grave

NOTA: Caso haja variação diurna, só a contagem referente à sua gravidade (1 ou 2 pontos no ítem 18B) é que deve ser incluída na contagem final. O ítem $18 \mathrm{~A}$ não deve ser computado.

19. DESPERSONALIZAÇÃO E PERDA DE NOÇÃO DE REALIDADE

Tais como: sensações de irrealidade, idéias niilistas

0 . Ausente

1. Leve.

2. Moderadas.

3. Graves.

4. Incapacitantes.

20. SINTOMAS PARANÓIDES

0 . Nenhum

1. Desconfiança.

2. Idéias de referência.

3. Delírio de referência e perseguição.

21. SINTOMAS OBSESSIVOS E COMPULSIVOS

0 . Nenhum

1. Leves.

2. Graves. 
Anexo H

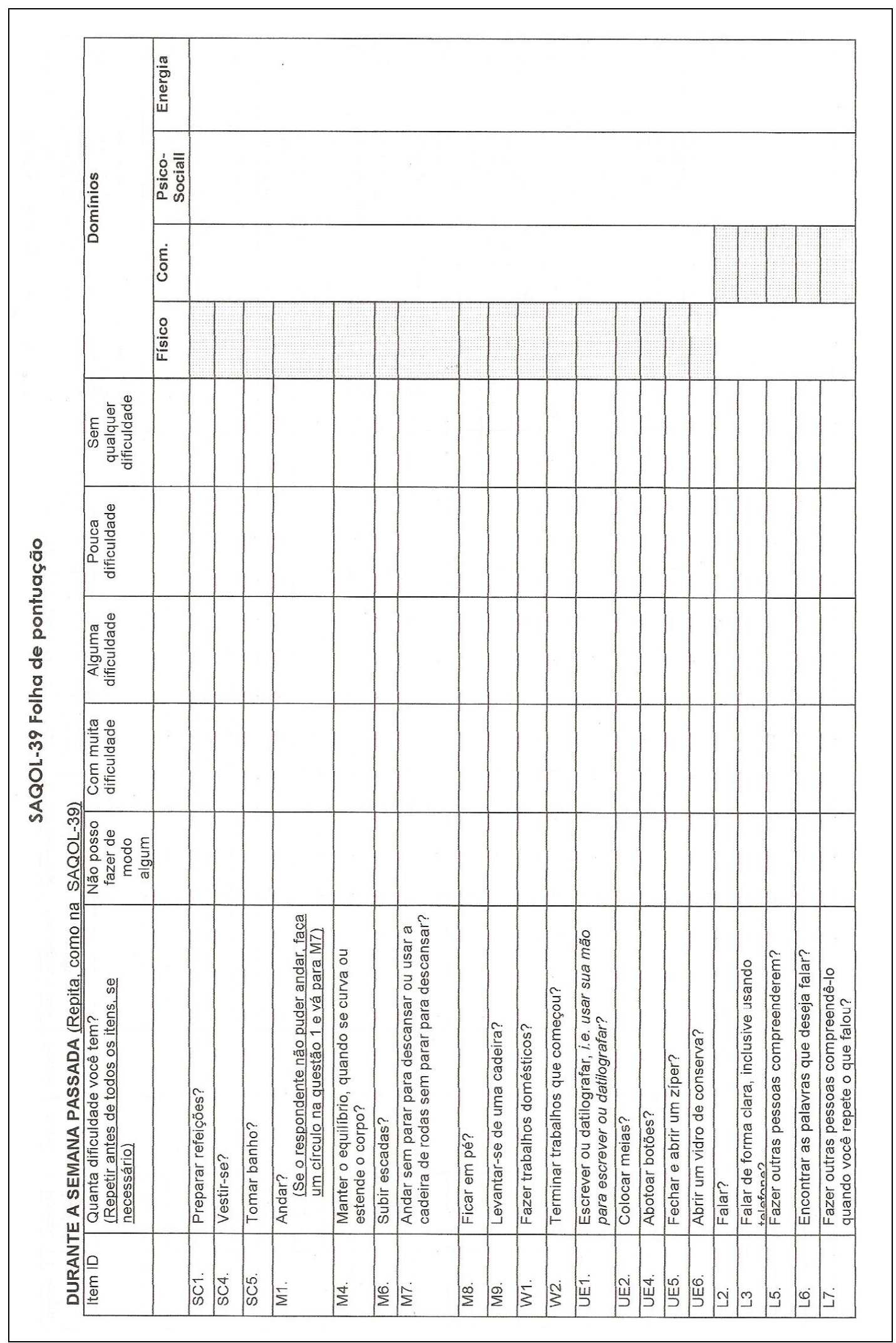




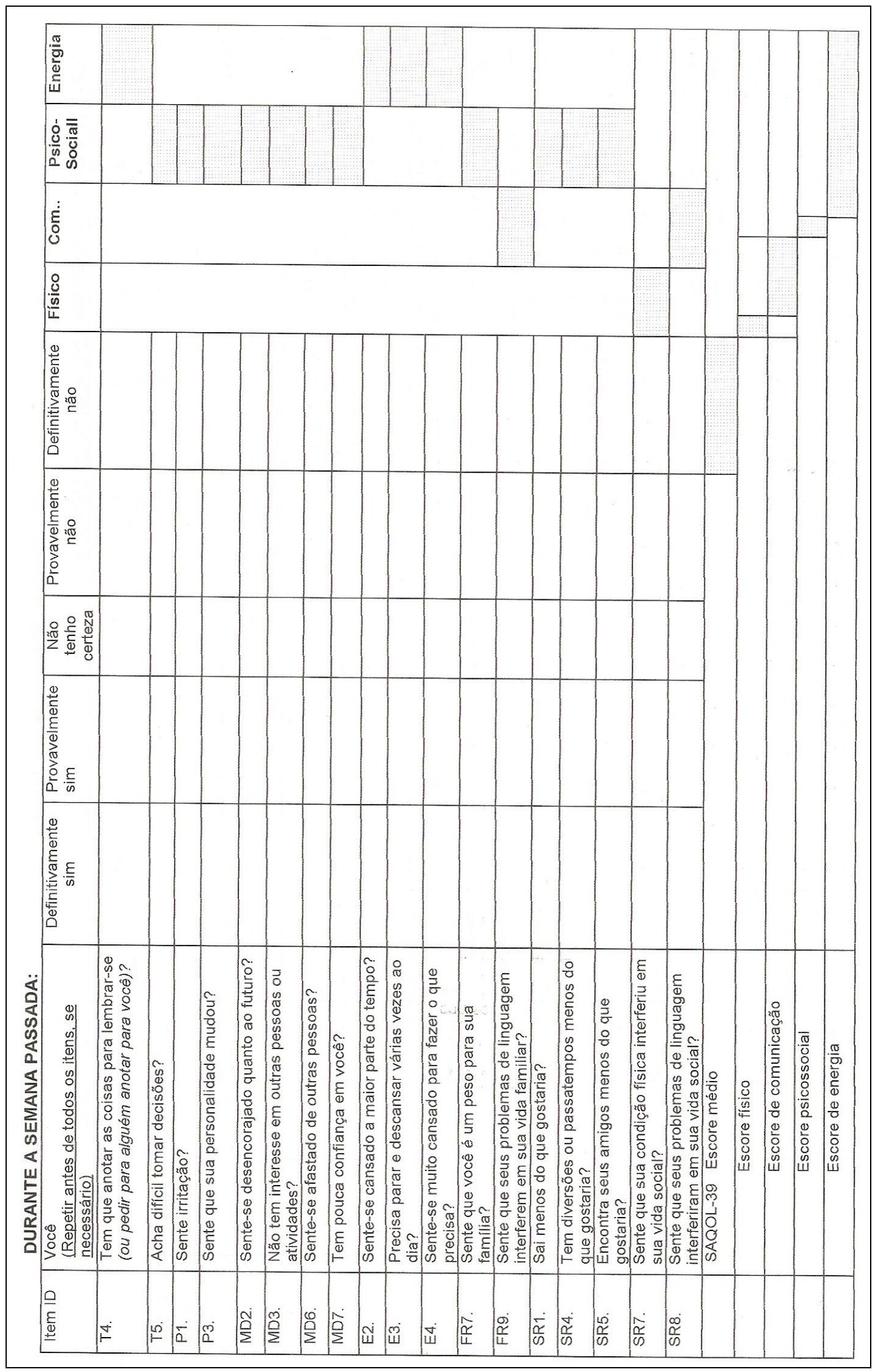


Anexo I

Teste de Trilhas - Parte A



Tabela de Correção

\begin{tabular}{|c|c|c|}
\hline Idade & Média em segundos & Desvio \\
\hline $50-59$ & 35.1 & 10.6 \\
\hline $60-69$ & 38.5 & 11.9 \\
\hline $70-74$ & 41.3 & 15.0 \\
\hline $75-79$ & 42.7 & 17.9 \\
\hline $80-85$ & 60.7 & 26.0 \\
\hline
\end{tabular}

Resultado:

segundos 
(15)

(17)

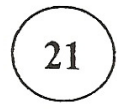

20

(19)

(16)

(18)

(4)

22

(5)

(13)

(6)

(7)

INICIO

(24)

(1)

(14)

(2)

(8) 10

(3)

9

FIM

(11) 25

23

12 
Anexo J

Teste de Trilhas - Parte B

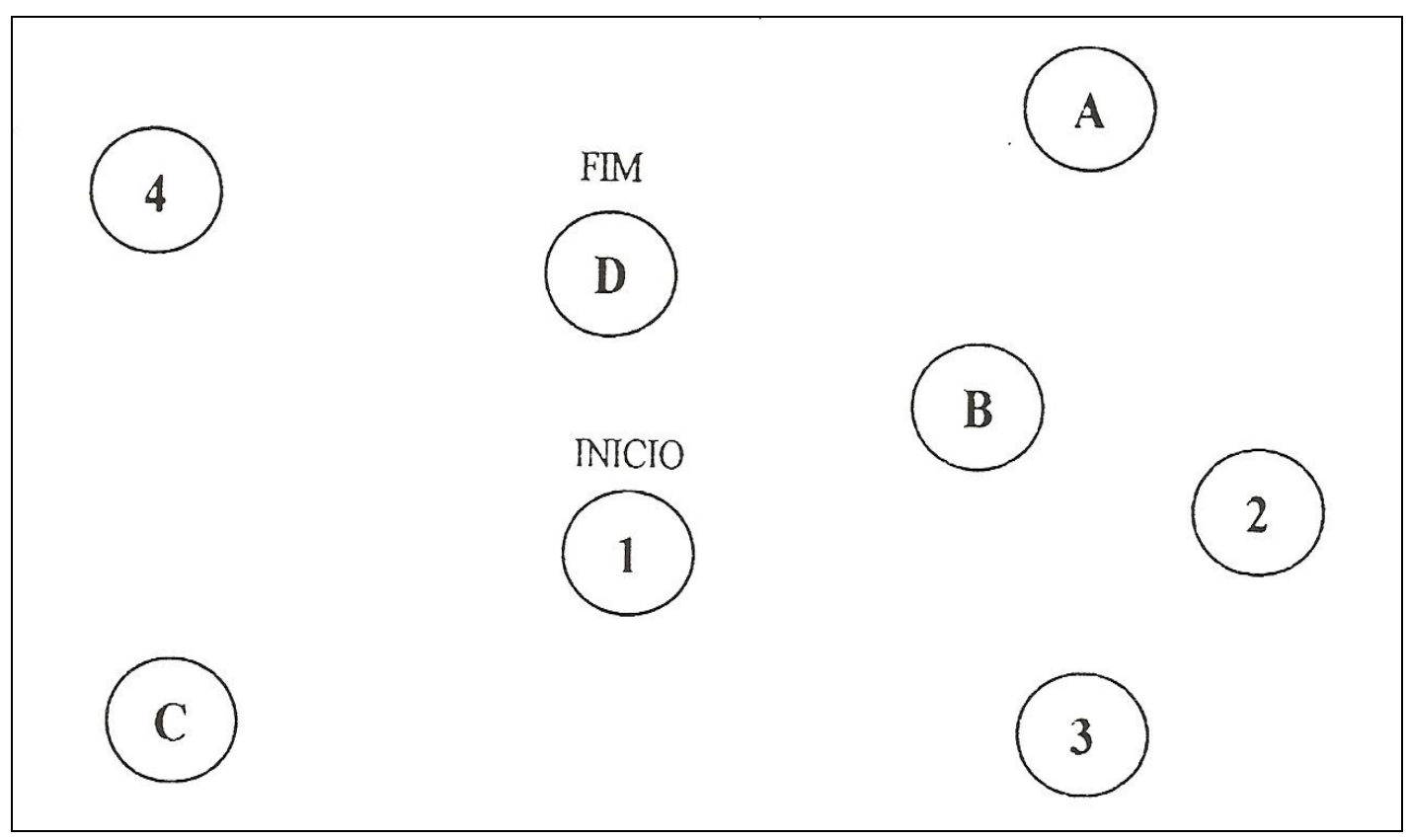

Tabela de Correção

\begin{tabular}{|c|c|c|}
\hline Idade & Média em segundos & Desvio \\
\hline $50-59$ & 77.7 & 23.8 \\
\hline $60-69$ & 81.2 & 38.5 \\
\hline $70-74$ & 111.4 & 72.2 \\
\hline $75-79$ & 119.4 & 50.2 \\
\hline $80-85$ & 152.2 & 83.1 \\
\hline
\end{tabular}

Resultado:

segundos 
FIM

(13)

(8)

(9)

(4)

(10)

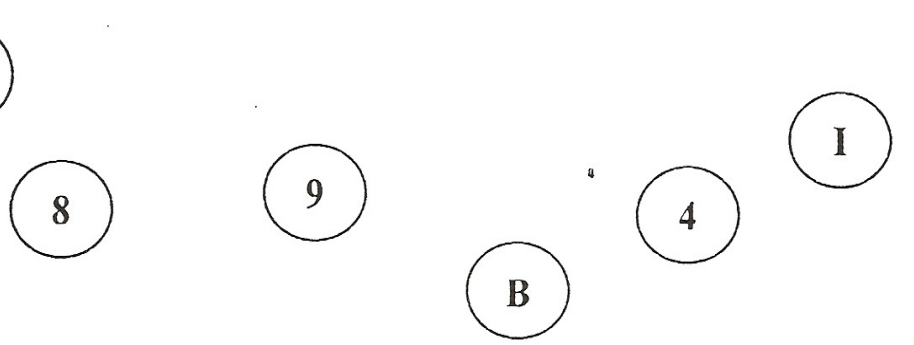

(D)

(3)

(7)

(1)

(5)

(H)

(12)

(C)

(G)

M

(2)

(A)

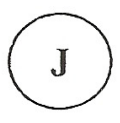

(F)

(6)

(E)

(L)

(11) 
Teste de Cancelamento

Anexo K

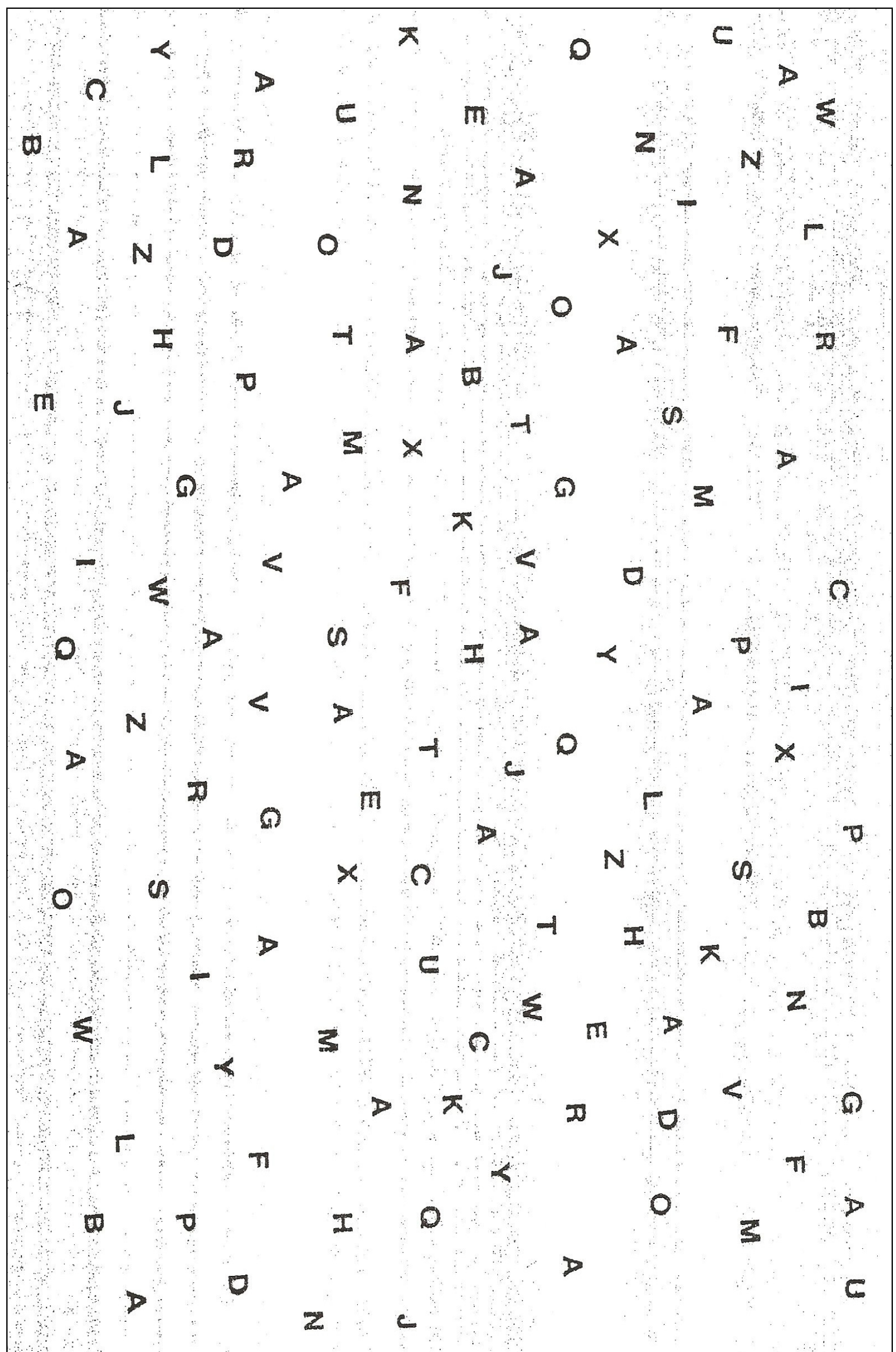


Anexo L

\section{Aprendizado de Palavras (CERAD)}

\section{Aprendizado de lista de palavras}

"Vou-Ihe mostrar dez palavras escritas em cartőes. Leia cada palavra em voz alta à medida que vou mostrando.

Mais tarde vou pedir-Ihe para me dizer de memória as dez palavras que the vou mostrar."

Tempo de exposição: uma palavra de dois em dois segundos

Tempo de evocação: máxima de 90 segundos para cada tentativa.

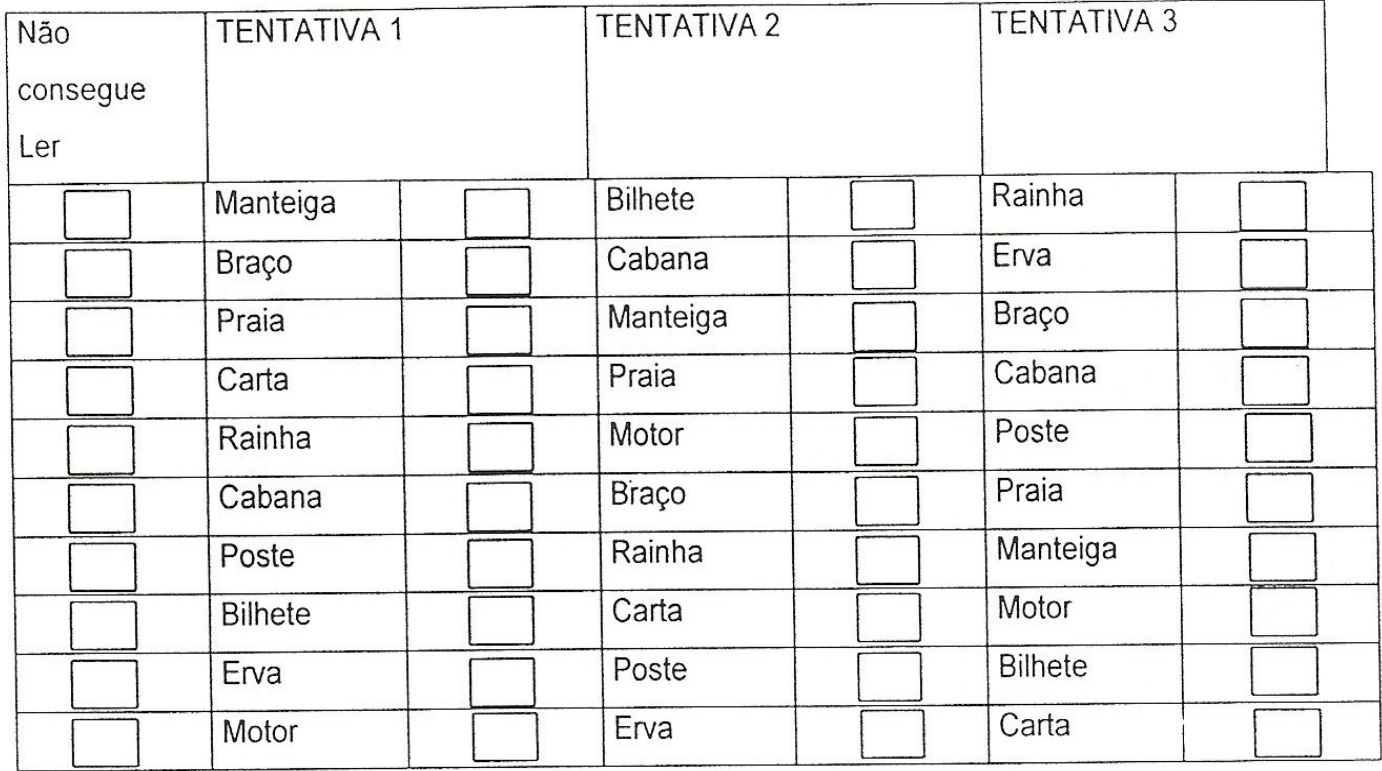

Intrusões

(palavras que não fazem parte da lista)

Total:

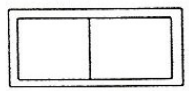

$<=$ Näo consegue ler

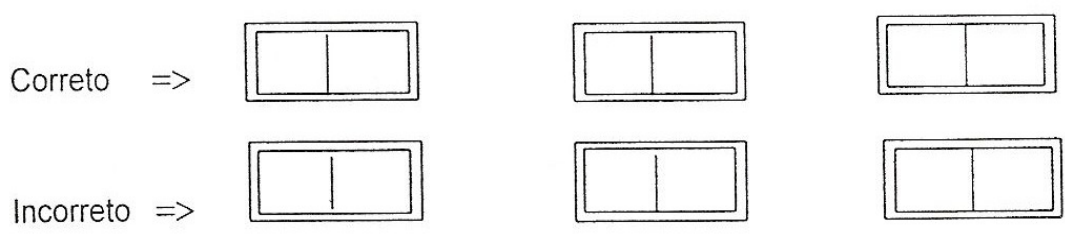

(Intrusões) 
Anexo M

Aprendizado de Palavras (CERAD) - Evocação

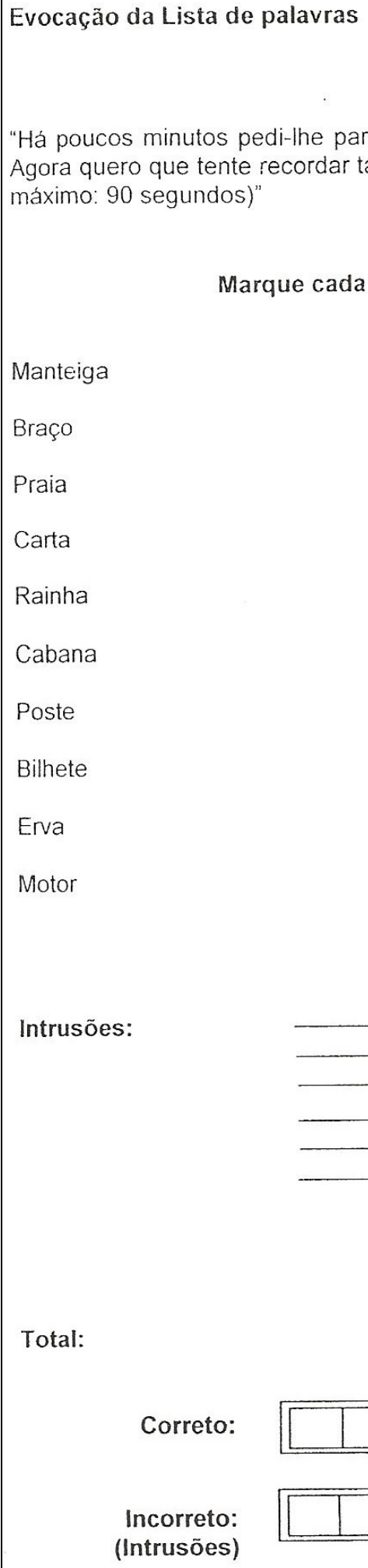

Intrusoes:

Total:

Correto:

Incorreto:

(Intrusões) 
Anexo N

\section{Aprendizado de Palavras - Reconhecimento}

"Agora vou mostrar-Ihe um conjunto de palavras impressas em cartðes. Algumas delas constavam da lista que the mostrei há pouco e outras não. Quero que me responda Sim se a palavra que Ihe mostrar agora tiver constado dessa lista." (só são aceitáveis respostas de sim ou não)

$$
\text { Resposta "Sim" correta Resposta "Não" correta }
$$

Igreja

Café

Manteiga*
Dólar

Braço*

$\begin{array}{ll}1 & 1 \\ 1 & 1 \\ 1 & 1\end{array}$

Praia*

Cinco

Carta*

Hotel

Montanha

1

1

1

1

1

Rainha*

Cabana*

Chinelo

Poste*

Aldeia

1

1

1

1

1

Corda

Bilhete* $^{*}$

Tropa

Erva*

Motor*

$\begin{array}{ll}1 & 1 \\ 1 & 1 \\ 1 & \end{array}$

Total de "Sim" corretas
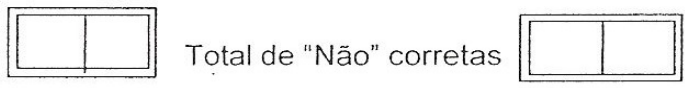

*Palavra original do exercício da memória de lista de palavras.

Escore: ("Sim" + "Não") $-10=$ 
Anexo 0

Praxias Construtivas (CERAD)

\section{Praxias Construtivas}

Item \# 1 Circulo

INCORRETO

CORRETO

a) círculo fechado (a $3 \mathrm{~mm}$ aproximadamente)

b) forma circular

Item \# 2 Losango

a) desenha 4 lados

1

b) fecha os 4 ângulos da figura

c) os lados são aproximadamente do mesmo comprimento

Item \# 3 Retângulos

a) duas figuras com 4 lados cada uma

b) sobreposição semelhante à do original

Item \# 4 Cubo

a) figura em 3 dimensões

0

b) face frontal corretamente orientada

c) Linhas internas corretamente desenhadas 0

d) lados opostos paralelos (a $10^{\circ}$ aproximadamente)

0

TOTAL DAS RESPOSTAS CORRETAS:

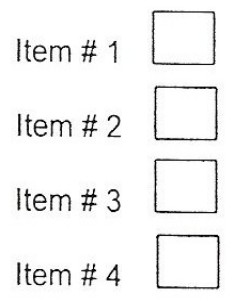


Anexo P

\section{Praxias Construtivas (CERAD) - Evocação}

\section{EVOCAÇÃO DA PRAXIA CONSTRUTIVA}

"Agora há pouco eu the mostrei alguns desenhos em pedaços separados de papel. Você olhou para cada desenho e então desenhou-se no mesmo pedaço de papel. Você se lembra deles? Eu gostaria que você os desenhasse neste papel, só que agora, lembrando-se deles".

demorada

1. CÍRCULO

a. circulo fechado

b. formato circular

Cópia

evocação

2. LOSANGOS
a. traça os quatro lados
b. fecha todos s quatro ângulos

$\begin{array}{ll}0 & 1 \\ 0 & 1\end{array}$

$\begin{array}{ll}0 & 1 \\ 0 & 1\end{array}$

$\begin{array}{cc}\text { NÃO } & \text { SIM } \\ 0 & 1 \\ 0 & 1\end{array}$

$\begin{array}{cc}\text { NÃO } & \text { SIM } \\ 0 & 1 \\ 0 & 1\end{array}$

b. fecha todos
RETÂNGULOS
a. figuras são de quatro lados
b. sobreposição assemelha-se com original

$\begin{array}{llll}0 & 1 & 0 & 1 \\ 0 & 1 & 0 & 1\end{array}$

4. CUBO
a. figura é tridimensional
b. face frontal corretamente desenhada
c. linhas internas corretamente desenhadas
d. lados opostos são paralelos
(dentro de 10 graus)

Se alguma figura for esquecida, dê uma lembrança: "Você se lembra de alguma outra figura?"

Se o individuo desenhar o pentágono do Mini-Mental, dê o escore:

5. PENTÁGONO

a. duas figuras de cinco lados

b. sobreposição

c. intersecção é figura de quatro lados

0

01

$\begin{array}{ll}0 & 1 \\ 0 & 1 \\ 0 & 1\end{array}$


Anexo Q

\section{Extensão de Dígitos (Wechsler,1987)}

\section{EXTENSÃO DE DÍGITOS}

"Eu vou dizer alguns números. Escute com "Eu vou dizer outros números. Quando eu terminar atenção e repila quando eu terminar de quero que você repita na ordem inversa. Por falar". (diga um número por segundo). exemplo, se eu disser 3-8, você deve repetir 8-3. Entendeu? Se não tiver entendido repita por mais três vezes até que compreenda. 


\section{Aprendizado de Figuras (BBRC-Edu)}

\section{Percepção Visual e Nomeação}

Mostre a folha contendo as 10 figuras e pergunte: "que figuras são estas?"

Percepçăo correta:

Nomeação correta:

Memória Incidental

Esconda as figuras e pergunte: "que figuras eu acabei de the mostrar?" (Tempo máximo de evocação: 60 segundos; Escore no verso)

Memória Imediata 1

Mostre a figuras novamente durante 30 segundos dizendo:

"Othe bem e procure memorizar esta figuras" (Se houver déficit visual importante, peça que memorize as palavras que você vai dizer; diga os nomes dos objetos lentamente, um nome/segundo; fale a série toda duas vezes).

Esconda as figuras e pergunte: "que figuras eu acabei de the mostrar?" (Tempo máximo de evocação: 60 segundos)

\section{Memória Imediata 2}

Mostre a figuras novamente durante 30 segundos dizendo:

"Olhe bem e procure memorizar esta figuras" (Se houver déficit visual importante, peça que memorize as palavras que você vai dizer; diga os nomes dos objetos lentamente, um nome/segundo; fale a série toda duas vezes).

Esconda as figuras e pergunte: "que figuras eu acabei de the mostrar?" (Tempo máximo de evocação: 60 segundos) 
Anexo S

\section{Aprendizado de Figuras (BBRC-Edu) - Estímulos}
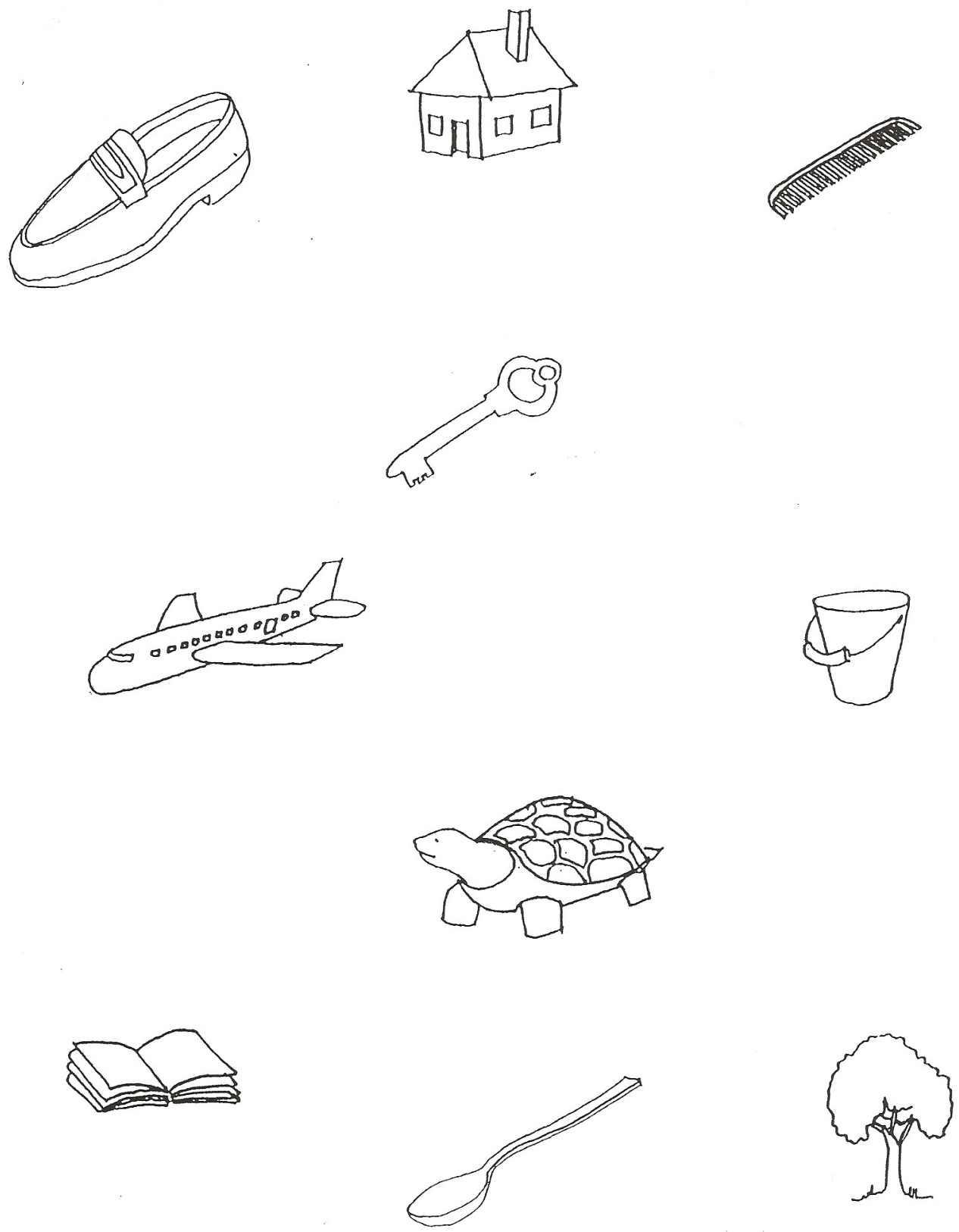
Anexo T

Aprendizado de Figuras (BBRC-Edu) - Folha de pontuação

\begin{tabular}{|c|c|c|c|c|c|}
\hline & Minc & Mlın1 & Mlm2 & M5 & Rec/o \\
\hline Sapato & & & & & \\
\hline Casa & & & & & \\
\hline Pente & & & & & \\
\hline Chave & & & & & \\
\hline Anão & & & & & \\
\hline Balde & & & & & \\
\hline Tartaruga & & & & & \\
\hline Livro & & & & & \\
\hline Colher & & & & & \\
\hline Árvore & & & & & \\
\hline Corretas & & & & & \\
\hline Intrusões & & & & & \\
\hline
\end{tabular}

Atenção: Para o Reconhecimento, o escore final é obtido pela subtração: corretas - intrusões.

Reconhecimento: 
Anexo U

\section{Aprendizado de Figuras - Reconhecimento}

Anexo V

\section{Desenho do Relógio}

Desenho do relógio (Sunderland et al., 1989)

Dê uma folha de papel em branco e diga: "desenhe um relógio com todos os números.

Coloque ponteiros marcando $2 \mathrm{~h} 45$ (guarde o desenho com a ficha).

Avaliação 10-6 Relógio e número estăo corretos.

10 - hora certa

9 - leve distúrbio nos ponteiros (p. ex.: ponteiro das horas sobre o 2)

8 - distúrbios mais intensos nos ponteiros (p. ex.: anotando 2:20)

7 - ponteiros completamente errados

6 - uso inapropriado (p. ex.: uso de código digital ou de círculos envolvendo números)

Avaliação: 5-1: desenhos do relógio e dos números incorretos

5 - números em ordem inversa ou concentrados em alguma parte do relógio

4 - números faltando ou situados fora dos limites do relógio

3 - números e relógio não mais conectados. Ausência de ponteiros

2 - alguma evidência de ter entendido as instruções mas com vaga semelhança com um relógio 1 - não tentou ou não conseguiu representar um relógio

\section{Memória tardia (5 minutos)}

"Que figuras eu the mostrei há 5 minutos?" Se necessário, reforce, dizendo figuras desenhadas numa folha de papel plastificada. ( 60 segundos)

\section{Reconhecimento}

Mostre a folha contendo as 20 figuras e diga: "aqui estão as figuras que eu the mostrei hoje e outras figuras novas; quero que você me diga quais você já tinha visto há alguns minutos." 
9 - REFERÊNCIAS

1. Kalbe E, Reinhold N, Brand M, Markowitsch HJ, Kessler J. A new test battery to assess aphasic disturbances and associated cognitive dysfunctions - German normative data on the aphasia check list. J Clin Exp Neuropsychol.. 2005 Oct;27(7):779-94.

2. Murray LL, Ramage AE, Hopper A. Memory impairments in adults with neurogenic communication disorders. Semin Speech Lang. 2001;22(2):12736.

3. Coslett HB. Language and attention. In: Berndt RS (Ed.). Language and aphasia. Amsterdam: Elsevier; 2001.

4. Borod JC, Carper M, Goodglass H. WAIS performance IQ in aphasia as a function of auditory comprehension and constructional apraxia. Cortex. 1982 Jul;18(2):199-210.

5. Glosser G, Goodglass H. Disorders in executive control functions among aphasic and other brain-damaged patients. J Clin Exp Neuropsychol. 1990 Aug;12(4):485-501

6. Della Sala S. Figure-object matching: another frequent nonverbal impairment of aphasics. Ital J Neurol Sci. 1987 Feb;8(1):43-9. 
7. Crosson B. Systems that support language processes: Attention. In: Nadeau SE, Gonzalez L, Rothi J, Crosson B (Eds.). Aphasia and Language. New York: The Guilford Press.

8. Sarno MT. Recovery and rehabilitation in aphasia. New York: Academic Press.

9. Nitrini R, Bacheschi LA. A neurologia que todo médico deve saber. São Paulo: Atheneu; 2004.

10. Centers for Disease Control. Achievements in public health, $1900-1999$. Morbidity and Mortality Weekly Report. 1999; 48 (30).

11. Flack JM, Yunis C. Therapeutic implications of the epidemiology and timing of myocardial infarction and other cardiovascular diseases. Journal of Human Hypertension. 1997; 11: 23 - 28.

12. Kuller LH. Stroke and diabetes. In: National Diabetes Data Group. Diabetes in America. 1995; 449-456.

13. Yusuf HR, Giles WH, Croft JB, Anda RF, Casper ML. Impact of risk factor profiles on determining cardiovascular disease risk. Preventive Medicine. 1998; $27(1): 1-9$. 
14. Chapey R. Language Intervention Strategies in Aphasia and Related Neurogenic Communication Disorders. Fourth Edition. Lippincott Williams \& Wilkins; 2002.

15. Fukujima MM. Acidente Vascular Cerebral. In: Ortiz KZ (org.). Distúrbios neurológicos adquiridos: linguagem e cognição. Manole Ltda. 2005; 34 - 46.

16. World Health Organization (WHO). The world health report. Geneva: WHO, 2000.

17. Lotufo PA, Benseñor IM. Stroke mortality in São Paulo (1997-2003): a description using the Tenth Revision of the International Classification of Diseases. Arq. Neuro-Psiquiatr. 2004; 62(4): 1008-11.

18. Lotufo PA. Stroke in Brazil: a neglected disease. Sao Paulo Med J. 2005; $123(1): 3-4$.

19. Rothwell P. Incidence, risk factors and prognosis of stroke and TIA: the need for high-quality, large-scale epidemiological studies and meta-analyses. Cerebrovascular Disease. 2003; 16 (3): 2-10.

20. Guyatt GH, Feeny DH, Patrick DL. Measuring health-related quality of life. Ann Intern Med. 1993; 118:622-29. 
21. 46. Mayo NE, Wood-Dauphinee S, Côté R, Durcan L, Carlton J. Activity, participation, and quality of life 6 Months postroke. Arch Phys Med Rehabil. 2002; 83:1035-42.

22. ASHA Committe on Language. Definition of Language. ASHA, 1983; 25 (6):44.

23. Chapey R. Language Intervention in adult aphasia. Baltimore: Williams \& Wilkins; 1996.

24. Ortiz KZ. Afasia. In: Ortiz KZ (org.). Distúrbios neurológicos adquiridos: linguagem e cognição. Manole Ltda.; 2005: 47-64.

25. Dronkers NF, Pinker S, Damasio A. Language and the aphasias. In: Kandel ER, Schwartz JH, Jessel TM. Principles of neural science. 4 ed. USA: MacGrax-Hill; 2000. p.1169-85.

26. Mansur LL, Senaha MLH. Distúrbios de linguagem oral e escrita e hemisfério esquerdo. In: Nitrini R, Caramelli P, Mansur LL. Neuropsicologia: das bases anatômicas à reabilitação. São Paulo: Clínica Neurológica do Hospital das Clínicas da Faculdade de Medicina da Universidade de São Paulo, 1996. p.183-201. 
27. Mansur LL, Radanovic M. Neurolingüística: princípios para a prática clínica. São Paulo: Edições inteligentes, 2004.344p.

28. Ortiz KZ. Avaliação das Afasias. In: Ortiz, KZ (org.). Distúrbios neurológicos adquiridos: linguagem e cognição. Editora Manole Ltda.; 2005. p.65-93.

29. Goodglass H, Kaplan E. The assessment of aphasia and related disorders. Philadelphia: Lea\&Febiger; 1972. 80p.

30. Crosson B, Nadeau SE. The role of subcortical structures in linguistic processes. Recent developments. In: Stemmer B, Whitaker HA (eds.). Handbook of Neurolinguistics. San Diego: Academic Press; 1998. p 431-45.

31. Mega MS, Alexander MP. Subcortical Aphasia: the core profile of capsulostriatal infarction. Neurology. 1994; 44: 1824-29.

32. Radanovic M, Mansur LL, Azambuja MJ, Porto CS, Scaff M. Contribution to the evaluation of language disturbances in subcortical lesions. Arq Neuropsiquiatr. 2004;62:51-7.

33. Radanovic M, Azambuja MJ, Mansur LL, Porto CS, Scaff M. Thalamus and language: Interface with attention, memory, and executive functions. Arq Neuropsiquiatr. 2003;61(1):34-42. 
34. Marquardsen J. The natural history of acute cerebrovascular disease: A retrospective study of 769 patients. Acta Neurologica Scandinavica. 1969; 45(38).

35. Scarpa M, Colombo A, Sorgato P, De Renzi E. The incidence of aphasia and global aphasia in left brain-damaged patients. Cortex. 1987;104:117-28.

36. Kauhanen ML, Korpelainen JT, Hiltunen $\mathrm{P}$, Maatta R, Mononen $\mathrm{H}$, Brusin E, Sotaniemi KA, Myllyla VV. Aphasia, depression, and non verbal cognitive impairment in ischemic stroke. Cerebrovascular Disease. 2000; 10:455- 61.

37. Viude A. Afasia em pacientes admitidos no Pronto Socorro do Hospital das Clínicas da Faculdade de Medicina da Universidade de São Paulo como diagnóstico de Acidente Vascular Cerebral entre setembro de 1997 a abril de 1998. [dissertação]. São Paulo: Faculdade de Saúde Pública; 1998.

38. Wade DT, Hewer RL, David RM. Aphasia after stroke: natural history and associated deficits. Journal Neurol Neurosurg Psychiatry. 1986; 49:11-16.

39. Pedersen PM, Jorgensen HS, Nakayama H, Raaschou HO, Olsen TS. Aphasia in acute stroke: incidence, determinants and recovery. Ann Neurol. 1995; 38: 659-66. 
40. National Institute for Deafness and Other Communication Disorders. Health Information: Voice, speech, and language. [on line]. Available: http://www.nidcd.nih.gov/health/voice/aphasia.htm.

41. Laska AC, Hellblom A, Murray V, Kahan T, Von Arbin M. Aphasia in acute stroke and relation to outcome. J Intern Med. 2001; 249:413-22.

42. Tiling K, Sterne JA, Rudd AG. A new method for predicting recovery after stroke. Stroke. $2001 ; 32: 2867-73$.

43. Paolucci S, Antonucci G, Pratesi L, Traballesi M, Lubich S, Grasso MG. Functional outcome in stroke impatient rehabilitation: predicting no, low and high response patients. Cerebrovascular Disease. 1998; 8:228-34.

44. Black-Shaffer RM, Osberg JS. Return to work after stroke: development of a predictive model. Arch Phys Med Rehabil. 1990; 71:285-90.

45. Ferro JM, Madureira S. Aphasia type, age and cerebral infarct localisation. J Neurol. 1997; 244:505-09.

46. Hier DB, Yoon WB, Mohr JP, Price TR, Wolf PA. Gender and aphasia in the Stroke Data Bank. Brain and Language. 1994; 47:155-67. 
47. Basso A, Capitani E, Moraschini S. Sex differences in recovery from aphasia. Cortex. 1982; 18:469-75.

48. Lubinski R. Perspectives on Aging and Communication. In: Lubinski R, Higginbotham DJ. Communication Technologies for the elderly. San Diego: Singular Publishing Group. 1997.

49. Brody J. When brain damage disrupts speech. New York Times. 1992; June 10, C3.

50. Mansur LL, Luiz MOR. Distúrbios da Linguagem: Afasias. In: Russo IP. Intervenção Fonoaudiológica na Terceira Idade. Rio de Janeiro: Revinter.1999: 101-19.

51. Bayles KA. Understanding the neuropsychological syndrome of dementia. Semin Speech Lang. 2001 Nov;22(4):251-59.

52. Lezak MD. Basic Concepts. In: Lezak MD, Howieson DB, Loring DW (eds). Neuropsychological assessment. 4a. edição. New York: Oxford University Press, 2004. Cap. 2, pp. $15-38$.

53. Luria AR. Higher cortical functions in man. New York: Basic Books, 1966. 
54. Cohen R, Kelter S. Cognitive impairment of aphasics in a colour-topicture matching task. Cortex. $1979 ; 15: 235-45$.

55. Gainotti G, Silveri MC, Villa G, Callagirone C. Drawing objects from memory in aphasia. Brain.1983; 106:613-22.

56. Basso A, Capitani E, Luzzatti C, Spinnler H, Zanobio ME. Different basic components in the performance of Broca's and Wernicke's aphasics on the Colour-Figure Matching Test. Neuropsychologia. 1985; 23(1):51-9.

57. Beeson PM, Bayles KA, Rubens AB, Kaszniak AW. Memory impairment and executive control in individuals with stroke-induced aphasia. Brain and Lang. 1993;45:253-75.

58. Burgio F, Basso A. Memory and aphasia. Neuropsychologia.1997; 35(6):759-66 .

59. Seniów J, Litwin M, Lésniak. The relationship between non-linguistic cognitive deficits and language recovery in patients with aphasia. Journal of the Neurological Sciences. 2009; 283:91-4.

60. De Renzi E, Nichelli P. Verbal and non-verbal short-term memory impairment following hemispheric damage. Cortex. 1975; Dec;11(4):341-54.

61. Van Mourik $M$, Verschaene $M$, Boon $P$, Paquier $P$ et al. Cognition in global aphasia: indicators for therapy. Aphasiology. 1992; 6(5): 491-99. 
62. Helm-Estabrooks N. Cognition and aphasia: a discussion and a study. $J$ Commun Disord. 2002; 35(2):171-86.

63. Helm-Estabrooks N. Cognitive Linguistic Quick Test. San Antonio: The Psychological Corporation, 2001.

64. Hincley JJ, Carr TH, Patterson JP. Relationship between cognitive abilities, treatment type, and treatment time in aphasia. Paper presented at the $31^{\text {st }}$ Annual Clinical Aphasiology Conference, Santa Fe, NM; 2001.

65. Nicholas M. Effect of cognitive and linguistic factors on response to alternative communication treatment. Paper presented at Aphasia Therapy Workshop: Current Approaches to Aphasia Therapy- Principle and Applications. Vienna, Austria; 2003.

66. Fillingham JK, Sage K, Lambon Ralph M. The treatment of anomia using errorless learning. Neuropsychol Rehabil. 2006;16(2):129-54.

67. Goodglass H, Kaplan E, Barresi B. The Boston Diagnostic Aphasia Examination. Philadelphia: Lippincot Williams Wilkins; 2001.

68. Hamilton M. Rating depressive patients. Journal of Clinical Psychiatry. 1980; 41:21-24. 
69. Hilari K, Byng S, Lamping DL, Smith SC. Stroke and Aphasia Quality of Life Scale - 39 (SAQOL-39): Evaluation of Acceptability, Reliability, and Validity. Stroke. 2003; 34:1944-50.

70. Ribeiro C. Avaliação da qualidade de vida em pacientes afásicos com protocolo específico - SAQOL-39. [dissertação]. São Paulo: Faculdade de Medicina, Universidade de São Paulo;2008.

70. Reitan RM. Validity of the Trail Making Test as an indicator of organic brain damage. Percept Mot Skills.1958; 8:271-6.

71. Mesulam, M-M. Behavioral neuroanatomy. In: Principles of behavioral and cognitive neurology. $2^{\text {nd }}$ ed. Mesulam, M-M (Ed.) - Capítulo 1, pp. 1-120. New York: Oxford University Press, 2000.

72. Morris JC, Heyman A, Mohs RC, Hughes JP, van Belle G, Fillenbaum G, Mellits ED, Clark C. The Consortium to Establish a Registry for Alzheimer's Disease (CERAD). Part I. Clinical and neuropsychological assessment of Alzheimer's disease. Neurology. 1989 Sep;39(9):1159-65.

73. Wechsler D. Wechsler Memory Scale-Revised Manual. San Antonio: The Psychological Corporation. 1987. 
74. Nitrini R, Caramelli P, Porto CS, et al. Brief cognitive battery in the diagnosis of mild Alzheimer's disease in subjects with medium and high levels of education. Dement Neuropsychol. 2007;1:32-36.

75. Sunderland T, Hill JL, Mellow AM, Lawlor BA, Gundersheimer J, Newhouse PA, Grafman JH. Clock drawing in Alzheimer's disease. A novel measure of dementia severity. J Am Geriatr Soc. 1989; 37(8): 725-29.

76. Oldfield R The assessment and analysis of handedness: the Edingurgh inventory. Neuropsycology 1971;9:97-113.

77. Korda RJ, Douglas JM. Attention deficits in stroke patients with aphasia. J Clin Exp Neuropsychol. 1997 Aug;19(4):525-42.

78. Heilman KM, Watson RT e Valenstein E. Neglect: clinical and anatomic issues. In: Feinberg TE e Farah MJ (eds.) Behavioral Neurology \& Neuropsychology. 2. edição. New York: McGraw-Hill, 2003, cap.25, pp. 303323.

79. Trojano L e Conson M. Visuospatial and visuoconstrutive deficits. In: Goldenberg, G e Miller BL (eds.). Handbook of Clinical Neurology, vol. 88 $\left(3^{\text {rd }}\right.$. series). Neuropsychology and behavioral neurology. New York: Elseveir, 2008, Cap. 19, pp. 373-391. 
80. Joanette Y, Ansaldo Al, Kahlaoui K, Cotê H, Abusamra V, Ferreres A, Roch-Lecours A. Impacto de las lesiones del hemisferio derecho sobre las habilidades lingüísticas: perspectivas teórica y clínica. Rev Neurol 2008; 46 (8): 481-488.

81.Goulet P, Joanette Y, Sabourin L, Giroux F. Word fluency after a right hemisphere lesion. Neuropsychologia 1997; 35: 1565-70.

82. Joanette $Y$, Goulet P. Criterion-specific reduction of verbal fluency in right brain-damaged right-handers. Neuropsychologia 1986; 24: 875-9.

83. Birn RM, Kenworthy L, Case L, Caravella R, Jones TB, Bandettini PA, Martin A. Neural systems supporting lexical search guided by letter and semantic category cues: A self-paced overt response fMRI study of verbal fluency. Neuroimage. 2010 Jan 1;49(1):1099-107. Epub 2009 Jul 23.

84. Papagno C, Della Sala S, Basso A. Ideomotor apraxia without aphasia and aphasia without apraxia: the anatomical support for a double dissociation. J Neurol Neurosurg Psychiatry. 1993 Mar;56(3):286-9.

85. Greene JD. Apraxia, agnosias, and higher visual function abnormalities. J Neurol Neurosurg Psychiatry. 2005 Dec;76 Suppl 5:v25-34. 
86. Ween JE, Verfaellie M, Alexander MP. Verbal memory function in mild aphasia. Neurology. 1996 Sep;47(3):795-801.

87. Risse GL, Rubens AB, Jordan LS. Disturbances of long-term memory in aphasic patients. A comparison of anterior and posterior lesions. Brain. 1984 Jun;107 (Pt 2):605-17.

88. Gainotti G, Cappa A, Perri R, Silveri MC. Disorders of verbal and pictorial memory in right and left brain-damaged patients. Int J Neurosci. 1994 Sep;78(1-2):9-20.

89. Cremonini W, De Renzi E, Faglioni P. Contrasting performance of rightand left-hemisphere patients on short-term and long-term sequential visual memory. Neuropsychologia. 1980;18(1):9.

90. Goodglass H, Denes $G$, Calderon $M$. The absence of covert verbal mediation in aphasia. Cortex. 1974 Sep;10(3):264-9.

91. Radanovic M, Mansur LL, Scaff M. Normative data for the Brazilian population in the Boston Diagnostic aphasia Examination: influence of schooling. Braz J Med Biol Research. 2004; 37(11):1731-38.

92. Machado TH, Fichman HC, Santos EL, Carvalho VA, Fialho PP, Koenig AM, Fernandes CS, Lourenço RA, Paradela EMP, Caramelli P. Normative 
data for healthy elderly on the phonemic verbal fluency task - FAS. Dementia \& Neuropsychologia. 2009; march 3(1):55-60.

93. Lezak MD. Perception. In: Lezak MD, Howieson DB, Loring DW (eds.) Neuropsychological Assessment 4th edition. New York: Oxford University Press, 2004, pp.375-413.

94. Figueiredo VLM, Nascimento E. Desempenhos nas duas tarefas do subteste de dígitos do WISC-III e do WAIS-III. Psicologia: Teoria e Prática. $2007 ; 23(3): 313-18$.

95. Bertolucci PH, Okamoto IH, Brucki SM, Siviero MO, Toniolo Neto J, Ramos LR. Applicability of the CERAD neuropsychological battery to Brazilian elderly. Arq Neuropsiquiatr. 2001 Sep;59(3-A):532-6. 
Apêndice A

Pontuações máximas e normas de referência consideradas, de acordo com as tarefas cognitivas não linguísticas

\begin{tabular}{|c|c|c|c|}
\hline Tarefas & $\begin{array}{l}\text { Pontuação } \\
\text { Máxima }\end{array}$ & $\begin{array}{l}\text { Norma de } \\
\text { Referência }\end{array}$ & Autores \\
\hline Fluência Verbal Semântica & - & $18,2(6,5)$ & $\begin{array}{l}\text { Radanovic, } \\
\text { Mansur e Scaff }\end{array}$ \\
\hline Fluência Verbal Fonológica & - & $26,1(7,1)$ & Machado et al. ${ }^{92}$ \\
\hline Teste de Cancelamento & - & $\begin{array}{l}\text { máximo } 2 \\
\text { omissões }\end{array}$ & Lezak $^{93}$ \\
\hline \multicolumn{4}{|l|}{ Teste de Trilhas } \\
\hline $\begin{array}{l}\text { Parte A } \\
\text { Parte B }\end{array}$ & - & $\begin{array}{l}38,5 \text { s }(11,9) \\
81,2 \text { s }(38,5)\end{array}$ & Reitan $^{70}$ \\
\hline \multicolumn{4}{|l|}{ Extensão de Dígitos } \\
\hline $\begin{array}{l}\text { Ordem Direta } \\
\text { Ordem Inversa }\end{array}$ & $\begin{array}{l}12 \\
12\end{array}$ & $\begin{array}{l}4,73(1,23) \\
3,52(1,25)\end{array}$ & $\begin{array}{l}\text { Figueiredo e } \\
\text { Nascimento }^{94}\end{array}$ \\
\hline \multicolumn{4}{|l|}{ Aprendizado de Palavras } \\
\hline Evocação & 10 & 3 & Bertolucci et al. ${ }^{95}$ \\
\hline Reconhecimento & 10 & 7 & \\
\hline Praxias Construtivas & 10 & 9 & Bertolucci et al. ${ }^{95}$ \\
\hline Evocação Praxias Construtivas & 10 & 4 & \\
\hline $\begin{array}{l}\text { Aprendizado de Figuras } \\
\text { Memória Incidental }\end{array}$ & 10 & 5 & \\
\hline Memória Imediata & 10 & 7 & Nitrini et al. ${ }^{58}$ \\
\hline Reconhecimento & 10 & 8 & \\
\hline $\begin{array}{l}\text { Teste do Desenho do Relógio } \\
\text { (Sunderland }{ }^{75} \text { ) }\end{array}$ & 10 & 9 & Nitrini et al. ${ }^{58}$ \\
\hline
\end{tabular}


Apêndice B



Ao

Departamento de Neurologia

A Comissão de Ética para Análise de Projetos de Pesquisa - CAPPesq da Diretoria Clínica do Hospital das Clínicas e da 16/12/2009, tomou conhecimento da alteracão de título do Protocolo de Pesquisa n 0595/07 "AFASIAS PÓs ACIDENTE VASCULAR ENCEFÁlICO: ASPECTOS EPIDEMIOLÓGICOS E IMPACTO NA QUALIDADE DE VIDA" para "RELAÇÃo EÑTRE ALTERAÇŌES DE LINGUAGEM E DÉFICITS CONGNITIVOS NÃO LINGUÍSTICOS EM INDIVÍDUOS AFÁSICOS APÓS ACIDENTE VASCULAR ENCEFÁLICO", bem como tomou ciência do relatório de andamento do projeto.

Pesquisador (a) Responsável: Dra. Márcia Radanovic

CAPPesq, 17 de dezembro de 2009

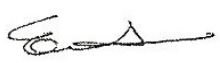

PROF. DR. EDUARDO MASSAD

Presidente da Comissão Ética para Análise de Projetos de Pesquisa

Comissão de Ética para Análise de Projetos de Pesquisa do HCFMUSP e da FMUSP Diretoria Clínica do Hospital das Clínicas da Faculdade de Medicina da Universidade de São Paulo Rua Ovidio Pires de Campos. $2255^{\circ}$ andar - CEP 05430010 - São Paulo - SP 